NBER WORKING PAPER SERIES

\title{
EDUCATION POLICY AND INTERGENERATIONAL TRANSFERS IN EQUILIBRIUM
}

\author{
Brant Abbott \\ Giovanni Gallipoli \\ Costas Meghir \\ Giovanni L. Violante \\ Working Paper 18782 \\ http://www.nber.org/papers/w18782 \\ NATIONAL BUREAU OF ECONOMIC RESEARCH \\ 1050 Massachusetts Avenue \\ Cambridge, MA 02138 \\ February 2013, Revised September 2018
}

This paper was originally circulated under the title Equilibrium Effects of Education Policies: A Quantitative Evaluation. We are grateful to six anonymous referees and the editor J. J. Heckman for helpful comments and guidance. We received valuable feedback from numerous individuals and participants at conferences and seminars. We are grateful to Chris Tonetti and Emily Nix for excellent research assistance at an early stage of this project. Costas Meghir thanks the ESRC for funding under the Professorial Fellowship RES-051-27-0204, the Cowles Foundation and the ISPS at Yale. Abbott and Gallipoli acknowledge financial support from the CLSRN and the SSHRC in Canada. We alone are responsible for all errors and interpretations. The views expressed herein are those of the authors and do not necessarily reflect the views of the National Bureau of Economic Research.

NBER working papers are circulated for discussion and comment purposes. They have not been peer-reviewed or been subject to the review by the NBER Board of Directors that accompanies official NBER publications.

(C) 2013 by Brant Abbott, Giovanni Gallipoli, Costas Meghir, and Giovanni L. Violante. All rights reserved. Short sections of text, not to exceed two paragraphs, may be quoted without explicit permission provided that full credit, including ()$^{\text {notice, }}$ is given to the source. 
Education Policy and Intergenerational Transfers in Equilibrium

Brant Abbott, Giovanni Gallipoli, Costas Meghir, and Giovanni L. Violante

NBER Working Paper No. 18782

February 2013, Revised September 2018

JEL No. E24,I22,J23,J24

\section{$\underline{\text { ABSTRACT }}$}

We examine the equilibrium effects of college financial aid policies building an overlapping generations life cycle model with education, labor supply, and saving decisions. Cognitive and non-cognitive skills of children depend on parental education and skills, and affect education and labor market outcomes. Education is funded by parental transfers that supplement grants, loans and student labor supply. Crowding out of parental transfers by government programs is sizable and cannot be ignored. The current system of federal aid improves long-run welfare by $6 \%$. More generous ability-tested grants would increase welfare and dominate both an expansion of student loans and a labor tax cut.

Brant Abbott

Queen's University

Department of Economics

94 University Ave

Kingston, Ontario, Canada

K7L 3N6

abbottbrant@gmail.com

Giovanni Gallipoli

Vancouver School of Economics

University of British Columbia

6000 - Iona Drive

Vancouver, BC V6T 1L4

CANADA

and RCEA

gallipol@mail.ubc.ca
Costas Meghir

Department of Economics

Yale University

37 Hillhouse Avenue

New Haven, CT 06511

and IZA

and also NBER

c.meghir@yale.edu

Giovanni L. Violante

Department of Economics

Princeton University

Julis Romo Rabinowitz Building

Princeton, NJ 08540

and NBER

glv2@princeton.edu 


\section{Introduction}

Investment in human capital is a key source of aggregate productivity growth and a powerful vehicle for social mobility. However, imperfections in insurance and credit markets can distort skill investment choices and lead to less than socially optimal educational attainment. Motivated by these considerations, governments promote the acquisition of education through a variety of interventions. Financial aid for college students is a pillar of education policy in many countries. For example, in 2012 the US Federal government spent 150 billion dollars on loans and grants for college students. ${ }^{1}$ Given their magnitude and scope, it is important to quantify the effects of policies intended to advance college attainment and understand the way they interact with private financing of education.

In this paper we build a life-cycle, heterogeneous-agent model with incomplete insurance and credit markets of the type popularized by Ríos-Rull (1995) and Huggett (1996), featuring intergenerational links in the tradition of Laitner (1992) and set in an overlapping generations context. Throughout their life cycles parents make savings and labor supply decisions and, when their children are old enough, they make financial transfers to them. These transfers depend on the policy environment, such as the availability of financial aid, and are motivated by both altruism and a paternalistic preference for children's education. Cognitive and non-cognitive skills, transmitted across generations, determine the non-pecuniary cost of education for students and productivity once entering the labor market. Government grants and loans, private loans, as well as labor supply during college complement parental resources as means of funding the financial cost of college education. Workers of different gender and education are imperfect substitutes in production. The government redistributes through a progressive tax system.

With this rich structure in hand, we study the impact of financial aid policies on college attainment, welfare, and the aggregate economy. Central to our analysis are the role of liquidity constraints and uninsurable income risk, policy-induced crowding out of private sources of funding, heterogeneity and selection, and general equilibrium feedbacks.

\footnotetext{
${ }^{1}$ See Trends in Student Aid, College Board, 2012.
} 
Since Becker (1964), the potential importance of liquidity constraints on education attainment is well understood. The extent to which credit market imperfections can distort college attendance depends on the capacity and willingness of parents to fund education for their children, the availability of government-sponsored grants and loans, and the earnings potential of students. ${ }^{2}$ Gale and Scholz (1994) show that inter vivos transfers (IVTs) for education are sizable. ${ }^{3}$ However, studies using data from the 1980s and 1990s concluded that family income played a small role in college-attendance decisions, after controlling for child ability and several family background characteristics (Cameron and Heckman, 1998; Keane and Wolpin, 2001; Carneiro and Heckman, 2002; Cameron and Taber, 2004). More recently, though, Belley and Lochner (2007) found that parental financial resources matter significantly for college attendance in the 2000s. In turn, Heckman and Mosso (2014) argue that much of the family income effect estimated in the 2000s results from low ability children, while high ability children were already in school. ${ }^{4}$

Earnings risk is pervasive and only partially insurable. ${ }^{5}$ It can affect individual decisions as well as the impact of policy, including the relative benefit of grants versus loans. ${ }^{6}$ Thus, we model earnings as a gender specific stochastic Roy model with a separate process for each education group and dependent on ability. We explicitly account for alternative channels of consumption insurance, including spousal labor supply as in Blundell et al. (2016b) and intra-family transfers.

In the model we allow for heterogeneity in both the returns to education and the psychic costs of schooling, which depend on both cognitive and non-cognitive ability. ${ }^{7}$ Modeling psychic costs is nec-

\footnotetext{
${ }^{2}$ Garriga and Keightley (2015) show that omitting the labor supply margin of college students may lead to large overestimates in the effects of tuition subsidies.

${ }^{3}$ Winter (2014) also argues that ignoring parental transfers may lead to wrong inference about the extent of credit constraints. Keane and Wolpin (2001) and Johnson (2013) estimate parental IVTs as a function of observable characteristics from the NLSY79. Brown et al. (2012) show that while parental contributions are assumed and expected in financial aid packages, they are not legally enforceable nor universally given, implying substantial heterogeneity in access to resources for students with observationally similar families.

${ }^{4}$ Carneiro et al. (2011) show that returns to college are in fact negative for low ability children.

${ }^{5}$ Blundell et al. (2008); Low et al. (2010); Heathcote et al. (2014)

${ }^{6}$ See for example Johnson (2013). As originally emphasized by Levhari and Weiss (1974), college education is a multiperiod investment requiring an ex-ante commitment of resources and time. Uncertainty in its return is a key determinant of education decisions. Hence, students may be unwilling to finance college using loans when risk about their future earnings and ability to repay is high.

${ }^{7}$ The first studies linking human capital investment to life cycle earnings (Mincer, 1958; Becker, 1964; Ben-Porath,
} 
essary because pecuniary returns can only account for part of the observed college attendance patterns by ability (see Cunha et al., 2005; Heckman et al., 2006a). From a policy perspective, accounting for such heterogeneity allows a meaningful examination of the importance of targeted interventions. The way cognitive and non-cognitive skills are transmitted across generations, as well as their effects on education choices and returns, are estimated from data. In particular, because parental education affects child skills in the model, thus making them endogenous, expanding schooling for the current generation reduces the cost of human capital accumulation for future generations, an original insight of T.W. Schultz. ${ }^{8}$

To complete our understanding of how government policy can affect educational attainment and wages we follow Heckman et al. (1998b,c), Lee (2005) and Lee and Wolpin (2006), amongst others, and set the model in a general equilibrium context, which allows wages to adapt to changes in the supply and composition of educated workers. ${ }^{9}$ In our model the aggregate production function depends on inputs from three types of education and allows for imperfect substitutability between males and females of the same skill.

Finally, to shed light on the welfare effects of education policy, we build on Benabou (2002) and develop a decomposition of welfare gains into aggregate productivity improvements, lower inequality in initial conditions, and reduced consumption uncertainty.

Our data is drawn from various US sources, including the Current Population Survey (CPS), the Panel Study of Income Dynamics (PSID), the National Longitudinal Survey of Youth (NLSY, 79 and 97), the National Center for Education Statistics (NCES), the Survey of Consumer Finances (SCF), and the National Accounts. The model is estimated in stages. We first estimate the wage processes, for each education group and gender, as well as the intergenerational transmission of ability and the

1967) sidestepped the important issue of self-selection into education, as described in the seminal contributions of Rosen (1977) and Willis and Rosen (1979).

${ }^{8}$ The dependence of child cognitive and noncognitive skills on parental education in part reflects how investments in child development vary with parental education (Cunha and Heckman, 2007; Cunha et al., 2010). This provides an important channel for the intergenerational impact of education policy.

${ }^{9}$ For a similar approach, see also the work of Bohacek and Kapicka (2012), Krueger and Ludwig (2016), Johnson and Keane (2013), and Garriga and Keightley (2015). 
aggregate production function. Then, having set few parameters based on the literature, we use the method of moments to estimate the rest of the model's parameters. The US federal system of grants and loans is represented in detail, allowing for the existing amount of means testing, to ensure that we capture the main sources of public funding for education and the way they are targeted in practice.

We establish that the model fits the data along a number of crucial dimensions that are not targeted in estimation. For example, cross-sectional life-cycle profiles of the mean and dispersion of hours worked, earnings, consumption, and wealth are consistent with their empirical counterparts. We are careful to match numerous statistics about student borrowing, including their average cumulative loans upon graduation. ${ }^{10}$ The intergenerational income-rank mobility implied by our model is within the range estimated by Chetty et al. (2014), and correlation of income between parents and children is close to the value documented by Solon (1999) for the US. Our modeling choices for federal financial aid imply marginal effects of parental wealth on college attainment, controlling for child's ability, that are similar to those estimated by Belley and Lochner (2007) from the NLSY97. The role of paternalism is key in explaining these facts. Moreover, when we use the model to simulate an artificial randomized experiment in which a (treated) group of high-school graduates receives an additional $\$ 1,000$ in yearly tuition grants and another (control) group does not, the simulated treatment effect on college attainment is consistent with the outcomes of quasi-randomized policy shifts surveyed by Kane (2003), and Deming and Dynarski (1995).

We conduct a number of different policy experiments, in which we change the size and nature (general/need-based/merit-based) of the federal grant program and government-sponsored loan limits. We find that the crowding out of the private (parental) source of funds is a very important feature and attenuates the effects of policy: every additional dollar of government grants crowds out 25-50 cents of parental IVTs on average, and a \$1,000 reduction in tuition fees lowers the annual earnings of college students by roughly $\$ 100$ on average. The amount of crowding out varies across the wealth distribution, with transfers from poorer parents being more sensitive to policy changes. Overall,

\footnotetext{
${ }^{10}$ Lochner and Monje-Naranjo (2011) stress that models may imply too little borrowing relative to data.
} 
however, the current level of federal aid (grants and loans) is welfare improving and accounts for over $4 \%$ of GDP, with the grants and loans being of roughly equal importance. Our estimated model also implies non-trivial welfare and efficiency gains from further expansions of grant programs. An additional $\$ 1,000$ of grants per year for every student (which increases grant spending by roughly $50 \%$ ) leads to a long-run increase in GDP of close to $1 \%$. While some of this gain derives from increased college attainment, a substantial part also arises from stronger sorting into college based on ability, which is efficient in the model. An ability-tested grant expansion is significantly more effective than a general expansion. One source of this result is the complementarity between parental education and ability in the production of children's skills. Finally, consistent with the literature, the general-equilibrium responses of wages, together with crowding out, imply that the aggregate long-run effects are less than half the immediate response.

The remainder of the paper is organized as follows. Section 2 outlines the model and defines equilibrium. Section 3 describes estimation. Section 4 explores the empirical implications of the model by assessing its behavior along several key dimensions not explicitly targeted in the parameterization. Section 5 presents all the policy experiments and offers a general discussion of the main findings. Section 6 concludes. An Online Appendix contains additional details on the parametrization and on the results of the policy experiments, as well as a sensitivity analysis.

\section{Model}

\subsection{Overview}

Men and women in the model start making choices at age 16. At that point cognitive and noncognitive skills are drawn from a distribution that depends on parental education and skills. Moreover, parents make financial transfers to their children with which they start them out in life. These inter vivos transfers (IVT) are in part unconditional (driven by altruism) and in part conditional on children attending college (driven by paternalism). The IVTs and the ability transmission drive intergener- 
ational mobility. Given these transmitted endowments of financial resources and abilities, children make their sequential education choices which can be one of three: less than high school, high school or college. During college students can finance education by borrowing from private markets, through government grants and loans, and also by working part time. Once education is completed individuals marry, drawing a spouse from a distribution that reflects the educational sorting in the data. Over the lifecycle they make consumption/savings and labor supply decisions and they exogenously have two children of the same gender. After their children have become independent decision makers, they continue with the standard lifecycle decisions and eventually retire off their savings and a government provided pension, living to a maximum age of 100 .

There is a set of overlapping generations at any point in time. Workers of different skills, gender and education combine to produce a consumption good, based on a production function where workers of different genders and education are imperfect substitutes for each other; skills enhance the efficiency units of labor supplied. We assume a closed economy in which capital is endogenously determined by the savings of households. Interest rate and wages clear the capital and labor markets. The government uses taxation to fund educational programs (grants and loans), pensions, and other (residual) expenditures.

We begin by describing the model's demographic structure, preferences, production technology, financial markets, and government policies. Next, we outline the life cycle of agents and define a competitive equilibrium. We abstract from aggregate shocks, and thus describe the economy in steady state. For this reason, to lighten notation, we omit time subscripts whenever possible. When discussing the choice of parameter values requires no detour, we do it as we present the model. This subset of parameter values is summarized in the tables in the Appendix. The rest of the parameterization is outlined in Section 3. 


\subsection{Preliminaries}

Time is discrete, indexed by $t$ and continues forever. There is no aggregate uncertainty. A period in the model corresponds to two years. The economy is populated by a continuum of individuals, equally many males and females. Gender is indexed by $g \in\{m, f\}$ and age by $j \in\{0,1, \ldots, J\}$. At each date a new cohort of measure one of each gender enters the economy. The first period of life in the model $(j=0)$ corresponds to age 16 and the last one $(j=J)$ to age 100. Individuals survive from age $j$ to $j+1$ with probability $\zeta_{j}$ (strictly less than 1 only after retirement) whose values are taken from the US Life Tables for the year 2000. Since cohort size and survival probabilities are time-invariant, the model's age distribution is stationary.

The life cycle of individuals comprises four stages: education from age $j=0$ to a maximum of age $j^{C L}$, marital matching at age $j^{C L}+1$, work until age $j^{R E T}-1$, and retirement from age $j^{R E T}$ to $J$. In the first stage the decision unit is the individual. In the last two, the decision unit is the household, i.e. a husband and wife pair.

Preferences. The consumption and leisure of an individual with gender $g \in\{m, f\}$ at age $j$ are denoted by $c_{j}^{g}$ and $\ell_{j}^{g}$, respectively. We will minimize/suppress subscripts wherever possible in the following discussion to improve readability. Individuals have gender and age specific preferences over consumption $c$ and leisure $\ell$

$$
u_{g j}(c, \ell)=\frac{c^{1-\gamma}}{1-\gamma}+\vartheta_{j}^{g} \frac{\ell^{1-\nu_{j}^{g}}}{1-\nu_{j}^{g}} .
$$

Some of the preference parameters above are pre-set, based on existing literature: the coefficient of relative risk aversion $\gamma$ is set to $1.5 .{ }^{11}$ For males, $\nu^{m}$ and $\vartheta^{m}$ do not depend on age; $\nu^{m}$ is set so that the (average) Frisch elasticity of labor supply is $1 / 3$, while $\vartheta^{m}$ is estimated. ${ }^{12}$ For women each of these parameters takes two values: one for when they have no children in the household - the same values

\footnotetext{
${ }^{11}$ See Attanasio and Weber (1995).

${ }^{12}$ See Meghir and Phillips (2009) for estimates of Frisch elasticities for men.
} 
they take for men - and one for when they do (ages 30-45). The Frisch elasticity for women with children is $2 / 3$, following Blundell et al. (2016a). As for males $\vartheta_{j}^{f}$ are estimated and take two values depending on whether women have children or not (which here just depends on age). ${ }^{13}$ The discount factor $\beta$, common across individuals, is a key determinant of wealth accumulation. To inform the estimation of this parameter, we therefore target an aggregate capital-output ratio of 3.5 annually, as in the US economy, and obtain an annualized value of $\beta=0.951$.

We assume full ex-ante commitment within the marriage. Married couples have household preferences

$$
u_{j}\left(c^{m}, c^{f}, \ell^{m}, \ell^{f}\right)=u_{m j}\left(c^{m}, \ell^{m}\right)+u_{f j}\left(c^{f}, \ell^{f}\right)+v^{m}+v^{f}
$$

where $v^{g}$ denotes transfers of utility between spouses (with $v^{m}+v^{f}=0$ ) that allow the initial commitment to be fulfilled ex-post. ${ }^{14}$

We follow Voena (2015) by modeling economies of scale in consumption as dependent on the sharing of resources. That is, total expenditure to consume $c^{m}$ and $c^{f}$ is $c=\left[\left(c^{m}\right)^{\tilde{\rho}}+\left(c^{f}\right)^{\tilde{\rho}}\right]^{\frac{1}{\tilde{\rho}}}$. The optimal allocation of consumption within the marriage requires $c^{m}=c^{f}$. Hence we have that $c=2^{\frac{1}{\tilde{\rho}}} c^{g}$, where $\tilde{\rho}=1.4$, as estimated by Voena (2015), implies sizable economies of scale for couples.

Production. All final goods are produced by a representative firm using aggregate physical capital $K$ and an aggregate human capital input $\mathcal{H}$ according to the production technology $Y=F(K, \mathcal{H})$, where $F$ is Cobb-Douglas. We exogenously set the capital share of output $\alpha$ to 0.33 and the annual capital depreciation rate $\delta$ to 0.06 .

We follow Katz and Murphy (1992) and Heckman et al. (1998a) in modelling aggregate labor input $\mathcal{H}$ as a constant elasticity of substitution aggregator of six types of labor inputs, $H^{e, g}$, indexed

\footnotetext{
${ }^{13}$ The key moments that identify the weight on non-market time $\vartheta_{j}^{f}$ and $\vartheta_{m}$ are the average hours worked. For men and childless women this is $35 \%$ of their time endowment. When children are present, women work $40 \%$ less than men (as in the CPS 2000 data).

${ }^{14}$ This specification is consistent with the transferable utility model described in Weiss (1997), pp.89-90.
} 
by gender $g$ and education attainment $e \in\{L H, H S, C L\}$, where $L H$ denotes those who did not complete high-school, $H S$ high-school graduates, and $C L$ college graduates:

$$
\mathcal{H}=\left[s^{L H}\left(H^{L H}\right)^{\rho}+s^{H S}\left(H^{H S}\right)^{\rho}+s^{C L}\left(H^{C L}\right)^{\rho}\right]^{\frac{1}{\rho}},
$$

where

$$
H^{e}=\left[s^{f, e}\left(H^{f, e}\right)^{\chi}+s^{m, e}\left(H^{m, e}\right)^{\chi}\right]^{\frac{1}{\chi}}, \quad e \in\{L H, H S, C L\}
$$

Both $\rho$ and $\chi$ are in $(-\infty, 1]$. Each labor market is assumed to be competitive. The estimation of the elasticities of substitution and the CES weight parameters $s^{g, e}$, based on data from the Current Population Survey (CPS) for 1968-2001, is done separately and prior to the main model estimation. It takes into account that individuals have different skills that affect the number of efficiency units of labor that they supply. This is discussed in Section 3.

Financial Markets. Markets are incomplete. Agents trade claims to physical capital and risk-free bonds, but cannot buy state-contingent insurance against individual risk. All financial contracts are transacted by competitive intermediaries (banks). Claims to capital and bond holdings pay the same return in equilibrium because of no-arbitrage. Households with positive savings receive from banks an equilibrium interest rate which equals $r$. Banks lend the funds to other households with borrowing needs at the rate $r^{-}=r+\iota$, where the wedge $\iota>0$ is the cost of overseeing the loan per unit of consumption intermediated. The wedge $\iota$ is an important determinant of the proportion of households who have negative net worth. In the $2001 \mathrm{SCF}$ data this proportion is $6.8 \%$, which we target in estimation. Our estimate of the unsecured borrowing wedge is $\iota=0.064$ annually.

Individuals face debt limits that vary over the life-cycle. High-school students, young (i.e. before marriage) workers, and retired households cannot borrow. Credit access for the college students is explained in detail below. Working-age married households are subject to borrowing constraints $\underline{a}^{e}$. The value of $\underline{a}^{e}$ is set to $-\$ 85,000$ if the most educated spouse is a college graduate, $-\$ 25,000$ if 
the most educated spouse is a high school graduate, and $-\$ 15,000$ if both spouses have attained less than high school. These exogenously specified parameters values are informed by self-reported limits on unsecured credit by family type from the SCF. ${ }^{15}$ All retired households can buy annuities at actuarially fair rates, which allows us to abstract from bequests. ${ }^{16}$

Government. The government levies flat taxes $\tau_{w}=0.27, \tau_{k}=0.40$ and $\tau_{c}=0.05$ on labor income, asset income and consumption, respectively (see Domeij and Heathcote, 2004; McDaniel, 2014). ${ }^{17}$ The government refunds a lump-sum amount of tax revenue $\psi$ to each individual. The value of $\psi$ largely determines the progressivity of the tax system (how average tax rates vary with income). We measure progressivity by the ratio of the variance of disposable income to the variance of pre-government income, which is about 0.61 in national data (see Heathcote et al., 2010). This progressivity statistic is important for identification of $\psi$ and thus we include it as a targeted moment in estimation. The government also runs a public pension system which pays an education specific benefit $p^{e}$ to retirees. The pension replacement rate is exogenously specified as $33 \%$ of average earnings within each respective education group (Mitchell and Phillips, 2006). Once the education and pension systems have been financed, excess tax revenues are spent on non-valued government consumption $G$.

\subsection{Life cycle}

The life cycle of an individual consists of four phases - education, marital matching, work, and retirement - which we now describe.

\footnotetext{
15 The lifetime natural borrowing limit (households cannot retire with debt) may be more restrictive for some households, particularly those approaching retirement.

${ }^{16}$ As explained, one reason financial markets are incomplete is that there are no state-contingent insurance markets for (i) individual labor-income risk. As it will be clear from the description of the rest of the model, there are also missing markets to insure (ii) the risk of being born with disadvantaged initial conditions (e.g. poor, uneducated, or low-ability parents), (iii) the shocks affecting the psychic cost of education, and (iv) adverse outcomes at the marital matching stage.

${ }^{17}$ The tax $\tau_{k}$ is levied only on positive capital income. We use $\tau_{k}$ throughout with the convention that if $a<0$ then $\tau_{k}=0$.
} 


\subsubsection{Education}

The education stage lasts three periods and includes two decisions. At the onset of the first period of adult life $(j=0)$ individuals choose whether to finish high school or enter the labor market. In the second period those who completed high school decide whether to attend college, which lasts for two periods if chosen. Since there is no uncertainty during college, in our model college students do not drop out. $^{18}$

As analyzed by Cunha et al. (2005) and Heckman et al. (2006a), psychic costs -reflecting preparedness or taste for education- are an important component of schooling decisions. In our model an individual's utility cost $\kappa_{g}^{e}$ of attaining education level $e$ depends on gender, standardized cognitive skills $\theta_{\text {cog }}$, standardized non-cognitive skills $\theta_{\text {non }}$ (with the pair summarized by the vector $\boldsymbol{\theta}$ ), and an idiosyncratic preference shock $\kappa_{\epsilon}$. This shock is common to high school and college (but with a different loading) and drawn from a standard normal distribution. Specifically, we assume the linear relationship

$$
\kappa_{g}^{e}\left(\boldsymbol{\theta}, \kappa_{\epsilon}\right)=\varsigma_{0}^{e}+\varsigma_{1}^{e} \mathbf{1}_{\{g=f\}}+\varsigma_{2}^{e} \log \left(\theta_{\text {non }}\right) / \sigma_{\text {non }}+\varsigma_{3}^{e} \log \left(\theta_{\text {cog }}\right) / \sigma_{\text {cog }}+\varsigma_{4}^{e} \kappa_{\epsilon}
$$

where $\left(\sigma_{n o n}, \sigma_{c o g}\right)$ are the standard deviations of the distributions of the two components of ability. The education specific coefficients $\left(\varsigma_{1}^{e}, \varsigma_{2}^{e}, \varsigma_{3}^{e}, \varsigma_{4}^{e}\right)$ are included in our main estimation and discussed in Section 3.

These education decisions involve comparison of lifetime values under the different scenarios. In what follows, let the value of continuing in school for an individual with gender $g$ and age $j$ be $V_{g j}^{*}$ and the value of entering the workforce with education $e$ be $V_{g j}^{e}$.

\footnotetext{
${ }^{18}$ Individuals can therefore enter the labor force either at age $j=0$ as with less than high school attainment, or at age $j=1$ as high-school graduates, or at age $j=3$ as college graduates. To avoid further complexity, we abstract from modeling the college drop-out decision. The vast majority of dropouts occur in the freshman year, and dropout rates are far higher for part-time than full-time students. Thus, for the most part, very little commitment has been made among the vast majority of those who choose not to complete college, and the absence of outlays of time and money by dropouts in our model of high school graduates is likely to be of little substance. When relating to the data we count only those who complete college as having attended.
} 
When individuals start out making choices they know their own cognitive and noncognitive ability $\boldsymbol{\theta}$, and the random component of psychic $\operatorname{cost} \kappa_{\epsilon}$ of continuing education. They also know the amount of transfers parents will make. Denote the unconditional transfer by $\hat{a}_{0}$ and the component of the transfer conditional on attending college by $\hat{a}^{C L}$. Finally, they know their eligibility status for college financial aid in the form of grants $\mathfrak{g}$ and loans $b$, denoted by the index $q \in\{1,2,3\}$, which as we explain later depends on parental income and wealth. Let this starting set of initial conditions be $\boldsymbol{x}_{0}^{*}=\left(\boldsymbol{\theta}, \kappa_{\epsilon}, \hat{a}, \hat{a}^{C L}, q\right)$. It is also useful to summarize the set of initial conditions for an individual who decides to stop schooling and enter the labor force as $\boldsymbol{x}_{0}=\left(\boldsymbol{\theta}, a_{0}=\hat{a}, z_{0}\right)$, where $a_{0}$ is the initial level of wealth, and $z_{0}$ is the initial productivity draw which is unknown at the time of the decision.

At the time of this first decision, the value of an individual can be therefore written as

$$
\mathcal{V}_{g 0}\left(\boldsymbol{x}_{0}^{*}\right)=\max \left\{V_{g 0}^{*}\left(\boldsymbol{x}_{0}^{*}\right)-\kappa_{g}^{H S}\left(\boldsymbol{\theta}, \kappa_{\epsilon}\right), \mathbb{E}_{0}\left[V_{g 0}^{L H}\left(\boldsymbol{x}_{0}\right)\right]\right\}
$$

where $\mathbb{E}_{0}$ is the expectation operator over the initial productivity draw. ${ }^{19}$ In all our policy counterfactuals of Section 5, welfare calculations are based on this initial value function $\mathcal{V}_{g 0}$.

Individuals who choose to enter the labor force at age $j=0$ with $e=L H$ (or at age $j=1$ with $e=H S$ ) solve the follow problem:

$$
\begin{aligned}
V_{g j}^{e}\left(\boldsymbol{x}_{j}\right) & =\max _{c_{j}, \ell_{j}, a_{j+1}} u_{g}\left(c_{j}, \ell_{j}\right)+\beta \mathbb{E}_{j}\left[V_{g, j+1}^{e}\left(\boldsymbol{x}_{j+1}\right)\right] \\
\text { s.t. } & \\
\left(1+\tau_{c}\right) c_{j}+a_{j+1} & =\left(1-\tau_{w}\right) w^{g, e} \varepsilon_{j}^{g, e}\left(\boldsymbol{\theta}, z_{j}\right)\left(1-\ell_{j}\right)+\psi+\left[1+r\left(1-\tau_{k}\right)\right] a_{j} \\
a_{j+1} & \geq 0, \quad c_{j} \geq 0, \quad \ell_{j} \in[0,1] \\
z_{j+1} & \sim \Gamma_{z}^{g, e}\left(z_{j+1} \mid z_{j}\right) .
\end{aligned}
$$

where $\mathbb{E}_{j}$ is the expectation operator conditional on the information set at age $j, \boldsymbol{x}_{j}=\left(\boldsymbol{\theta}, a_{j}, z_{j}\right)$,

\footnotetext{
${ }^{19}$ Note that, the state vector for those who continue into high school (HS) is the same as the initial one because no new information is revealed to them at that point, which explains the use $\boldsymbol{x}_{0}^{*}$ on the right hand side of equation (2.6).
} 
and $w^{g, e}$ is the gender and education specific price for a unit of human capital. The gender, age and education specific function $\varepsilon_{j}^{g, e}$ relates ability $\boldsymbol{\theta}$ and idiosyncratic productivity shock $z_{j}$ to productive efficiency per unit of labor supplied. The exact dependence of $\varepsilon_{j}^{g, e}$ on $\boldsymbol{\theta}$ and $z_{j}$ and the Markov process of the productivity shock $\Gamma_{g z}^{e}$ are described in detail in Section 3.

The value of completing high-school as seen from age $j=0$ is defined by

$$
\begin{aligned}
V_{g 0}^{*}\left(\boldsymbol{x}_{0}^{*}\right)= & \max _{c_{0}, a_{1}} u_{g}\left(c_{0}, 1-\bar{t}\right)+\beta \max \left\{V_{g 1}^{*}\left(\boldsymbol{x}_{1}^{*}\right)-\kappa_{g}^{C L}\left(\boldsymbol{\theta}, \kappa_{\epsilon}\right), \mathbb{E}_{0}\left[V_{g 1}^{H S}\left(\boldsymbol{x}_{1}\right)\right]\right\} \\
& \text { s.t. } \\
a_{1}= & {\left[1+r\left(1-\tau_{k}\right)\right] \hat{a}_{0}-c_{0}\left(1+\tau_{c}\right)+\psi } \\
a_{1} \geq & 0, \quad c_{0} \geq 0 .
\end{aligned}
$$

High-school students can neither borrow nor work. They study for a fraction $\bar{t}=0.25$ of their time endowment, and consume the rest as leisure. If they decide to continue to college, their state vector gets updated to $\boldsymbol{x}_{1}^{*}=\left(\boldsymbol{\theta}, a_{1}+\hat{a}^{C L}, q\right)$, since they receive the conditional transfer from their parents.

College lasts for two (two-year, $j=1$ and $j=2$ ) periods. Thus, the values of being in college in the initial and final period are, respectively

$$
V_{g 1}^{*}\left(\boldsymbol{x}_{1}^{*}\right)=\max _{c_{1}, \ell_{1}, a_{2}, b_{2}} u_{g}\left(c_{1}, \ell_{1}\right)+\beta V_{g 2}^{*}\left(\boldsymbol{x}_{2}^{*}\right)
$$

and

$$
V_{g 2}^{*}\left(\boldsymbol{x}_{2}^{*}\right)=\max _{c_{2}, \ell_{2}, a_{3}, b_{3}} u_{g}\left(c_{2}, \ell_{2}\right)+\beta \mathbb{E}_{3}\left[V_{g 3}^{C L}\left(\boldsymbol{x}_{3}\right)\right]
$$

where $\boldsymbol{x}_{2}^{*}=\left(\boldsymbol{\theta}, a_{2}, b_{2}, q\right)$ and the expectation operator in the second value function captures the uncertainty with respect to the initial productivity draw of college graduates. ${ }^{20}$ These two maximization problems are subject to a number of constraints. First, the non-negativity of consumption $c \geq 0$.

\footnotetext{
${ }^{20}$ The state vector $\boldsymbol{x}_{3}$ is described in detail in Section 2.3.2.
} 
Second, the time allocation constraint $\ell_{j} \in[0,1-\bar{t}]$ : labor supply in college is flexible, but the time endowment available for work is reduced by $\bar{t}$ units to reflect the time required for learning. Working students supply high-school equivalent labor. ${ }^{21,22}$

We now turn to college students' budget constraints, which also illustrates how government programs affect schooling choices. All students have access to unsubsidized student loans up to a value $\underline{b}$. Unsubsidized loans cumulate interest at rate $r^{u}$ both during and after college. Students with financial need, measured by their parents' resources $(q=1)$, have access to subsidized loans up to a limit $\underline{b}^{s}$. Interest on subsidized loans is forgiven during college. Those with wealthy parents $(q=3)$ have access to private loans at the rate $r^{p}$. Because $r^{p}<r^{u}$, and because the credit limit on private loans $\underline{a}^{p}$ allows them to fully fund college through private credit, students with $q=3$ who choose to borrow always select this option. ${ }^{23}$ Federal grants $\mathfrak{g}$ are awarded by the government through a formula that makes them a function of both parental wealth and student abilities. Hence, we allow grants to be both need-based and merit-based. To simplify notation, we refer to $\phi(q, \boldsymbol{\theta})$ as tuition fees $\phi$ net of grants $\mathfrak{g}(q, \boldsymbol{\theta})$. Next, we state the college students' budget constraints.

A student with wealthy parents $(q=3)$ has the option to borrow privately and faces the following

\footnotetext{
21 For simplicity their labor productivity, $\varepsilon_{j}^{g, H S}$ in the budget constraint below is allowed to depend only on gender, age $j$ and ability $\boldsymbol{\theta}$. Implicitly, we are assuming every college student has idiosyncratic productivity value equal to the population mean $(z=0)$. Moreover, in our model we do not allow for potential disruptions to schooling effort associated with working while in college. See Garriga and Keightley (2015) for a model where time devoted to work competes with time needed to cumulate credits in college.

${ }^{22}$ Our model generates average hours worked by students approximately equal to 15 hours per week. In comparison, Garriga and Keightley (2015) report 20 hours per week worked by students on average. In addition to this, our model fits reasonably well the extensive margin too. For example, in the NCES Baccalaureate and Beyond data for graduating seniors $2007-8,19 \%$ of students reported not working and in our model 14\% of students choose not to work.

${ }^{23}$ Implicitly, interest rates on private education loans depend on credit scores. See Ionescu and Simpson (2016). As a result, poor families with low credit scores face high borrowing rates on private education loans. Implicitly, we assume that these rates are so high that poor families choose not to use the private market to finance their children's education.
} 
budget constraint:

$$
\begin{aligned}
& \left(1+\tau_{c}\right) c_{j}+a_{j+1}-\left(1-\tau_{w}\right) w^{g, H S} \varepsilon_{j}^{g, H S}\left(\boldsymbol{\theta}, z_{j}=0\right)\left(1-\bar{t}-\ell_{j}\right)+\phi(q, \boldsymbol{\theta})-\psi= \\
= & \begin{cases}{\left[1+r\left(1-\tau_{k}\right)\right] a_{j}} & \text { if } a_{j} \geq 0, \\
\left(1+r^{p}\right) a_{j} & \text { otherwise }\end{cases} \\
& a_{j+1} \geq-\underline{a}^{p}
\end{aligned}
$$

A student who qualifies only for unsubsidized government loans $(q=2)$ faces the budget constraint:

$$
\begin{aligned}
& \left(1+\tau_{c}\right) c_{j}+a_{j+1}+b_{j+1}-\left(1-\tau_{w}\right) w^{g, H S} \varepsilon_{j}^{g, H S}\left(\boldsymbol{\theta}, z_{j}=0\right)\left(1-\bar{t}-\ell_{j}\right)+\phi(q, \boldsymbol{\theta})-\psi= \\
= & \begin{cases}{\left[1+r\left(1-\tau_{k}\right)\right] a_{j}} & \text { if } a_{j} \geq 0, \quad b_{j}=0 \\
\left(1+r^{u}\right) b_{j} & \text { if } a_{j}=0, \quad b_{j}<0\end{cases} \\
& a_{j+1} \geq 0 \quad b_{j+1} \geq-\underline{b}
\end{aligned}
$$

A wealth-poor student who qualifies for a subsidized government loan $(q=1)$ faces the budget constraint:

$$
\begin{aligned}
& \left(1+\tau_{c}\right) c_{j}+a_{j+1}+b_{j+1}-\left(1-\tau_{w}\right) w^{g, H S} \varepsilon_{j}^{g, H S}\left(\boldsymbol{\theta}, z_{j}=0\right)\left(1-\bar{t}-\ell_{j}\right)+\phi(q, \boldsymbol{\theta})-\psi= \\
= & \text { if } a_{j} \geq 0, \quad b_{j}=0 \\
\left.1+r\left(1-\tau_{k}\right)\right] a_{j} & \text { if } a_{j}=0, \quad 0>b_{j} \geq-\underline{b}^{s} \\
b_{j} & \text { if } a_{j}=0, \quad b_{j}<-\underline{b}^{s} \\
-\underline{b}^{s}+\left(1+r^{u}\right)\left(b_{j}+\underline{b}^{s}\right) &
\end{aligned}
$$

We parameterize tuition costs, grants and student loans using data published by the NCES for the year 2000 (source: Student Financing of Undergraduate Education: 1999-2000, Statistical Analysis Report). In Appendix A we provide a detailed description of the federal system of financial aid to 
college students (as in the year 2000) that we aim to reproduce in estimation.

Some of these parameters can be set externally, because they have an exact counterpart in the data (see Table 6.1). We define the cost of college as tuition fees plus the cost of books and other academic material net of institutional and private grants, and we compute an average across all full-time, fullyear dependent students enrolled in private not-for-profit and public 4-year colleges in the year 2000. We obtain an average annual cost $\phi$ of $\$ 6,700$. Federal and state grants $\mathfrak{g}$ are means-tested, with children of low $(q=1)$, middle $(q=2)$ and high $(q=3)$ wealth parents receiving $\$ 2,820, \$ 668$ and $\$ 143$ per year, respectively. Thus, net annual tuition $\phi(q, \boldsymbol{\theta})$ is $\$ 6,700$ minus the applicable federal grant, depending on $q$.

Cumulative borrowing limits for federal loans to (dependent) students were $\$ 23,000$ in year 2000, of which a maximum $\$ 17,250$ could be subsidized if the student qualified. We use these values to set $\underline{b}$ and $\underline{b}^{s}$ and we specify $\underline{a}^{p}$ so that cumulative private and federal borrowing limits are equal. Moreover, in 2000 the interest rate on federal student loans was prime $\left(r^{-}\right.$in our model $)$plus $2.6 \%$, in addition to initiation fees that are on average $0.5 \%$. Thus we set $r^{u}=r^{-}+\iota^{u}$, where $\iota^{u}=0.031$ annually.

The rest of the parameters are internally estimated. In 2000, to qualify for a subsidized loan (status $q=1$ ) a child's family must pass two tests. The first is a potential income test, which stipulates that the higher earning parent would earn less than a full-time equivalent of $\$ 55,000 .{ }^{24}$ The second test is a parental wealth test based on a threshold which is included as a parameter in our main estimation. A higher wealth threshold, also internally estimated, determines eligibility for unsubsidized loans (status $q=2$ ). Students of type $q=3$ with parental wealth above this second threshold borrow privately at the rate $r^{p}=r^{-}+\iota^{p}$, where $\iota^{p}$ is to be estimated as well. We include three moments in estimation that are especially informative about these three parameters: (i) federal student loans were taken out by $62.1 \%$ of graduating seniors, (ii) subsidized federal loans were taken out by $41.9 \%$ of such students, and (iii) $13.4 \%$ of students did not use any form of government aid. We estimate the two eligibility thresholds to be approximately $\$ 124,000$ and $\$ 168,000$ and the private student loan annual interest

\footnotetext{
${ }^{24}$ The NCES data indicate that very few subsidized loans are given to children from families with high incomes.
} 
premium to be 0.029 .

To simplify the computation we assume that at the end of college all student debt (private and federal loans) is refinanced into a single private bond that carries the interest rate $r^{-}$. Define $\tilde{a}_{3}$ to be the student net asset position based on assets $a_{3}$ (possibly negative for those borrowing from the private sector), federal student loans $b_{3}$ and the qualification indicator $q$. For those students who graduate with debt, $\tilde{a}_{3}$ is computed as the present value of all future payments that must be made on student loans, depending on the amount borrowed and applicable interest rates, discounted at rate $r^{-}$. When making this calculation we assume that fixed payments would have been made for 10 periods following graduation. This approach provides a close approximation to a setting where fixed installments are required for a given number of periods, but households can use unsecured debt to make these payments if necessary. ${ }^{25}$ Appendix A illustrates this conversion scheme in more detail. Because of this simplification, at the end of period $j=3$, college graduates enter the marital matching stage with $\boldsymbol{x}_{3}=\left(\boldsymbol{\theta}, \tilde{a}_{3}, z_{3}\right)$.

\subsubsection{Marital Matching}

Matching takes place at the same age (at the end of period $j=3$ ) for everyone. Although men and women are heterogeneous in several dimensions upon entering the matching stage (education, ability, wealth, and productivity) we assume that (i) probabilistic matching between men and women is based only on education and that (ii) everyone marries. Matching rates in the model are based on observed CPS data, for which educational pairing frequencies are provided in Table 2.1. The heavy weight on the diagonal is a manifestation of the pronounced assortative matching.

Our policy experiments modify the shares of men and women in each education group which requires us to take a stand on how these changes affect the conditional matching probabilities. Our approach is to represent the observed matching matrix of Table 2.1 with an assortative component and a random component, like in Fernández and Rogerson (2001): with some probability, the individual

\footnotetext{
${ }^{25}$ Without this debt consolidation, the state space of married couples would have two additional state variables (student debt of each spouse).
} 


\begin{tabular}{c|ccc}
\hline \hline & \multicolumn{3}{|c}{ Wife's Education } \\
Husband's Education & $\begin{array}{c}\text { Less than High } \\
\text { School }\end{array}$ & High School & College \\
\hline Less than High School & 0.107 & 0.030 & 0.002 \\
High School & 0.027 & 0.498 & 0.042 \\
College & 0.002 & 0.056 & 0.236 \\
\hline
\end{tabular}

Table 2.1: Husband-Wife Matching on Education. Cell frequencies are the percentage of all marriages involving a particular match, i.e. these frequencies sum to one. Source: CPS 2000.

is assigned to a partner of the same education level (or the closest level, if not enough partners of that education group are available in the marriage market) and with the complementary probability she draws randomly from the pool of available men. In counterfactual, we keep this probability constant and thus we maintain the same degree of assortative matching. Appendix B.2 explains this approach in detail.

We assume that the value of marriage is shared equally with full commitment ex-ante and that there is no possibility of divorce. ${ }^{26}$ Full commitment implies that the wealth levels of the two spouses after marriage get combined into a household wealth level. Appendix B contains more details on the calculation of value functions at this stage.

\subsubsection{Working-Age Families}

In this stage, each family solves a standard life-cycle problem akin to the one in equation (2.7). The key difference is that the choice variables include consumption and labor supply of both members of the household. The structure of the shocks is the same, with uncertainty over efficiency units of human capital for both husband and wife, as specified before. Total household expenditures allow for economies of scale, as specified in Section 2.2. The couple's value function $W_{j}\left(\boldsymbol{x}_{j}\right)$, together with the relevant budget constraint, is shown in Appendix C.

\footnotetext{
${ }^{26}$ There are no singles in the model. Consequently there is no well defined outside option to marriage. If there was an alternative to marriage, then the sharing rule would be defined as a share of surplus computed based on outside options. This would add the complexity of a heterogeneous and possibly age-varying Pareto weight in the case of limited commitment, i.e. two additional state variables for the couple.
} 
The household problem becomes slightly different when the children (a pair) are born because parents know the gender of children right away, which adds a state variable from $j=($ age $)$ on. Parents do not know exactly what a child's cognitive and non-cognitive skills will turn out to be yet, but they can forecast them based on parental skills and education. Abilities and education preferences (the random component of the psychic shock) of a child are revealed to their parents at the stage when inter vivos transfers to the children are chosen. The household problem in the period of the inter vivos transfers is described in more detail in Section 2.4 below.

\subsubsection{Retirement}

After inter vivos transfers have been made and children have left home, parents continue working until retirement age $j^{R E T}-1$. Once retired, they solve a simplified problem with labor supply fixed at zero. Their income is augmented by social security payments, which depend on the level of education. Retirees may die at age $j$ with probability equal to the empirical mortality rates (US Life Tables, 2000). We assume perfect annuity markets during retirement, thus the return to saving is increased in line with the mortality rate for the relevant age because the assets of expiring households are redistributed within cohorts. We show the problem of retired households in Appendix C.

\subsection{Intergenerational Linkages}

The two crucial mechanisms for intergenerational linkages in our model are (i) the transmission of skills and (ii) inter-vivos transfers, both from parents to children.

Transmission of Abilities. We view skills as being formed during childhood and crystalized by age 16, the starting point for choices. Given the available data we assume that cognitive and noncognitive skills are drawn from a joint distribution that depends on the mother's own cognition and her education. The dependence on mother's education endogenizes the intergenerational transmission of skills and reflects the dependence of investments in children on educational attainment of parents, which 
is consistent with the literature: Cunha and Heckman (2008) and Cunha et al. (2010) estimate that parental background and child investments have a strong effect on the development of child skills, while Carneiro et al. (2013) find that both maternal education and AFQT test scores are important determinants of child ability.

In counterfactual simulations we assume that the relationship of skills with parental education, conditional on parental cognitive skills, can be taken as causal; hence as the parents change their education choices as a result of policy, they affect child skills based on our estimated relationship. ${ }^{27}$

Intervivos Transfers. Individuals start their life with some wealth and funding for their education, which is the result of parental transfers. To reduce the computational burden, we posit that each family has two identical children. Hence, the family makes the same transfers to each of them. The unconditional transfers $\hat{a}_{0}$ are paid to the child immediately, whereas the college-conditional transfers $\hat{a}^{C L}$ are committed to a trust account when the child is 16 , and then paid to the child upon entering college at 18 .

Utility from children and the resulting transfers, arises from both altruism and paternalism. In what follows, we denote variables for the child with the ^ symbol. The altruistic weight parents put on their child's expected lifetime utility is $\omega_{\hat{g}}$. Beyond altruism, parents may enjoy a utility gain $\xi$ if their child goes to college, reflecting paternalistic preferences. This is an important feature which may explain why, in the data, lower ability children of wealthier parents attend college. It is also relevant for the extent to which private transfers are (or are not) crowded out by government programs. The additional value that parents obtain from their children at the age where the latter start making their own choices is therefore given by

$$
\omega_{\hat{g}} \mathcal{V}_{g 0}\left(\boldsymbol{x}_{0}^{*}\right)+\xi \cdot \mathbb{I}_{\{\hat{e}=C L\}},
$$

where $\mathbb{I}_{\{\hat{e}=C L\}}$ indicates whether the child attends college. At the time of the transfer, parents know

\footnotetext{
${ }^{27}$ Details on estimation of these transition matrices using the the CNLSY79 data are reported in Section 3.
} 
both the abilities of the child $(\hat{\boldsymbol{\theta}})$ and her random shock to education preferences $\left(\hat{\kappa}_{\epsilon}\right)$, which are included in the child's state variables $\boldsymbol{x}_{0}^{*}$. We allow altruism to depend on gender because we observe gender differences in inter vivos transfers; however, we restrict paternalism to be the same across genders because we do not observe gender differences in the influence of parental wealth on education.

Transfers are determined by augmenting the parent's value function by the value defined in equation (2.14) and maximizing with respect to the conditional and unconditional transfers, subject to the constraint that these amounts cannot be negative. The cost of the transfer to the parent is the reduction in their wealth. Gains from transfers accrue to the parents for two reasons. First, the children's value $\mathcal{V}_{g 0}^{*}\left(\boldsymbol{x}_{0}\right)$ is increasing in $\left(\hat{a}_{0}, \hat{a}^{C L}\right)$ and parents are altruistic. Second, a large enough conditional transfer $\hat{a}^{C L}$ can induce the child to choose to attend college, and since parents are paternalistic they experience an extra utility gain $\xi$ from this choice. Because of the fixed nature of the utility gain, this paternalistic motive is stronger for wealthy parents whose marginal utility from consumption is low. Thus to identify the parameters linking generations through altruism and paternalism we will use data on inter-vivos transfers as well as data on educational attainment by parental wealth and child ability. In particular the rate of college attendance for lower ability children is driven exclusively by parental wealth, and this feature helps distinguish pure altruism from paternalistic preferences for college attendance.

The formal structure of the dynamic problem of the family in the period of the inter vivos transfers is presented in Appendix $\mathrm{C}$ and details of the estimation of altruism and paternalism parameters are contained in Section 3.

\subsection{Equilibrium}

We solve for the stationary equilibrium of our economy numerically. In equilibrium, individuals maximize their expected lifetime utility by choosing their education level, federal loans as college students, consumption and saving, labor supply, and inter-vivos transfers to their children. Firms maximize profits by choosing capital and labor inputs. Prices clear all markets. The government 
budget constraint is balanced period by period. Stationarity implies that the cross-sectional allocations for any given cohort of age $j$ are invariant over time. A detailed definition of the stationary equilibrium and its numerical computation is presented in Appendix C.

\section{Estimation Results}

There are three sets of parameters in the model: those that we fix externally based on the literature, such as the intertemporal elasticity of substitution for consumption and labor supply (see Table 6.1 for a complete list); those that are estimated separately, namely the production function, the wage process and the intergenerational transmission of abilities; and those that are estimated within the equilibrium model using the method of moments, conditional on the two previous sets. This last group includes parameters determining the psychic costs of education, some preference parameters (including the discount factor, altruism and paternalism) and several others, listed in Table 6.2.

In what follows, we discuss in more detail the estimation strategy and results for the second set of parameters and for the psychic costs, altruism and paternalism parameters.

\subsection{Aggregate Production Function}

Recall our aggregate technology specification in equations (2.3) and (2.4). Under the assumption that all labor markets are competitive, we estimate the technology parameters and test the iso-elasticity assumptions using CPS data on wage bills and hours worked for the different gender-education groups for the years 1968-2001. Details of our estimation and tests, including robustness checks using different instruments and specifications, are presented in Appendix D.

In the numerical analysis we set the elasticity of substitution between education aggregates to 3.3 (i.e. $\rho=0.7$ ). This is within the range of our estimates and in line with values reported in the literature. ${ }^{28}$ Our specification of technology also allows for imperfect substitutability of male

\footnotetext{
${ }^{28}$ Many estimates in the literature are based on a coarser two-type skilled/unskilled classification for labor, with no
} 
and female efficiency units. ${ }^{29}$ We use a baseline value of $\chi=0.45$ in the numerical simulations, corresponding to an 'education-conditional' elasticity of roughly 1.8 between men and women, a number within our range of estimates. The values of the gender/education CES weights $s^{g, e}$ are reported in appendix D. ${ }^{30}$

This specification of aggregate technology, together with the equilibrium selection mechanism of the model, yields college and high school wage premia that are consistent with the data. Applying the estimation approach of Goldin and Katz (2007) to data simulated from our model, the log college/high-school wage differential is estimated to be 0.58 , and the HS graduate - less than HS log wage differential is 0.37 . These values are close to the estimates presented in Goldin and Katz (2007, Table A8.1) for the year 2000 which place the college premium between 0.58 and 0.61 , and the high-school premium between 0.26 and 0.37 . When we examine gender gaps, recent work by Goldin (2014) indicates that median full-time earnings of women (in the year 2000) were roughly 74\% those of men, and our model generates a corresponding figure of $73 \%$.

\subsection{Wage Process and the Impact of Ability on Earnings}

The wage process is an important ingredient of the model as it determines the career profile as well as the amount of uninsurable uncertainty faced by individuals. We allow individual wage dynamics to depend on age, gender, education and abilities. Heckman et al. (2006b) document that the effects of cognitive skills on earnings are 4-5 times larger than those of non-cognitive skills. In light of this

gender differences. Katz and Murphy (1992) estimate the elasticity of substitution to be 1.41; Heckman et al. (1998a) report a favorite estimate of 1.44. Card and Lemieux (2001) obtain an elasticity of substitution between college and high school workers of about 2.5; however, their estimated elasticity, when accounting for imperfect substitutability across age groups, ranges between 4 and 6. Finally, using a nested specification with three human capital types Goldin and Katz (2007) suggest a preferred elasticity between college and non-college workers of 1.64.

${ }^{29}$ Existing evidence suggests that equally-skilled individuals of different gender are not perfect substitutes, see for example Johnson and Keane (2007).

${ }^{30}$ Our production function specification does not display capital-skill complementarity. Krusell et al. (2000) find evidence of complementarity between equipment capital (but not structure) and college educated workers. Given the richness of the household side of the model, we chose to maintain the production side relatively stylized and opted for one type of capital. In our policy experiments the aggregate capital stock changes very little (policy changes only affect the saving behavior of the wealth-poor, who account for a small share of aggregate wealth). Therefore, the additional effect of changes in capital on the college premium would be fairly small with capital-skill complementarity. 


\begin{tabular}{|c|c|c|}
\hline Education group & Male Gradient & Female Gradient \\
\hline & $0.428(0.054)$ & 0.184 \\
\hline HS C & $0.517(0.030)$ & $0.601(0.036)$ \\
\hline College Graduate & $0.797(0.109)$ & $0.766(0.099)$ \\
\hline
\end{tabular}

Table 3.1: Estimated ability gradient $\lambda^{g, e}$ (NLSY79). Standard errors in parentheses.

finding, we make the simplifying assumption that only cognitive ability directly affects earnings in the labor market.

The idiosyncratic labor productivity process $\varepsilon_{j}^{g, e}$ is specified as (dropping the individual subscript $i$ to ease notation):

$$
\log \varepsilon_{j}^{g, e}=\lambda^{g, e} \log \theta_{c o g}+A_{j}^{g, e}+z_{j}^{g, e},
$$

where $A_{j}^{g, e}$ is the gender- and education-specific deterministic age profile (proxied by a quadratic polynomial) and

$$
z_{j}^{g, e}=\varrho^{g, e} z_{j-1}^{g, e}+\eta_{j}^{g, e}, \quad \eta_{j}^{g, e} \stackrel{i i d}{\sim} N\left(0, \sigma_{\eta}^{g, e}\right)
$$

The initial value $z_{0}^{g, e}$ is drawn from a normal distribution with mean zero and variance $\sigma_{z_{0}}^{g, e}$. The impact of cognitive skills on wages $\lambda^{g, e}$, the persistence of idiosyncratic productivity shocks $\varrho^{g, e}$, and the variance of idiosyncratic productivity innovations $\sigma_{\eta}^{g, e}$ all vary by gender and education attainment. This heterogeneity in returns to schooling will in part drive differences in education choices between men and women and across ability groups.

We estimate wage processes correcting for selection into work, which provided significant adjustments for women but not for men. In Appendix $\mathrm{E}$ we discuss aspects of the estimation and report the resulting deterministic age profile for each education group, which is by now standard: the higher the level of education, the steeper the increases of wages with earnings.

The estimates of the ability gradient and the stochastic process of the shocks are reported in Tables 3.1 and 3.2 respectively. The ability gradient for wages increases with education, implying a strong complementarity between the two. It is also the case that the returns to ability increase by more for 


\begin{tabular}{|c|c|c|c|c|c|c|}
\hline \multicolumn{7}{|c|}{ Males } \\
\hline & \multicolumn{2}{|c|}{ Less than HS } & \multicolumn{2}{|c|}{ HS Graduates } & \multicolumn{2}{|c|}{ College graduates } \\
\hline Persistence & $\varrho^{m}$ & $0.955(0.010)$ & $\varrho^{m}$ & $0.952(0.005)$ & $\varrho^{m}$ & $0.966(0.015)$ \\
\hline Permanent shock & $\sigma_{\eta}^{m}$ & $0.015(0.002)$ & $\sigma_{\eta}^{m}$ & $0.017(0.001)$ & $\sigma_{\eta}^{m}$ & $0.017(0.005)$ \\
\hline Initial dispersion & $\sigma_{z 0}^{m}$ & $0.037(0.005)$ & $\sigma_{z 0}^{m}$ & $0.059(0.003)$ & $\sigma_{z 0}^{m}$ & $0.094(0.009)$ \\
\hline \multicolumn{7}{|c|}{ Females } \\
\hline Persistence & $\varrho^{f}$ & $0.852(0.023)$ & $\varrho^{f}$ & $0.953(0.003)$ & $\varrho^{f}$ & $0.983(0.016)$ \\
\hline Permanent shock & $\sigma_{\eta}^{f}$ & $0.026(0.005)$ & $\sigma_{\eta}^{f}$ & $0.019(0.001)$ & $\sigma_{\eta}^{f}$ & $0.018(0.004)$ \\
\hline Initial dispersion & $\sigma_{z 0}^{f}$ & $0.035(0.011)$ & $\sigma_{z 0}^{f}$ & $0.041(0.003)$ & $\sigma_{z 0}^{f}$ & $0.076(0.007)$ \\
\hline
\end{tabular}

Table 3.2: The Stochastic Process of Wages. Estimates of parameters of the process for individual efficiency units $\varepsilon_{j}^{g, e}$ (NLSY79). The $\sigma$ parameters denote variances of the respective shock. Annualized values. Standard errors in parentheses.

women than for men, particularly at lower education levels. Shocks are highly persistent, and close to being a random walk for all but females with less than high school. Notably, even for given ability, the variance of initial productivity draws increases with education for women, and even more so for men. This uncertainty is particularly difficult to insure against, since at young ages individuals tend to be wealth-poor.

\subsection{Intergenerational Transmission of Cognitive and Non-Cognitive Skills}

To measure the transmission of cognitive and non-cognitive skills between generations, we use data from the 'Children of the NLSY79' survey, which provides test scores of cognitive skills and education for mothers, as well as cognitive and non-cognitive skills for children. We approximate noncognitive skills using the first principal component factor among five measures from the behavioral problems index (antisocial, anxiety, headstrong, hyperactive and peer conflicts). Children's cognitive skills are measured as the first principal components among PIAT math, reading recognition and reading comprehension scores. Mothers' cognitive skills are approximated by AFQT scores. Mothers are 


\begin{tabular}{lcccc}
\hline \multirow{2}{*}{ Mother's Education } & \multicolumn{4}{c}{ Child Cognition Tercile } \\
& Mother's AFQT Tercile & 1 & 2 & 3 \\
\hline \multirow{3}{*}{ Less than High School } & 1 & 0.446 & 0.321 & 0.232 \\
& 2 & 0.412 & 0.332 & 0.255 \\
\multirow{3}{*}{ High School } & 3 & 0.343 & 0.346 & 0.311 \\
& 1 & 0.364 & 0.343 & 0.293 \\
College & 2 & 0.319 & 0.347 & 0.334 \\
& 3 & 0.298 & 0.346 & 0.356 \\
& 1 & 0.320 & 0.347 & 0.333 \\
& 2 & 0.260 & 0.339 & 0.402 \\
& 3 & 0.224 & 0.324 & 0.452 \\
\hline
\end{tabular}

Table 3.3: Ability transition probabilities by Mother's Education and Ability. Cognitive achievement of children conditional on mother's education and AFQT tercile (tercile 1 lowest, tercile 3 highest).

also classified into three education attainment levels.

We begin by grouping individuals into terciles of each skill variable (separately mother and children). The discretization of skills and the level of detail we choose is designed to make the computational problem tractable. Having discretized skill levels in this way, we characterize each mother by an education/cognitive achievement pair, and each child by a cognitive/non-cognitive achievement pair. In this way we are able to estimate a $9 \times 9$ transition matrix $\Gamma_{\theta}$ of empirical frequencies, linking mothers' education and cognitive skills to the cognitive and non-cognitive achievement of their children. The entire transition matrix is reported in online appendix Table F.1. In Table 3.3 we summarize the full transition matrix by reporting the distribution of child cognitive outcomes conditional on maternal cognition tercile and education. A mother's education and cognition are both important for her child's cognitive skills. These results confirm the presence of a strong relationship between maternal inputs and child skills as documented in papers already cited above. 


\subsection{The Method of Moments Estimation}

Table 6.1 in the appendix lists parameters that we set in advance. Given these parameters, as well as the production function, income processes and transition matrices for intergenerational transmission of cognitive and non-cognitive skills that we have just discussed, we estimate the remaining parameters by minimizing an unweighted quadratic distance criterion between data moments and corresponding moments implied by the model. The moments implied by the model can be computed explicitly without simulation, exploiting the fact that we discretize the state space. We then use the Efficient Global Optimization algorithm (Jones et al., 1998), which is derivative free, saving computational time in practice. In what follows we discuss results on psychic costs of education and intergenerational linkages in preferences.

Table 6.2 shows the remaining estimated parameters with corresponding standard errors (computed with pre-set and pre-estimated parameters taken as given), and Tables 6.3-6.6 show the fit of the model with respect to the distribution of educational attainment by parental wealth and cognitive skills.

\subsection{Psychic Cost of Education}

Schooling is determined by the discrete choice problems in equations (2.6) and (2.8). Variability in educational attainment by cognitive and non cognitive skills, for which we have measures, helps identify $\varsigma_{2}^{e}$ and $\varsigma_{3}^{e}$. The expression for the psychic costs of education also includes the parameter $\varsigma_{4}^{e}$, which defines the variance of unobserved shocks to the costs of education. This raises an identification question: normally in a discrete choice model this scale parameter would not be identified, which would mean that the psychic costs of schooling would be identified up to scale only. Here, however, the choice between education levels depends on the expected value implied by each educational option. These value functions have a scale that is entirely determined by the flow of leisure and consump- 


\begin{tabular}{|c|c|c|c|c|c|}
\hline \multicolumn{2}{|c|}{ Parameter } & \multicolumn{2}{|c|}{ High School } & \multicolumn{2}{|c|}{ College } \\
\hline \multirow{3}{*}{$\varsigma_{0}^{e}$} & \multirow{3}{*}{ Constant } & Coefficient & Marginal effect & Coefficient & Marginal effect \\
\hline & & 0.6501 & & 0.8244 & \\
\hline & & $(0.0208)$ & & $(0.0261)$ & \\
\hline \multirow{2}{*}{$\varsigma_{1}^{e}$} & \multirow[t]{2}{*}{ Female } & 0.1133 & -0.076 & -0.0313 & 0.017 \\
\hline & & $(0.0121)$ & & (0.0196) & \\
\hline \multirow{2}{*}{$\varsigma_{2}^{e}$} & \multirow{2}{*}{$\log \left(\theta_{\text {non }}\right) / \sigma_{\text {non }}$} & -0.0608 & 0.050 & -0.0670 & 0.035 \\
\hline & & $(0.0081)$ & & $(0.0124)$ & \\
\hline \multirow{2}{*}{$\varsigma_{3}^{e}$} & \multirow{2}{*}{$\log \left(\theta_{\operatorname{cog}}\right) / \sigma_{\operatorname{cog}}$} & -0.0896 & 0.075 & -0.1621 & 0.086 \\
\hline & & (0.0349) & & $(0.0335)$ & \\
\hline \multirow{2}{*}{$\varsigma_{4}^{e}$} & \multirow{2}{*}{$\kappa_{\epsilon}$} & 0.1270 & -0.093 & 0.3342 & -0.19 \\
\hline & & $(0.0221)$ & & $(0.0317)$ & \\
\hline
\end{tabular}

Table 3.4: Parameters of the psychic cost functions. When coefficients are negative it means that increasing the corresponding variable reduces the psychic costs of education. Reported marginal effects are changes in the proportion attending the respective education level (high school or college) as a result of increasing the corresponding right hand side variable by one standard deviation in the psychic costs function, for that education level only, and keeping everything else the same. For the case of "Female" the marginal effect corresponds to changing male preferences to be identical to females. Asymptotic standard errors are in parentheses.

tion. ${ }^{31}$ In other words, once we specify a preference class and assign values to its parameters, value functions are completely determined, including their scale. Moreover, these values enter the education choice with a unit coefficient and thus determine the scale of the psychic costs in the same util units in which the values themselves are defined (see equations 2.6 and 2.8). ${ }^{32}$

The parameters of the psychic costs of education are presented in Table 3.4. In interpreting these values note that all right hand side variables are standardized to have unit variance and mean zero.

Being a woman increases the cost of high school but has no significant effect on college psychic costs, although the point estimate is negative. Non cognitive and cognitive skills reduce costs of education. Cognitive skills have a particularly important effect in reducing costs of college.

In Table 3.5 we present the value of psychic costs for High School graduates and College gradu-

\footnotetext{
${ }^{31}$ Obviously, a convenient, but innocuous, normalization is implicit in the model to convert dollars into units of the final good, whose price is set to one.

${ }^{32}$ See also Heckman and Navarro (2007), Cunha et al. (2005), Eisenhauer et al. (2015) for identification issues of dynamic discrete choice models.
} 


\begin{tabular}{lcc}
\hline \hline & High School & College \\
\hline Average in the population & $9.4 \%$ & $20.1 \%$ \\
Average among graduates & $8.9 \%$ & $13.5 \%$ \\
\hline Explained Variance $\left(R^{2}\right)$ & $60.5 \%$ & $37.3 \%$ \\
\hline \hline
\end{tabular}

Table 3.5: Psychic costs of education expressed as a percentage of average life-cycle consumption $(\$ 583,000)$. Explained variance relates to the proportion of the population variance of psychic costs accounted for by the observable variables: cognitive skills, non-cognitive skills and gender. Psychic costs of college include the cost of completing both high school and college.

ates. These are the total realized costs for completing the respective level of education born by those making this choice. These numbers are thus lower than the corresponding population ones because of self-selection. As already discussed the psychic costs include an observable and an unobservable component. The explained variance $\left(R^{2}\right)$ for high school graduates is $60.5 \%$ of the total, while for college graduates it is $37.3 \%$. Thus while measurable cognitive and non-cognitive skills play an important role, there is a large part of the psychic costs of education that remains unexplained, particularly for college, as also found by Eisenhauer et al. (2015) amongst others.

\subsection{Altruism, Paternalism and Inter Vivos Transfers}

The NLSY97 provides information on family transfers received by young individuals. In particular, it asks respondents about any gifts in the form of cash (not including loans) from parents. Appendix G describes the sample we construct and the methodology we use to measure early inter vivos transfers, and it reports basic facts about parental gifts to young individuals, as recorded in the NLSY97. Since we model early inter vivos transfers as one-off gifts from parents to children occurring before college age, we restrict attention to the cumulative transfer between age 16 and 22. In our calculations we also include imputed rents for students living in their parents' home. ${ }^{33}$

In the data we observe male children receiving somewhat larger transfers than female children.

\footnotetext{
${ }^{33}$ We find that the co-residence component makes up a large fraction of the total inter vivos transfers, as also emphasized by Johnson (2011).
} 
The average transfer gifted to a male child is just above $\$ 33,000$, while the average transfer gifted to a female child is around $\$ 29,000$.

Paternalistic preferences for college, beyond pure altruism, may motivate wealth transfers. To help identify the effect of paternalism, we use information about the relative college attainment rate of children from wealthy and high income families relative to poorer families for different ability levels of the children. College attainment in the NLSY97 is strongly and positively correlated with reported parental income and net worth. For example, children whose parents are in the fourth quartile of the wealth distribution are nearly three times as likely to become college graduates as those whose parents are in the first quartile. More importantly, low ability children from wealthy families are much more likely to attend college than similar children from less wealthy families. This difference helps identify paternalistic preference. Among the estimation moments we include the fractions of college graduates and those with less than High School within each parental wealth quartile and parental income quartile.

The resulting estimated altruism parameters are $\omega_{\hat{m}}=0.518($ s.e. $=0.107)$ for males and $\omega_{\hat{f}}=$ 0.470 (s.e. $=0.076)$ for females, showing a small preference for boys which translates into some gender differences in inter vivos transfers across counterfactual policy experiments. ${ }^{34}$

The paternalism parameter is estimated to be $\xi=0.28$ (s.e. $=0.04)$, which corresponds to a parental willingness to pay for college attendance of the child of $\$ 21,500$ on average or $3.7 \%$ of average lifecycle consumption. The economic importance of this parameter can be seen in the fact that in our model about $30 \%$ of college graduates receive conditional transfers from their parents. Among students receiving conditional transfers, 2/3 have parents in the top quartile of net worth and the remaining $1 / 3$ have parents in the third quartile of net worth. Without the paternalistic preference for college, the model would not be able to explain the extent to which college attainment rates among children of wealthy parents exceed those among children of poorer parents, particularly for lower ability children.

\footnotetext{
${ }^{34}$ Imposing an equal parameter for altruism between genders would, however, fail to fully close the $\$ 4,000$ gap in transfers estimated in the data, suggesting that this difference has more to do with heterogeneity in market returns.
} 


\section{Implications of the Model}

We examine the behavior of the model along six dimensions. First, we analyze the implied lifecycle profiles for hours worked, earnings, consumption, and wealth. None of these moments are explicitly targeted in the parameterization (only those for wages are). Second, we study the determinants of parental transfers to children. Third, we measure the degree of intergenerational persistence of educational attainment and income in the model (also, not targeted). Fourth, we examine the role of parental wealth in determining educational achievement. Fifth, we reinforce the empirical plausibility of the model by simulating an artificial randomized experiment where a (treatment) group of highschool graduates receives a college tuition subsidy and a (control) group does not. This last simulation shows that the elasticity of college attainment with respect to tuition in our model is comparable to estimates from the empirical literature on schooling. Finally, we assess the role of assortative matching in determining the return to education and other aggregate equilibrium outcomes. In Appendix $\mathrm{H}$ we show that the model also provides reasonably good out-of-sample predictions on college attendance rates and wage premia when extrapolated to the year 2010.

\subsection{Life-Cycle Profiles}

Figure 4.1 plots averages and dispersion of log earnings, log consumption, and wealth over the life cycle for our three education groups. It also reports log hours worked separately by gender.

Average hours worked by men follow a canonical hump-shape over the life-cycle, which is a reflection of the hump-shape in the exogenous age-productivity profiles. There is considerable dispersion in the early career hours of men, followed by a steady rise from the early 30 's to retirement. Women's hours worked exhibit, as expected, changes due to the presence of children in the household. Average female hours fall as preferences for non-market time increase during child raising years. The dispersion of hours also increases during this period as female labor supply elasticities are larger with children. 

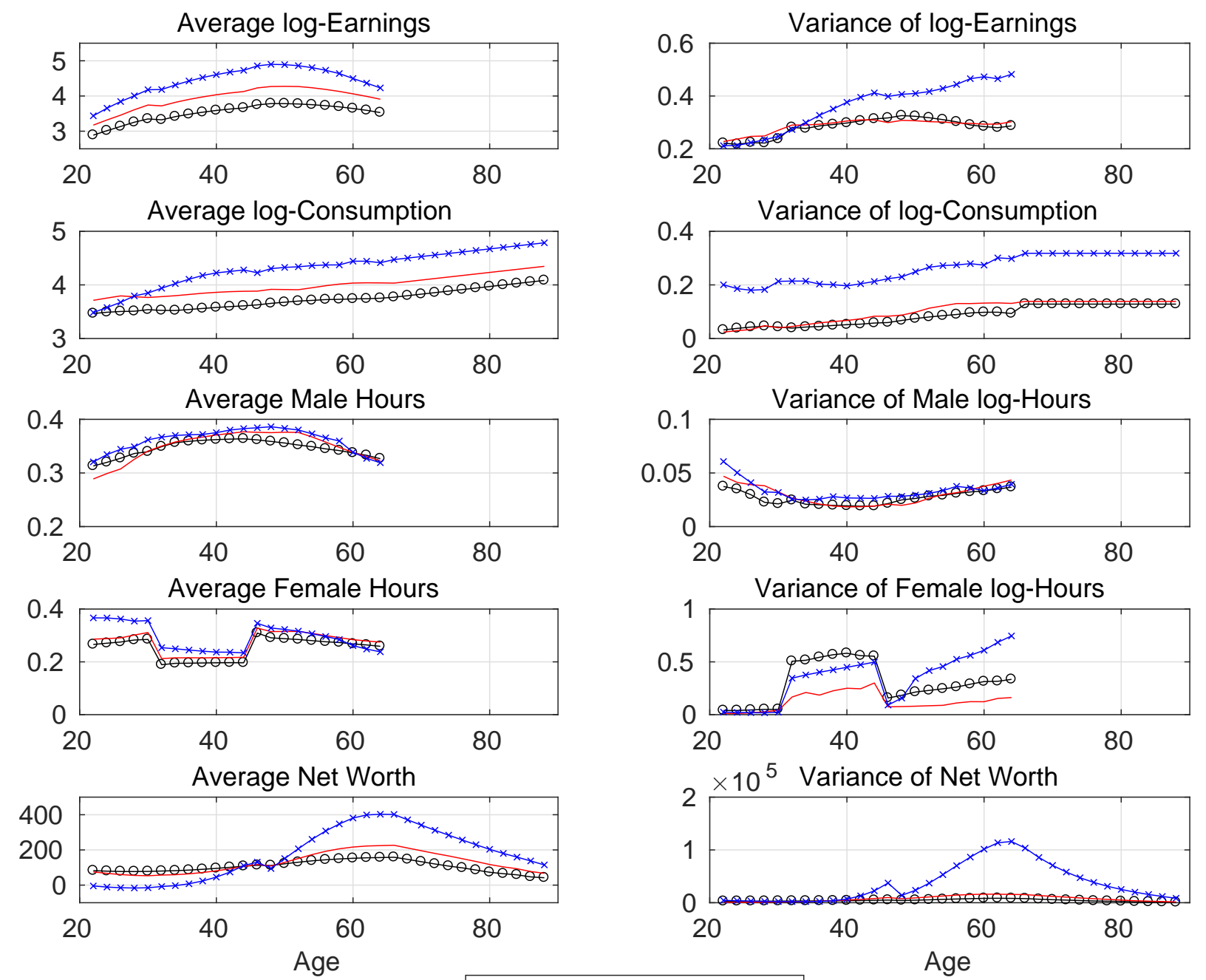

$\multimap \mathrm{LHS}-\mathrm{HSG} \rightarrow \mathrm{CL}$

Figure 4.1: Statistics are presented by education. Lines marked with ' $x$ ' are headed by a college graduate, and those marked with 'o' are headed by someone with degree less than High School. For family level variables (consumption and wealth) the education of the head (male) is used for classification. 
The rise in average earnings over the life cycle is more pronounced for more educated households and the changes in the variance of log earnings between ages 25 and 60 are quantitatively consistent with empirical evidence -for an example, see Guvenen (2009, Figure 4). ${ }^{35}$

A comparison between consumption and earnings paths (both their mean and dispersion) reveals that consumption smoothing through borrowing and saving is quite effective after the schooling phase. During working life the variance of log consumption grows $0.1 \log$ points for college grads and a bit less for households with less educated heads. These changes compare to a rise twice as large in the variance of households' log earnings. During retirement, the combination of annuity markets and interest rate above the discount rate implies a linear upward sloping consumption pattern and constant dispersion in logs.

Wealth accumulation features the typical hump-shaped pattern. In the model, the drop in household wealth at age 48 arises as a consequence of the inter vivos transfer to children. The drop is much larger for the highly educated families, whose children are the most likely to attend college. Young college students and college graduates decumulate their wealth and borrow to enroll in college and to smooth consumption in their first years of working life.

\subsection{Determination of Inter Vivos Transfers}

Several forces shape parental decisions on how much to transfer to their children. The first purpose is narrowing the gap between parent's and child's lifetime utilities, and the extent to which parents want to close this gap depends on the degree of altruism $\left(\omega_{\hat{g}}\right)$. This motive (intergenerational smoothing) is strongest for low ability and low earning-potential children, especially those with rich parents. Paternalism, as explained, pushes in this same direction. The second purpose is that of alleviating the financial constraints of children in the event they choose to go to college. This second motive (college education financing) is strongest for high ability children whose return to attending college is the highest.

\footnotetext{
${ }^{35}$ Households are categorized by the highest education within a household.
} 

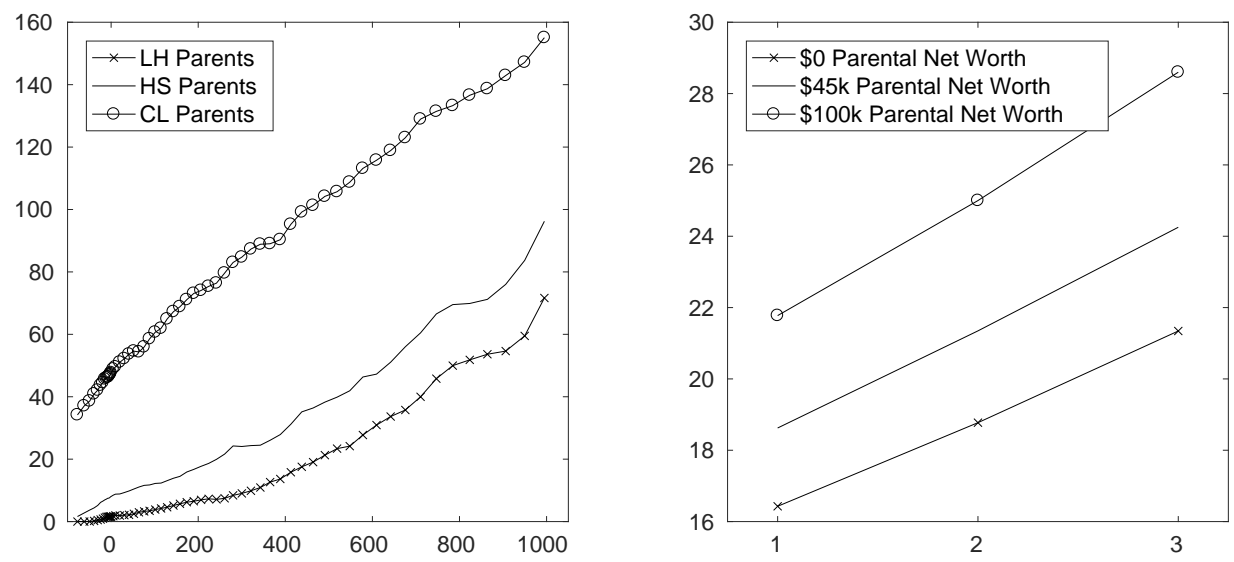

Figure 4.2: Parental transfers to children as a function of: household head's education and parental wealth (left panel); parental wealth and child's ability (right panel).

The left panel of Figure 4.2 shows that in the model inter vivos transfers (IVTs) increase monotonically with parental wealth at the age of the transfer (age 48). For some poor families (about $15 \%$ in our model) the marginal cost of transferring to the children is too high in terms of their own foregone consumption, and they make no transfer. ${ }^{36}$ Finally, this plot also shows that, for given wealth, highly educated parents save more for the IVT, as they expect their children to be on average of a high ability type as well, therefore with large gains from college education. The right panel of Figure 4.2 shows that transfers tend to be increasing in the ability of the child (holding the parents' abilities constant) because greater financial resources are needed to pay for education.

\subsection{Intergenerational Persistence of Education and Income}

The model generates a realistic intergenerational correlation of college attainment. In the model $50.0 \%$ of those whose mother is a college graduate, and $47.4 \%$ of those whose father is a college graduate, become college graduates themselves. Furthermore, $52.1 \%$ of those for whom both parents are college graduates become college graduates themselves. Although these statistics are not targeted in the estimation, we do well in replicating patterns observed in data. For example, in the NLSY79

\footnotetext{
${ }^{36}$ Indeed, in many cases parents would be better off with a negative transfer (i.e., receiving a transfer from their child) as they expect their child to earn more, eventually.
} 


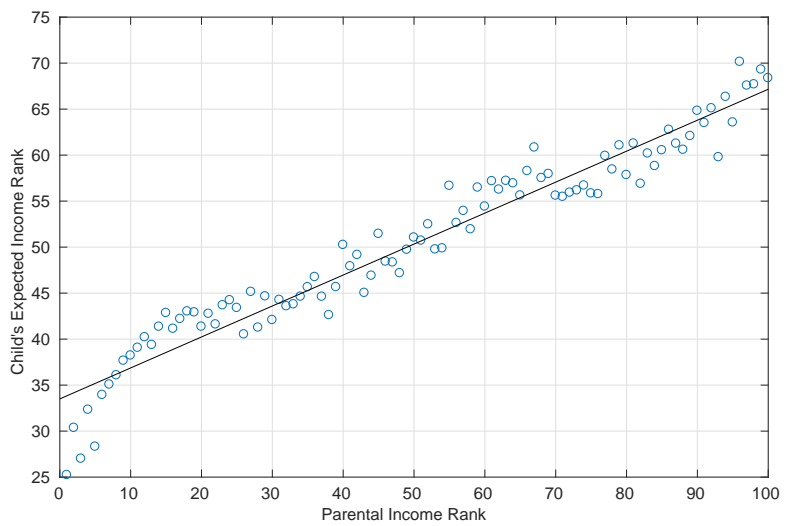

Figure 4.3: Intergenerational rank-rank regression

$47.2 \%$ of children whose mother is a college graduate also attain a college degree, while $55.3 \%$ of those for whom both parents are college graduates attain a college degree.

The model is able to replicate these high degrees of persistence in part because it includes cognitive and non-cognitive skills and paternalism. The skills are important both directly and indirectly. Directly because parental cognitive skills in part determine the children's cognitive skills, which in turn drive college attendance and wages. Indirectly because parental education leads to the improvement of child skills, which in turn reduces the psychic costs of college for children of educated parents. Paternalism increases the tendency for rich parents to 'send' their child to college, further increasing persistence.

We also evaluate model performance in terms of intergenerational income persistence. Chetty et al. (2014) use IRS tax data to study the relationship between the mean child income rank and parents' income rank for cohorts of children born between 1971-1986, and estimate a linear regression slope between 0.25 and 0.35 for male children, depending on the birth year. We repeat this exercise on our simulated data, with the same definition of pre-tax household income averaged over ages 31-46 for both children and parents, and find a slope of 0.33 , thus within the above range. Furthermore, as can be seen in Figure 4.3, we find that a child's expected income rank is well approximated by a linear function of their parent's rank in our model, just as Chetty et al. (2014) find in IRS data. Note 


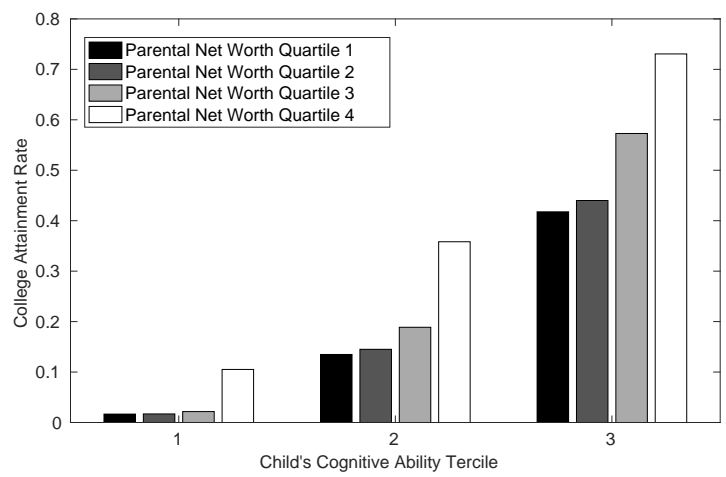

College attainment rate

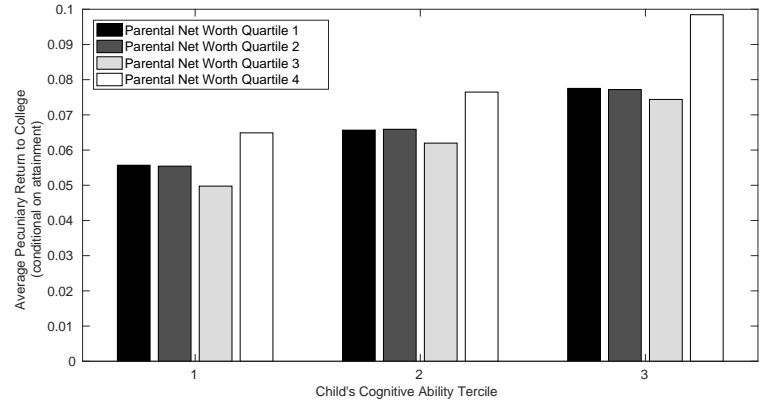

Financial returns to education

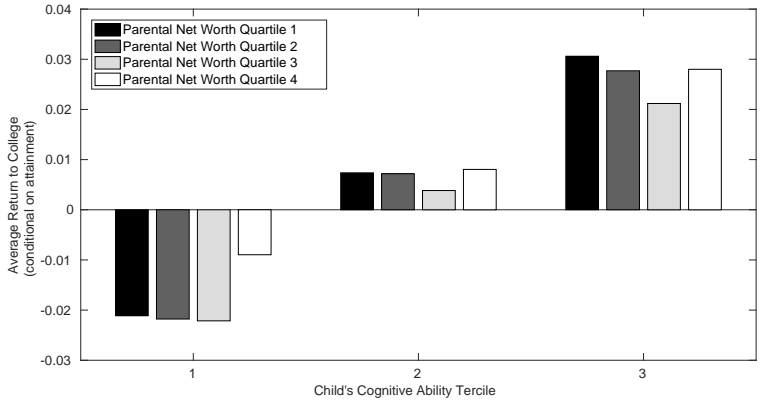

Total returns to education

Figure 4.4: College attainment and returns to college for graduates, by ability and parental wealth: model simulations

however, that below the 20th percentile of income we observe a steeper slope of about 1.0.

The more traditional intergenerational log-log earnings correlation in our simulated sample is 0.34. Jantti et al. (2006) estimate this elasticity for the US at 0.36, and similar values are found by Solon (1999).

\subsection{Parental Wealth and Educational Achievement}

In this section we examine the relative roles of family background and cognitive ability in the determination of education outcomes.

First, we analyze the correlation between cognition, wealth and income across households to make sure that in our model parental skills and parental resources are distributed as in the data. Zagorsky 
(2007) uses the 2004 module of the NLSY79 to estimate a correlation between income (net worth) and AFQT test scores of 0.30 (0.16, respectively) in a sample of individuals aged 40 and 47 . In our benchmark simulation, the correlation between income (wealth) and cognitive ability $\theta_{\operatorname{cog}}$ for the same age range is similarly $0.30(0.24$, respectively).

Next, we plot a bar graph that displays college graduation rates by child's ability tercile and by parental net worth quartile in the model. The top panel of Figure 4.4 shows a positive gradient in both dimensions, a feature that is very similar to the findings of Belley and Lochner (2007).

A striking feature of this plot is the large role played by parental wealth at every ability level. Even amongst higher ability children, parental wealth plays an important role with $40 \%$ college attendance for those whose parents are in the lowest quartile of wealth, increasing to $70 \%$ attendance for top wealth quartile. Among the lowest ability children almost none attend college unless their parents are from the highest wealth quartile. Paternalism plays a key role in generating this pattern in the model: wealthy parents induce children with lower ability to attend college. ${ }^{37}$

The importance of paternalism becomes especially evident in the lower panels of Figure 4.4, where we plot the financial returns (the left panel) and the total returns -financial returns net of the monetized value of the psychic cost — for those graduating, by parental wealth and child ability.

The financial returns are computed by calculating the proportion of consumption that would have to be given to individuals who graduate from college in the model if they, instead, had not enrolled in college in order to make them indifferent between the two choices. Specifically, the financial return is the number $\varphi$ that solves the following equation:

$$
\sum_{g=m, f} \int_{S_{1}^{g, *}} V_{g 1}^{*}\left(\boldsymbol{c}^{C L}, \boldsymbol{l}^{C L} ; \boldsymbol{x}_{\mathbf{1}}^{*}\right) d \mu_{1}^{g, *}=\sum_{g=m, f} \int_{S_{1}^{g, *}} \mathbb{E}_{z}\left[V_{g 1}^{H S}\left((1+\varphi) \boldsymbol{c}^{H S}, \boldsymbol{l}^{H S} ; \boldsymbol{x}_{\mathbf{1}}^{*}, z\right)\right] d \mu_{1}^{g, *}
$$

The left-hand side is simply the expected value of a college degree for all those who optimally choose

\footnotetext{
${ }^{37}$ Indeed among the lowest ability group all college graduates receive conditional transfers that compensate them for this loss. In the middle ability group 50\% of those from the two lower wealth groups receive such transfers and $60 \%$ of the two higher groups. Finally among the highest ability group $20 \%-30 \%$ receive conditional transfers with the wealthier group transferring more, conditional on attendance, as we would expect.
} 
to attend. The right-hand side is the counterfactual expected value if the same set of individuals (distributed accordingly to $\mu_{1}^{g, *}$, the distribution of college students at $j=1$ ) had started working as HS graduates instead of going to college. Note that on the right-hand side we also need to integrate over initial productivity. The sequences $\boldsymbol{c}^{e}$ and $\boldsymbol{l}^{e}$ are the state contingent life-cycle consumption and leisure plans of such individuals as college and high-school educated workers. Conditional inter-vivos transfers are given to individuals also in the counterfactual, thus they do not affect the calculation of returns. Financial returns to college thus capture (i) the additional consumption associated to the college wage premium; (ii) the consumption-equivalent value of being more likely to meet a college- educated partner on the marriage market, and (iii) the additional consumption-equivalent value (through altruism and paternalism) of being a college-educated parent, and thus having children with better skills and better economic outcomes. To compute total returns (as opposed to simple financial ones) we subtract $\kappa_{g}^{C L}\left(\boldsymbol{\theta}, \kappa_{\epsilon}\right)$, the additional psychic costs incurred due to college attendance, from the college value function inside the integral on the left hand side. Thus total returns also incorporate the consumption-equivalent value of the psychic cost.

The financial returns are always positive and increasing by ability, ranging between $5 \%$ in the lowest ability group to $10 \%$ in the highest ability one. ${ }^{38}$ What is striking, however, is that the total returns are negative for those in the lowest ability group once psychic costs are taken into account. Those from this group who attend college only do so because of the conditional parental transfers due to paternalism.

\subsection{Tuition Elasticity of College Attainment}

The simulated response of aggregate college attainment to a small change in tuition fees is also similar to responses measured in actual data. To measure this response in our model we perform a partial equilibrium simulation in which we reduce tuition fees by $\$ 1,000$ per year just before a single cohort

\footnotetext{
${ }^{38}$ The effect of parental wealth on these returns reflects different selection into college.
} 
of children make their education decisions. ${ }^{39}$ The aggregate graduation rate of this cohort increases by 3.95 percentage points.

This response is consistent with existing empirical evidence. Kane (2003) and Deming and Dynarski (1995) provide a synopsis of the empirical estimates from similar quasi-natural experiments in which a discrete change in aid policy affects one group of individuals but not others, and conclude that enrollment into college by high-school graduates benefitting from an additional tuition grant of $\$ 1,000$ rises between 3 and 5 percentage points. ${ }^{40}$ Other studies use cross-state variation in tuition costs to estimate that enrollment would rise by 4 to 6 percentage points per $\$ 1,000$ reduction in tuition costs (Cameron and Heckman, 1998; Kane, 1994).

\subsection{Marriage Market}

The marriage market plays an important role in our model. The education of the partner has an impact on the human capital of children both directly (through the mother) and indirectly through wealth. Thus, the amount of marital sorting affects the intergenerational transmission of ability and of wealth. To illustrate the practical importance of these features we conduct two extreme counterfactual simulations in which (a) we impose random matching and (b) we impose perfectly assortative matching. ${ }^{41}$

The results in Table 4.1 confirm that the structure of the marriage market plays a significant role for economic outcomes. Moving from current levels of assortativeness to random matching would imply declines in welfare, output and educational attainment, particularly for women. Moving to perfect sorting has opposite but smaller effects, because the baseline economy is quite assortative in the first place.

\footnotetext{
${ }^{39}$ This is the P.E. version of out $\$ 1,000$ grant expansion counterfactual, reported in section 5.3.

${ }^{40}$ Among the policy changes surveyed in these studies, the closest to our simulated experiment are the Georgia Hope Scholarship program, the Social Security Student Benefit program, the Washington DC Tuition Assistance Grant program, the Cal Grant program, and other similar examples of discontinuities in fellowship eligibility at individual institutions.

${ }^{41}$ We can do this by manipulating the matrix governing assortativeness as explained in Section 2.3.2.
} 


\begin{tabular}{lcc}
\hline \hline \multirow{2}{*}{ Outcome } & \multicolumn{2}{c}{ Marital Sorting } \\
& Random & Perfect \\
\hline College Grads. - Males & $-0.76 \mathrm{pp}$ & $0.3 \mathrm{pp}$ \\
College Grads - Females & $-1.2 \mathrm{pp}$ & $0.5 \mathrm{pp}$ \\
Output & $-0.73 \%$ & $0.27 \%$ \\
Welfare & $-0.54 \%$ & $0.35 \%$ \\
\hline \hline
\end{tabular}

Table 4.1: Marriage market sorting (random or perfect) and economic outcomes. Changes from baseline economy ( $\mathrm{pp}$ denotes percentage points).

\section{Policy Experiments}

In this section we conduct two sets of policy experiments. The first is aimed at assessing the role of the existing federal financial aid system — loans and grants - while the second examines the effects of marginal expansions in financial aid. ${ }^{42}$

Our main focus will be on the long run responses, which allow parental transfers and factor prices to change as well as budget balancing fiscal adjustments to take place. All these components are important because they can mitigate the effects of policy. At the same time, the long run equilibrium also allows for changes in the distribution of ability, through the impact of education on cognitive and non-cognitive skills, which may in turn reinforce policies that encourage education.

We present our results in two steps. The first step, which we call 'partial equilibrium (PE) shortrun', computes changes in outcomes of interest for the first affected cohort, holding prices and fiscal variables constant. The policy announcement is made just before parents choose their inter vivos transfer, hence this experiment incorporates only the short-run behavioral response of parents (e.g. transfers) and children (e.g. labor supply in college) to the policy. We then consider an experiment we call 'general equilibrium (GE) long-run, in which we compute the long run steady-state with new market clearing prices and the new stationary distribution of individuals across education, wealth, and ability. Government expenditures $G$ are held constant in this experiment, thus in this latter experiment

\footnotetext{
${ }^{42}$ In all policy experiments we assume that college fees do not change and financial markets do not offer new or modified loan products.
} 
adjustments of marginal labor income tax rates are required to balance the government's budget. Note that in such an economy with liquidity constraints and uninsurable idiosyncratic risk it is not obvious whether expanding (cutting) federal aid programs will require a higher (lower) tax rate on labor. For example, broadening these programs can be self-financing through a wider tax base, particularly with imperfectly substitutable human capital aggregates (see Findeisen and Sachs, 2015, for a discussion of these issues).

A key aspect of the results from our GE experiments is the analysis of welfare changes induced by the policy reform. We express these changes as a percentage of lifetime consumption for a newborn economic agent (an individual at age $j=0$ ) behind the veil of ignorance with respect to her initial conditions (wealth and ability). To understand what drives the total welfare effect, we decompose it into three separate components: (i) a "level" effect on average consumption; (ii) an "uncertainty" effect due to changes in the volatility of individual consumption paths; and (iii) an "inequality" effect due to changes in the distribution of initial conditions. In Appendix I we provide a derivation of this welfare decomposition that builds on Benabou (2002).

\subsection{Value of Existing Federal Aid Programs}

In this section we explore how equilibrium outcomes would change in the model if federal aid programs were entirely removed from our benchmark representing the US economy. Key results are shown in Table 5.1. A variety of additional results are reported in Appendix J. Moreover, in Appendix $\mathrm{K}$ we assess the robustness of the grant and loan removal experiments under fixed interest rates (an open economy model), and for different values of the elasticity between human capital aggregates.

Removing Tuition Grants. Removing tuition grants induces a noticeable reduction in college attainment in the long-run. The loss of college students is partly mitigated by equilibrium price adjustments. As shown in the top panel (A) of Table 5.1, attainment in the short-run PE scenario would be roughly 7.5 percentage points lower. In GE this scarcity effect puts upward pressure on the college 


\begin{tabular}{|c|c|c|c|c|}
\hline \multicolumn{5}{|c|}{ Panel A: Removal of Grants } \\
\hline & & Benchmark & $\begin{array}{c}\text { P.E. } \\
\text { Short-run }\end{array}$ & $\begin{array}{c}\text { G.E. } \\
\text { Long-run }\end{array}$ \\
\hline & Men & 0.294 & 0.212 & 0.268 \\
\hline College & Women & 0.282 & 0.210 & 0.248 \\
\hline Graduation & Men - top $1 / 3$ of cognitive skills & 0.538 & 0.426 & 0.504 \\
\hline \multirow[t]{4}{*}{ Rates } & Women - top $1 / 3$ of cognitive skills & 0.519 & 0.418 & 0.474 \\
\hline & Total - top $1 / 3$ of parental wealth & 0.399 & 0.385 & 0.467 \\
\hline & Total - bottom $1 / 3$ of parental wealth & 0.205 & 0.073 & 0.104 \\
\hline & Crowding out of IVTs - Male & - & $+\$ 2,502$ & $+\$ 685$ \\
\hline Other & Crowding out of IVTs - Female & - & $+\$ 2,681$ & $-\$ 776$ \\
\hline \multirow[t]{3}{*}{ Statistics } & Student labor supply & - & $+5.85 \%$ & $+0.62 \%$ \\
\hline & Aggregate output & - & - & $-1.97 \%$ \\
\hline & Welfare gain & - & - & $-2.81 \%$ \\
\hline \multicolumn{5}{|c|}{ Panel B: Removal of Student Loans } \\
\hline & & Benchmark & $\begin{array}{c}\text { P.E. } \\
\text { Short-run }\end{array}$ & $\begin{array}{c}\text { G.E. } \\
\text { Long-run }\end{array}$ \\
\hline & Men & 0.294 & 0.191 & 0.267 \\
\hline College & Women & 0.282 & 0.194 & 0.248 \\
\hline Graduation & Men - top $1 / 3$ of cognitive skills & 0.538 & 0.377 & 0.488 \\
\hline \multirow[t]{4}{*}{ Rates } & Women - top $1 / 3$ of cognitive skills & 0.519 & 0.383 & 0.476 \\
\hline & Total - top $1 / 3$ of parental wealth & 0.399 & 0.383 & 0.479 \\
\hline & Total - bottom $1 / 3$ of parental wealth & 0.205 & 0.046 & 0.076 \\
\hline & Crowding out of IVTs - Male & - & $+\$ 5,486$ & $+\$ 4,645$ \\
\hline Other & Crowding out of IVTs - Female & - & $+\$ 5,214$ & $+\$ 2,105$ \\
\hline \multirow[t]{3}{*}{ Statistics } & Student labor supply & - & $+5.08 \%$ & $+6.69 \%$ \\
\hline & Aggregate output & - & - & $-1.98 \%$ \\
\hline & Welfare gain & - & - & $-2.84 \%$ \\
\hline
\end{tabular}

Table 5.1: Removal of existing federal aid programs from the benchmark economy. 
premium which, in turn, induces a compensating rise in college graduation rates. The final long-run GE drop in college attainment is almost 3 percentage points, still a sizable magnitude.

This drop in attainment comes about with significant alterations in the composition of the college student body. Skill quality is lower and family wealth becomes more important for college selection, as some able children from poorer families no longer find it feasible and/or optimal to attend college: college attainment in the lowest wealth tercile drops about three times as much as it does in the entire population.

Students are forced to gather additional resources through an increase in their labor supply while in college: in the long-run student labor supply grows by $0.6 \%$. However, most of the adjustment occurs through parental transfers. In PE, families increase transfers to their college bound children by about $\$ 2,500$ on average; however, in the long-run parental transfers only increase by $\$ 685$ relative to the benchmark because parental incomes and wealth fall. ${ }^{43}$

Wealth-poor $(q=1)$ families are the most affected by removal of grants, and they are only able to compensate for a fraction of this loss: Table J.6 shows that in the long-run such families increase transfers to college-bound children by about $\$ 3,250$ total, whereas the students' grants have been cut by $\$ 2,800$ per year (i.e. $\$ 11,200$ total). In turn, students from wealthy backgrounds increase their college participation relative to the baseline: these students are in a position to take advantage of high returns to education. The most evident consequence of this decline in quality and quantity of college students is in terms of productive efficiency of the economy: output falls by 2 percent permanently.

One notable aspect of the results in panel (A) of Table 5.1 is the differential effect of the policy change on men and women: in GE the drop in female college attainment is about $25 \%$ larger than that for men. Gender-bias in altruism partly accounts for the differences between men and women, as women rely on grants more than men due to the smaller transfers they receive from parents. We also observe that, while college attainment falls more for women, the gender wage-gap among college graduates marginally widens. This follows from the fact that our estimates of labor shares imply that

\footnotetext{
${ }^{43}$ Note that we control for changes in the distribution of college student characteristics when calculating parental transfer changes.
} 
$s^{m, C L}>s^{f, C L}$ in the production function (2.4). Thus, even though the fall in quality-adjusted female college labor input is larger than for its male counterpart, the positive impact on its marginal product is smaller.

The total ex-ante welfare loss in consumption equivalent units is sizable, at 2.8 percent. The welfare losses due to a lower average level of consumption and more unequal initial conditions are $-2.4 \%$ and $-1.7 \%$ respectively (see appendix Table J.5). As explained, in this economy average productivity suffers from lower schooling levels and worse sorting of children by ability. Inequality in initial conditions deteriorates for two reasons. One is that grants provide a substantial source of insurance "behind the veil of ignorance" against lower than average draws on parental characteristics. The second is the change in relative prices: the rise in the college premium redistributes against low-income low-ability individuals who do not enroll in college.

However, there is an offsetting positive welfare effect $(+1.3 \%)$ due to a reduction in average volatility of consumption in the population. This counteracting force arises because, as seen in Table 3.2, the wage processes of non-college workers (now more numerous) display less uncertainty than those of college educated workers. ${ }^{44}$ This is particularly evident for the initial variance of the productivity shock, which is the most difficult component to insure because it affects young workers with low savings or in debt.

Removing Federal Loans. When federal loans are removed, college attainment drops by 9.5 percentage points in PE (see bottom panel of Table 5.1). This strong response suggests that, in spite of the large crowding-in of inter vivos transfers (which increase by $\$ 6,000$ on average), in the short run many families are unable or unwilling to make up for the elimination of the loans available to college students, and so their children are no longer able to finance education.

In GE, the overall drop in the college graduation rate is much smaller ( 3 percentage points) because of the factor price adjustments, but also because of the substantial increase in family savings: faced

\footnotetext{
${ }^{44}$ Table 3.2 also shows that the persistence of the shocks is higher for college-graduates, making self-insurance harder.
} 
with the harmful removal of a large source of college financing, families devote more resources to saving for college despite being, on average, poorer in the new equilibrium (aggregate income falls by $2 \%$ ). Given the large size of the federal loans program those families who cannot count on private credit (types $q=1,2$ ) are compelled to save much more to send their children to college. Table J.3 shows that inter vivos transfers in households whose children enroll in college increase by $\$ 5,200$ for $q=1$ families and by $\$ 10,500$ for $q=2$ families, compared to a reduction of $\$ 23,000$ in borrowing capacity. This behavior represents a crowding in of roughly 24 percent for the wealth-poor and 46 percent for middle-class households relative to the size of the loans program.

There is, again, a significant worsening of selection on ability and on family wealth, which is even more substantial than that occurring after removing grants, suggesting that many highly skilled people rely on existing federal loans to finance college. The change in college attainment of children in the bottom tercile of the wealth distribution is large, from 20 percent to less than 8 percent. The welfare losses are slightly larger and, as for the grant removal, are associated to the level and inequality effects. (Table J.2).

Removing both Federal Grants and Loans. Removing the entire existing structure of financial aid results in qualitative patterns that are similar to what we find after removing either grants or loans. However, cumulative effects are larger. Table J.7 in the Appendix shows that college attainment in the long run drops by 5 percentage points and it becomes much less sensitive to ability and much more sensitive to parental wealth. College attendance in the top terciles of cognitive and non-cognitive ability drops significantly more than when removing grants or loans alone. Moreover, college attainment among children from the bottom tercile of parental wealth drops precipitously: it falls from $20 \%$ in the benchmark to less than $1 \%$. The poorest parents cannot afford to replace lost financial aid, and children who persist in education even without financial aid are those who received relatively large transfers in the benchmark. To understand how student labor supply and parental transfers react in this experiment it is important to remember that this new equilibrium selects heavily against college 
attendance for those from poor families. Thus for example, average student labor supply actually falls because wealthy students do not need to work in college to finance their studies.

Aggregate output falls by $4.1 \%$ and ex-ante welfare drops by $5.8 \%$. Notably, the average labor income tax increases by 1.9 percentage points: the same amount of expenditures $G$ must be financed through a smaller tax base. Appendix tables J.7 through J.9 document these findings in more detail.

The role of the intergenerational transmission of skills. Reinforcing patterns to these policies emerge through the intergenerational transmission of skills. The child skills depend on the maternal levels of skills and her education. Thus when grants and loans are removed, the cognitive and noncognitive factors for future generations decline (see Table J.8). Both affect educational attainment, and the cognitive factor also has a direct impact on wages.

To quantify what this decline means, we compute the resulting effect on average wages, using as weights the proportions attending each education level at baseline. ${ }^{45}$ We find that when both types of financial aid policies are suppressed the overall skill loss amounts to a $0.46 \%$ decline in wages.

This decline is then compounded by the resulting fall in education levels leading to a reduction in the returns to skills. ${ }^{46}$ Thus the decline in skill is an important channel for the overall reduction in output (and welfare) resulting from eliminating these student aid policies.

Part of the return to investing in college for children is that the grandchildren will tend to have higher abilities (which is internalized by the current generation to an extent driven by the amount of altruism). This is one of the reasons selection into education by parental wealth increases in the long-run after financial aid programs are removed.

Small Open Economy. Our sensitivity analysis in Appendix K shows that, when these same experiments are run under the assumption of a fixed interest rate (i.e., a small open economy), the results

\footnotetext{
${ }^{45}$ More precisely, we calculate a counterfactual average wage in a way that holds the proportion of each ability type attending each education level constant at baseline, but varies the proportion of each ability type according to the counterfactual ability distribution.

${ }^{46}$ Remember the returns to skill are lower for wages corresponding to lower education levels.
} 
are qualitatively similar. However, both welfare and GDP losses are smaller. The reason is that in the closed economy the fall in household saving (and thus of the capital-labor ratio) is reflected in a reduction in average wages. In the small open economy version, this effect is moderated by the fact that capital flows from the rest of the world and keeps domestic wages from falling too much.

\subsection{Expansion of Loans Program: An Upper Bound}

Expansions of the federal loan program are potentially valuable if many individuals in the economy are initially constrained in their choice of education. To assess the severity of institutional borrowing limits, we study how allocations and choices would change in an 'unconstrained' economy. Namely, we compute the long-run equilibrium of an economy where there is no ad-hoc credit constraint with the exception of the 'natural borrowing limit' implying that all liabilities must be extinguished upon retirement (Hai and Heckman, 2017, see for example). All borrowing is done through private markets at the prevailing equilibrium rate $r^{-}$. The aim of this exercise is to compute an upper bound for the gains that a Federal unsubsidized student loan program can achieve, if expanded over and above its current configuration. ${ }^{47}$

Table 5.2 shows that, in the long-run equilibrium of the unconstrained economy, college attainment is about two percentage points higher. Sorting on ability improves somewhat, especially for children from poor households who suffer from scarce family resources and low transfers in the benchmark. Conditional on going to college, the financing mix of education changes: private debt replaces parental transfers and earnings from part-time work of college students.

In this 'unconstrained economy' aggregate output grows by $1.7 \%$, a rise attributable to higher levels of education and more efficient sorting into education by ability. Aggregate welfare rises substantially, by $4.2 \%$. The gain due to level effects is $1.7 \%$, welfare improvements due to equalization of initial endowments are worth $1.5 \%$ of consumption annually, while an improvement in consumption smoothing induces a welfare gain of nearly $1 \%$.

\footnotetext{
${ }^{47}$ To focus on the role of credit, we maintain tuition subsidies at their benchmark values.
} 


\begin{tabular}{|c|c|c|c|}
\hline \multicolumn{4}{|c|}{ "Unconstrained" Economy } \\
\hline & & Benchmark & $\begin{array}{c}\text { G.E. } \\
\text { Long-run }\end{array}$ \\
\hline & Men & 0.294 & 0.317 \\
\hline College & Women & 0.280 & 0.300 \\
\hline Graduation & Men - top $1 / 3$ of cognitive skills & 0.538 & 0.561 \\
\hline \multirow[t]{4}{*}{ Rates } & Women - top $1 / 3$ of cognitive skills & 0.519 & 0.543 \\
\hline & Total - top $1 / 3$ of parental wealth & 0.399 & 0.394 \\
\hline & Total - bottom $1 / 3$ of parental wealth & 0.205 & 0.238 \\
\hline & Crowding out of IVTs - Male & - & $-\$ 4,987$ \\
\hline Other & Crowding out of IVTs - Female & - & $-\$ 3,771$ \\
\hline \multirow[t]{3}{*}{ Statistics } & Student labor supply & - & $-25.6 \%$ \\
\hline & Aggregate output & - & $+1.73 \%$ \\
\hline & Welfare gain & - & $+4.23 \%$ \\
\hline
\end{tabular}

Table 5.2: Counterfactual economy with loose private credit limits and without any federal student loan programs.

These results suggest that there is only a small fraction of children (approximately $2 \%$ ) whose education decisions are affected by credit constraints. However, these children tend to be high ability, and for that reason the long-run impact of credit frictions in the economy is non-trivial. Since our calculation is an upper bound, we conclude that the gains from an expansion of the federal loan program would be rather limited. Detailed results for this experiment are reported in Appendix Tables J.10-J.12.

\subsection{Expansion of the Grants Program}

Next, we turn our attention to how expansion of the existing federal grants program would affect equilibrium outcomes. We consider three possible ways to expand the current system of tuition subsidies. The first approach is to simply increase by $\$ 1,000$ per year the amount by which every college graduate's education is subsidized. Any additional net costs from this expansion must be paid for and we choose to adjust labor income tax rates to this end.

Our second approach strengthens the progressivity of the existing federal grants program by increasing grants proportionally. The result of this means-tested expansion is that poorer $(q=1)$ 
students benefit the most and richer $(q=3)$ students the least in terms of the absolute amounts of the subsidy. The proportional increase we implement is $53 \%$, chosen so that the immediate (PE) cost to the government equals that of the general $\$ 1,000$ per year expansion.

Finally, we implement an ability tested grant expansion, where increased funding is proportional to cognitive skills. Here grants are increased above their benchmark values according to a linear function of cognitive skills, of the form $1.72 \times \theta_{\operatorname{cog}}$. This expansion provides a median ability child with an extra $\$ 860$ per year in grants, and one in the top tercile with an additional $\$ 1,100$ per year. Once again, the short-run fiscal costs of this policy reform are the same as in the general grant expansion. Table 5.3 summarizes the results of these three experiments.

Qualitatively, all three experiments feature the same pattern: the college graduation rate increases in the long run. Sorting on ability rises and sorting on wealth falls. Overall, the larger and better stock of college graduates produces improvements in equilibrium output and welfare. Grants crowd-out inter vivos transfers and student labor supply. For each additional dollar of grants, transfers fall, on average, by 25-50 cents and student earnings (from their labor supply while in college) by 10 cents. Both of these crowding-out effects mitigate the effect of the policy.

All grant expansions result in welfare gains: $+1.4 \%$ for means-tested, $+1.7 \%$ for a general expansion, and $+1.9 \%$ for ability tested. These welfare gains are accompanied by different levels of growth in average skills and output, with the biggest gain (+0.2\% for skills and $+1.2 \%$ for GDP) associated with the ability-tested grant expansion. This program is better at targeting those with high ability who would otherwise not attend college, hence generating the largest efficiency and welfare gains.

One important source of these gains is that mothers' skills and education interact positively in the production of the next generation's skills. Individuals do not fully internalize the impact of their education decisions on the skills of future generations because of imperfect altruism. The reforms that encourage more high ability individuals to opt for college, like ability-tested grants, partly correct for this distortion between private returns and intergenerational social returns. ${ }^{48}$ Detailed results for these

\footnotetext{
${ }^{48}$ See Bovenberg and Jacobs (2005) who explore the role education subsidies in an optimal taxation framework.
} 
Panel (A): General Tuition Grant Expansion $\mathbf{( \$ 1 , 0 0 0 )}$

\begin{tabular}{ccccc}
\hline \multirow{4}{*}{ College } & Men & Benchmark & P.E. short-run & G.E. long-run \\
Graduation & Women & 0.294 & 0.335 & 0.311 \\
& Top 1/3 of cognitive skills & 0.280 & 0.318 & 0.296 \\
& Total - top 1/3 of parental wealth & 0.399 & 0.577 & 0.544 \\
& Total - bottom 1/3 of parental wealth & 0.205 & 0.416 & 0.405 \\
& Crowding out of IVTs - Male & - & $-\$ 2,694$ & $-\$ 1,157$ \\
Other & Crowding out of IVTs - Female & - & $-\$ 1,989$ & $-\$ 778$ \\
Statistics & Student labor supply & - & $-4.55 \%$ & $-6.24 \%$ \\
& Aggregate output & - & - & $+1.10 \%$ \\
& Welfare gain & - & - & $+1.72 \%$ \\
\hline
\end{tabular}

Panel (B): Means-tested Grant Expansion (53\%)

\begin{tabular}{|c|c|c|c|c|}
\hline & Men & $\begin{array}{c}\text { Benchmark } \\
0.294\end{array}$ & $\begin{array}{c}\text { P.E. short-run } \\
0.342\end{array}$ & $\begin{array}{c}\text { G.E. long-run } \\
0.310\end{array}$ \\
\hline College & Women & 0.280 & 0.325 & 0.294 \\
\hline \multirow[t]{4}{*}{ Graduation } & Top $1 / 3$ of cognitive skills & 0.528 & 0.585 & 0.536 \\
\hline & Total - top $1 / 3$ of parental wealth & 0.399 & 0.406 & 0.371 \\
\hline & Total - bottom $1 / 3$ of parental wealth & 0.205 & 0.288 & 0.248 \\
\hline & Crowding out of IVTs - Male & - & $-\$ 1,237$ & $-\$ 1,358$ \\
\hline Other & Crowding out of IVTs - Female & - & $-\$ 1,006$ & $-\$ 1,061$ \\
\hline \multirow[t]{3}{*}{ Statistics } & Student labor supply & - & $-4.19 \%$ & $-4.56 \%$ \\
\hline & Aggregate output & - & - & $+0.77 \%$ \\
\hline & Welfare gain & - & - & $+1.40 \%$ \\
\hline \multicolumn{5}{|c|}{ Panel $(\mathbf{C})$ : Merit-based Grant Expansion $\left(1.72 \times \theta_{\text {cog }}\right)$} \\
\hline & & Benchmark & P.E. short-run & G.E. long-run \\
\hline & Men & 0.294 & 0.325 & 0.310 \\
\hline College & Women & 0.280 & 0.310 & 0.295 \\
\hline \multirow[t]{4}{*}{ Graduation } & Top $1 / 3$ of cognitive skills & 0.528 & 0.566 & 0.550 \\
\hline & Total - top $1 / 3$ of parental wealth & 0.399 & 0.412 & 0.405 \\
\hline & Total - bottom $1 / 3$ of parental wealth & 0.205 & 0.249 & 0.225 \\
\hline & Crowding out of IVTs - Male & - & $-\$ 1,803$ & $-\$ 1,438$ \\
\hline Other & Crowding out of IVTs - Female & - & $-\$ 1,482$ & $-\$ 623$ \\
\hline \multirow[t]{3}{*}{ Statistics } & Student labor supply & - & $-3.39 \%$ & $-6.69 \%$ \\
\hline & Aggregate output & - & - & $+1.20 \%$ \\
\hline & Welfare gain & - & - & $+1.89 \%$ \\
\hline
\end{tabular}

Table 5.3: Three alternative expansions of the federal tuition grant program. All expansions financed through the same short-run budget (identical short-run costs). 


\begin{tabular}{ccccc}
\hline \hline & $\begin{array}{c}\text { Ability-tested } \\
\text { Expansion }^{i}\end{array}$ & $\begin{array}{c}\text { Means-tested } \\
\text { Expansion }^{i i}\end{array}$ & $\begin{array}{c}\text { Loan Subsidization } \\
\text { Expansion }^{\text {iii }}\end{array}$ & $\begin{array}{c}\text { Labor Income } \\
\text { Tax Rate Cut }^{i v}\end{array}$ \\
\hline Aggregate Output & $2.24 \%$ & $1.52 \%$ & $0.50 \%$ & $0.34 \%$ \\
Welfare gain & $3.05 \%$ & $2.48 \%$ & $0.45 \%$ & $1.30 \%$ \\
College - Overall Attainment & $2.87 \mathrm{pp}$ & $2.75 \mathrm{pp}$ & $0.78 \mathrm{pp}$ & $0.29 \mathrm{pp}$ \\
College - Top 1/3 of cognition & $4.09 \mathrm{pp}$ & $1.24 \mathrm{pp}$ & $0.04 \mathrm{pp}$ & $0.34 \mathrm{pp}$ \\
\hline \hline
\end{tabular}

Table 5.4: Alternative uses of windfall expenditures. We compare the outcomes of using a windfall of public funds to: expand grants; expand loan subsidization; or cut labor income taxes. (i) The ability-tested expansion increases grants by a factor equal to $3.6 \times \theta_{\operatorname{cog}}$. (ii) The means-test expansion increases benchmark grants proportionally by $210 \%$. (iii) Expansion of loan subsidization expands eligibility to all students and all amounts borrowed, and additionally forgives $3.04 \%$ of the principal owing at graduation. (iv) The tax-cut afforded by the available resources is $0.7 \%$, so that the tax rate drops from $27 \%$ to $26.3 \%$. pp is percentage points.

experiments are reported in Appendix Tables J.13 to J.21.

\subsection{Optimal Marginal Expansions of Student Aid}

Solving for the optimal public policy is very complex. Here we explore a simpler approach: we consider how best to spend a windfall of $1 \%$ of residual government expenditure $(G)$ among four specific alternatives: (i) an ability-tested grant expansion, (ii) an expansion of the existing meanstested grants program, (iii) extending student loans subsidization, and (iv) cutting the labor income tax rate.

In the long run equilibrium this windfall allows ability-tested grants to increase by the proportional transfer rule $3.6 \times \theta_{\text {cog. }}$. This amounts to an extra $\$ 2,300$ per year among the top $1 / 3$ of the ability distribution. Alternatively, for the means tested case we can increase grants by $210 \%$ above their benchmark amounts. For the case of increased loan subsidization we assume the government forego interests on all loans during college years. Additionally, the small amount of government funds that remain after this change are used to forgive $3 \%$ of the principal students owe at graduation. We compare these student aid policies to a tax cut, where taxes are reduced by $0.7 \%$ of aggregate labor income, and therefore the marginal tax rate is cut from 0.27 to 0.263 .

As seen in Table 5.4, these simulations suggest that ability tested grants improve welfare the most 
by better targeting those who are best suited to attend college, in terms of ability. Second best are means tested grants, that also allow some of those with low wealth parents and high ability to attend. However, this type of grant is not as effective at targeting the right group and distorts prices in such a way that some lower ability individuals increase attendance too. The next best alternative are tax cuts: they reduce labor market distortions and realign the returns to education closer to the marginal product. However, they are not nearly as effective as expanding grants. Finally, the expansion of subsidized loans is the least effective approach to improving welfare in this economy, in line with the results from our unconstrained economy.

\subsection{Discussion}

The design of education finance programs is an issue at the top of the policy and research agenda. How valuable is the existing system of tuition grants and student loans? How large are the potential gains from expanding these programs further? And, to what extent these policy interventions crowd out the private provision of resources devoted to financing education costs? In this section, we addressed these key questions.

A clear-cut conclusion of our policy experiments is that the existing student aid program, including grants and subsidized loans, is welfare improving. This welfare gain accrues because our model, carefully crafted to mimic the US economy, features several departures from social efficiency. First, the private cost of education exceeds the social one because of liquidity constraints which, in particular, prevent some high-ability students from enrolling in college. Federal aid realigns private and social cost. Our quantitative analysis, however, shows that this market failure is not especially significant. Second, the private return to education is below its social counterpart for three reasons: (i) uninsurable income uncertainty makes education a risky investment; (ii) distortionary progressive taxation reduces the gain from investing; (iii) imperfect parental altruism means that individuals do not fully internalize that as educated parents they raise children with better skills. Tuition grants increase the private financial return to college, thus shrinking the gap with social returns. Finally, market in- 
completeness is a source of pecuniary externalities. By increasing the quantity and quality of college graduates, these policies reduce the college premium and redistribute towards the more needy households. Key, for this channel, is the imperfect substitutability of men and women and of workers of three different education levels in production - a feature emphasized before us by Heckman et al. (1998b,c), Lee (2005), Lee and Wolpin (2006) and Johnson and Keane (2013), for example.

Another important result of our policy counterfactuals is that there is room for an expansion of federal aid, but this room varies substantially across types of intervention. We find that a windfall government expenditure is best spent expanding grants for college students rather than on increasing loan limits. The reason is that, as explained above, liquidity constraints are not widely binding for the marginal population, whereas grants are effective at increasing the return to college. Amongst grants, those targeted to high ability children are superior to simply means-tested ones because they are better at inducing into college those children for whom the gains are largest.

In line with this discussion, our welfare decomposition identifies two main sources of welfare changes from policy reforms that increase college attainment and improve sorting by making attendance depend more on skills and less on parental wealth: (i) improvements in aggregate output due to a higher stock of human capital; (ii) reduced inequality in initial conditions due to a redistribution of income occurring through a shrinking relative price of college-educated labor.

Finally, we have highlighted two key margins of adjustment that are not typically considered in the traditional policy evaluation literature. The first channel is the adjustment of funding by parents through inter vivos transfers, which is a sizable source of support during college in the data. The second channel is students' labor supply. Our experiments show that both margins are quite elastic with respect to policy interventions and, as such, mitigate their effects. We find that an additional dollar in grants provided by the government crowds out, on average, 35 cents of private parental transfers in the long-run equilibrium. There is, however, substantial heterogeneity in crowding-out effects. More generous grants displace transfers in different proportions depending on family resources, with the transfers made by wealthy families being generally crowded out the most. Also student labor 
supply is sensitive to policy. Across experiments, an extra dollar in grants crowds out 10 cents in labor earnings by students in college. Accounting for the existing patchwork of policies, adjustments in these alternative means of privately funding education replace/displace around 45 cents of every dollar subtracted/added to federal grants. This result suggests that policy evaluations that omit these joint adjustment margins might be misleading.

Our model is rich and realistic in many dimensions. At the same time, its computational complexity forced us to abstract from a number of additional aspects that might influence policy evaluation.

We modeled the endogeneity of the distribution of abilities by assuming that a child's ability depends on parental education and skills in a mechanical way. A parallel line of research (e.g., Caucutt and Lochner, 2012; Cunha and Heckman, 2007; Cunha et al., 2010; Heckman and Mosso, 2014) stresses the importance of complementarities between college-age policies and interventions during critical phases of child development. Explicitly modeling sequential human capital investments at different stages of a child's life would flesh out the extent to which early interventions may improve the effectiveness of tertiary education policies and how this affects intergenerational transmission.

Another interesting generalization would account for heterogeneity in college types (e.g. Fu, 2014) allowing for the endogenous determination of returns based on demand and supply of different college types, thereby recognizing that more able and richer students are, in equilibrium, matched with better colleges. This complementarity may strengthen the role of financial aid policies that improve sorting. Similarly, the role that choice of college major has is an important but relatively under researched area (see for example, Altonji et al., 2012).

Recent work (see Ionescu and Simpson, 2016; Lochner and Monje-Naranjo, 2011) has emphasized the expansion of private provision of student credit. Nesting endogenous borrowing constraints within an equilibrium framework, similar to the one developed in this paper, would allow for explicit codetermination of all credit and skill prices. Such a model, while significantly more complex, could answer interesting questions about how the price of borrowing in private markets would endogenously respond to education policy reforms. 
In all our counterfactual policy experiments we kept the configuration of all other fiscal policies unchanged, although we did compare the relative merits of expanding student aid to reducing taxes on labor. As emphasized by Krueger and Ludwig (2016), there is a certain degree of substitutability between progressive taxation and education subsidies: both policies induce some redistribution, the former through fiscal instruments, the latter through relative prices of different types of labor. An implication of this observation to bear in mind when interpreting our findings is therefore that they are conditional on the prevailing degree of progressivity of the tax/transfer system, but major tax reforms could significantly affect the landscape of effective education policies. However, locally, we show that student aid is more effective at improving overall welfare than tax cuts.

Finally, an important issue we do not consider here are transitional effects. Many of these policies may have upfront costs for longer term benefits to future generations, as we move from one steady state to another. As Krueger and Ludwig (2016) show, the costs during the transition costs may change our view about the merits of policy and certainly raises the issue of how a policy should be introduced and financed. For example, long term government debt, with the costs falling on future generations, may be a better way of financing the transition, instead of taxes falling on the current ones. However, our model has little to say about these issues and this would have to be left to future research.

\section{Conclusions}

The capacity of people to optimally invest in education is crucial for economic prosperity and social mobility, and is an important determinant of the income distribution (see Becker and Tomes, 1979; Loury, 1981). In the presence of insurance and credit market imperfections that prevent those individuals with the highest returns to education from investing in schooling, education policies can improve allocations and welfare.

In this paper, we have assessed the role played by the existing system of government financial aid to college. For this purpose, we have specified and estimated a general-equilibrium life-cycle model of 
the US economy that features: (i) intergenerational linkages through altruism and paternalism which determine the extent to which parent are willing to finance their children education; (ii) intergenerational transmission of abilities that is affected by parental education and is, consequently, endogenous; (iii) non-pecuniary psychic costs of education that depend on cognitive and non-cognitive abilities; (iv) liquidity constraints that limit access to credit; (v) idiosyncratic uninsurable earnings risk that makes education an investment with an uncertain outcome; (vi) various means of financing the pecuniary cost of education - over and above what is offered by the government - such as parental transfers, private borrowing, and labor supply in college; (vii) imperfect substitution between gender and education groups in production, which leads to redistributive implications of education policies through relative prices.

We use microeconomic data from various sources to estimate the structural parameters of the model. The model fits the data well, including responses to actual policies that we do not target in the estimation. It also provides valuable insights on the intergenerational transmission of income and education.

Through the lenses of our model, our bottom line is that the current configuration of federal loans and grant programs has substantial value in terms of both output and welfare. Our results indicate that further expansions of grant programs would be welfare improving. Amongst the alternative policies we consider, the best way of expanding student aid is via ability tested grants. Part of the efficacy of this form of grants is that parental ability and education interact positively in the production of skills of the next generation. 


\section{References}

Altonji, J., E. Blom, And C. Meghir (2012): "Heterogeneity in Human Capital Investments: High School Curriculum, College Major, and Careers," Annual Review of Economics, 4, 185-223.

Attanasio, O., AND G. Weber (1995): "Is Consumption Growth Consistent with Intertemporal Optimisation? Evidence from the Consumption Expenditure Survey," Journal of Political Economy, 103(6), 11211157.

Becker, G. S. (1964): Human Capital. National Bureau of Economic Research, New York, NY.

BeCKer, G. S., AND N. TOMES (1979): "An Equilibrium Theory of the Distribution of Income and Intergenerational Mobility," Journal of Political Economy, 87, 1153-89.

Belley, P., And L. Lochner (2007): "The Changing Role of Family Income and Ability in Determining Educational Achievement," Journal of Human Capital, 1, 37-89.

Ben-Porath, Y. (1967): “The Production of Human Capital and the Life Cycle of Earnings," Journal of Political Economy, 75(4), 352-365.

Benabou, R. (2002): "Tax and Education Policy in a Heterogeneous-Agent Economy: What Levels of Redistribution Maximize Growth and Efficiency?," Econometrica, 70(2), 481-517.

Blundell, R., M. C. Dias, C. Meghir, And J. M. Shaw (2016a): "Female Labour Supply, Human Capital and Welfare Reform,” Econometrica, 84(5), 1705-1753.

Blundell, R., L. Pistaferri, AND I. Preston (2008): “Consumption Inequality and Partial Insurance," American Economic Review, 98(5), 1887-1921.

Blundell, R., L. Pistaferri, AND I. SAPORTA-Eksten (2016b): "Consumption Inequality and Family Labor Supply," American Economic Review, 106(2), 387-435.

BohaceK, R., AND M. KAPICKA (2012): "A Quantitative Analysis of Educational Reforms in a Dynastic Framework," Manuscript, University of California Santa Barbara.

BovenberG, A. L., AND B. JacoBs (2005): "Redistribution and education subsidies are Siamese twins," Journal of Public Economics, 89(11).

Brown, M., J. K. Scholz, And A. Seshadri (2012): “A New Test of Borrowing Constraints for Education," Review of Economic Studies, 79, 511-538.

Cameron, S. V., And J. J. Heckman (1998): "Life Cycle Schooling and Dynamic Selection Bias: Models and Evidence for Five Cohorts of American Males," Journal of Political Economy, 106(2), 262-311.

CAMERon, S. V., AND C. TABer (2004): "Estimation of Educational Borrowing Constraints Using Returns to Schooling," Journal of Political Economy, 112(1), 132-182.

CARD, D., AND T. LEMIEUX (2001): "Can Falling Supply Explain The Rising Return To College For Younger Men? A Cohort-Based Analysis," The Quarterly Journal of Economics, 116(2), 705-746.

Carneiro, P., And J. J. Heckman (2002): "The Evidence on Credit Constraints in Post-Secondary Schooling," The Economics Journal, 112, 705-734.

Carneiro, P., J. J. Heckman, And E. J. Vytlacil (2011): "Estimating Marginal Returns to Education," American Economic Review, 101(6), 2754-81. 
Carneiro, P., C. Meghir, and M. Parey (2013): "Maternal Education, Home Environments, and the Development of Children and Adolescents," Journal of the European Economic Association, 11, 123-160.

Caucutt, E. M., And L. Lochner (2012): "Early and Late Human Capital Investments, Borrowing Constraints, and the Family," Discussion paper, National Bureau of Economic Research.

Chetty, R., N. Hendren, P. Kline, E. Saez, And N. Turner (2014): "Is the United States Still a Land of Opportunity? Recent Trends in Intergenerational Mobility," in American Economic Review, Papers and Proceedings.

Cunha, F., And J. Heckman (2007): “The Economics of Human Development: The Technology of Skill Formation," The American Economic Review, 97(2), 31-47.

Cunha, F., J. Heckman, And S. NAVArRo (2005): "Separating Uncertainty from Heterogeneity in Life Cycle Earnings," Oxford Economic Papers, 57(2), 191-261.

CunHa, F., AND J. J. HeCKMAN (2008): "Formulating, Identifying and Estimating the Technology of Cognitive and Noncognitive Skill Formation," The Journal of Human Resources, 43(4), 738-782.

Cunha, F., J. J. Heckman, And S. M. Schennach (2010): "Estimating the Technology of Cognitive and Noncognitive Skill Formation," Econometrica, 78(3), 883-931.

Deming, D., And S. Dynarski (1995): "Into College, Out of Poverty? Policies to Increase the Postsecondary Attainment of the Poor," in Targeting Investments in Children, ed. by P. B. Levine, and D. J. Zimmerman, chap. 10. The University of Chicago Press.

Domeis, D., And J. Heathcote (2004): “On The Distributional Effects Of Reducing Capital Taxes,” International Economic Review, 45, 523-554.

Eisenhauer, P., J. J. Heckman, And S. Mosso (2015): "Estimation of dynamic discrete choice models by maximum likelihood and the simulated method of moments," International Economic Review, 56(2), 331-357.

FERnÁndeZ, R., AND R. Rogerson (2001): “Sorting and long-run inequality," The Quarterly Journal of Economics, 116(4), 1305-1341.

Findeisen, S., AND D. SAChs (2015): “Designing Efficient College and Tax Policies,” Discussion paper, CESifo Working Paper Series.

FU, C. (2014): "Equilibrium Tuition, Applications, Admissions, and Enrollment in the College Market," Journal of Political Economy, 122(2), 225-281.

Gale, W., AND J. Scholz (1994): "Intergenerational Transfers and the Accumulation of Wealth," Journal of Economic Perspectives, 8(4), 145-160.

Garriga, C., And M. Keightley (2015): "A General Equilibrium Theory of College with Education Subsidies, In-School Labor Supply, and Borrowing Constraints,” FRB St. Louis Working Paper 2007-015A.

Goldin, C. (2014): “A Grand Gender Convergence: Its Last Chapter," The American Economic Review, 104(4), 1091-1119.

Goldin, C., AND L. F. KATZ (2007): "The Race between Education and Technology: The Evolution of U.S. Educational Wage Differentials, 1890 to 2005,” NBER Working Paper 12984.

Guvenen, F. (2009): “An Empirical Investigation of Labor Income Processes," Review of Economic Dynamics, 12(1), 58-79. 
HAI, R., AND J. J. HECKMAN (2017): "Inequality in human capital and endogenous credit constraints," Review of Economic Dynamics, 25, 4-36.

Heathcote, J., F. Perri, And G. L. Violante (2010): "Unequal We Stand: An Empirical Analysis of Economic Inequality in the United States, 1967-2006," Review of Economic Dynamics, 13(1), 15-51.

Heathcote, J., K. Storesletten, And G. L. Violante (2014): “Consumption and Labor Supply with Partial Insurance: An Analytical Framework,” American Economic Review, 104(7), 2075-2126.

Heckman, J., L. LOChner, AND C. TABer (1998a): "Explaining Rising Wage Inequality: Explorations with a Dynamic General Equilibrium Model of Labor Earnings with Heterogeneous Agents," Review of Economic Dynamics, 1(1), 1-58.

(1998b): "General Equilibrium Treatment Effects: A Study of Tuition Policy," American Economic Review, Papers and Proceedings, 88(2), 381-386.

(1998c): "Tax Policy and Human Capital Formation," American Economic Review, Papers and Proceedings, 88(2), 293-297.

Heckman, J., L. Lochner, AND P. Todd (2006a): "Earnings Functions, Rates of Return and Treatment Effects: The Mincer Equation and Beyond," Handbook of the Economics of Education, 1, 307-458.

Heckman, J. J., And S. Mosso (2014): "The Economics of Human Development and Social Mobility," Annual Review of Economics, 6.

HeCKMAn, J. J., AND S. NAVARRo (2007): “Dynamic discrete choice and dynamic treatment effects," Journal of Econometrics, 136(2), 341-396.

Heckman, J. J., J. Stixrud, S. Urzua, et Al. (2006b): "The Effects of Cognitive and Noncognitive Abilities on Labor Market Outcomes and Social Behavior," Journal of Labor Economics, 24(3), 411-482.

Huggett, M. (1996): "Wealth Distribution in Life-Cycle Economies," Journal of Monetary Economics, 38(3), 469-494.

IONESCU, F., AND N. SIMPSON (2016): "Default Risk and Private Student Loans: Implications for Higher Education Policies," Journal of Economic Dynamics and Control.

Jantti, M., B. Bratsberg, K. Røed, O. RaAum, R. Naylor, E. Österbacka, A. Bjorklund, AND T. ERIKSSON (2006): "American Exceptionalism in a New Light: A Comparison of Intergenerational Earnings Mobility in the Nordic Countries, the United Kingdom and the United States," Discussion paper, Institute for the Study of Labor (IZA).

Johnson, M., And M. KeAne (2013): “A Dynamic Equilibrium Model of the US Wage Structure, 19681996," Journal of Labor Economics, 31(1), 1-49.

Johnson, M. T. (2013): “Borrowing Constraints, College Enrollment, and Delayed Entry," Journal of Labor Economics, 31(4), 669-725.

Jones, D. R., M. SChOnlaU, AND W. J. WelCh (1998): "Efficient global optimization of expensive blackbox functions," Journal of Global optimization, 13(4), 455-492.

KANE, T. (1994): "College Entry by Blacks Since 1970: The Role of College Costs, Family Background, and the Returns to Education," Journal of Political Economy, 102(5), 878-911.

KANE, T. (2003): “A Quasi-Experimental Estimate of the Impact of Financial Aid on College-Going," NBER Working Paper 9703. 
KatZ, L. F., AND K. M. MurPhy (1992): "Changes in Relative Wages, 1963-1987: Supply and Demand Factors," Quarterly Journal of Economics, 107(1), 35-78.

KeAne, M., AND K. WolPin (2001): "The Effect of Parental Transfers and Borrowing Constraints on Educational Attainment," International Economic Review, 42(4), 1051-1103.

Krueger, D., AND A. Ludwig (2016): "On the Optimal Provision of Social Insurance: Progressive Taxation versus Education Subsidies in General Equilibrium,” Journal of Monetary Economics, 77, 72 - 98.

Krusell, P., L. Ohanian, J.-V. Rios-Rull, and G. Violante (2000): "Capital-Skill Complementarity and Inequality: A Macroeconomic Analysis," Econometrica, 68(5), 1029-1054.

LAitner, J. P. (1992): "Random Earnings Differences, Lifetime Liquidity Constraints, and Altruistic Intergenerational Transfers," Journal of Economic Theory, 58, 135-170.

LEE, D. (2005): “An Estimable Dynamic General Equilibrium Model of Work, Schooling and Occupational Choice," International Economic Review, 46, 1-34.

LeE, D., AND K. Wolpin (2006): "Intersectoral Labor Mobility and the Growth of the Service Sector," Econometrica, 47, 1-46.

LevhaRi, D., AND Y. WeIss (1974): “The Effect of Risk on the Investment in Human Capital," American Economic Review, 64, 950-63.

Lochner, L., And A. Monje-Naranjo (2011): "The Nature of Credit Constraints and Human Capital," American Economic Review, 101(6), 2487-2529.

LOURY, G. C. (1981): "Inter-generational Transfers and the Distribution of Earnings," Economica, 49(4), 843-67.

Low, H., C. Meghir, And L. Pistaferri (2010): "Wage Risk and Employment Risk over the Life Cycle," American Economic Review, 100(5), 1432-67.

MCDAnIEL, C. (2014): "Average Tax Rates on Consumption, Investment, Labor and Capital in the OECD 1950-2003,” Mimeo, Arizona State University.

Meghir, C., And D. Phillips (2009): "Labour Supply and Taxes," in Dimensions of Tax Design: The Mirrlees Review, ed. by J. Mirrlees, S. Adam, T. Besley, R. Blundell, S. Bond, R. Chote, M. Gammie, P. Johnson, G. Myles, and J. Poterba. Oxford University Press for Institute for Fiscal Studies.

Mincer, J. (1958): “Investment in Human Capital and Personal Income Distribution,” Journal of Political Economy, 66(4), 281-302.

Mitchell, O., AND J. Phillips (2006): "Social Security Replacement Rates for Own Earnings Benchmarks," Pension Research Council Working Paper 2006-6.

Ríos-Rull, J.-V. (1995): "Models with Heterogenous Agents," in Frontiers of Business Cycle Research, ed. by T. F. Cooley, chap. 4. Princeton University Press, Princeton.

Rosen, S. (1977): "Human Capital: Relations between Education and Earnings," in Frontiers of Quantitative Economics, ed. by M. D. Intriligator, vol. 3b. Amsterdam: North Holland.

Solon, G. (1999): "Intergenerational Mobility in the Labor Market," in Handbook of Labor Economics, ed. by O. C. Ashenfelter, and D. Card, vol. 3A, pp. 1761-1800. New-Holland, Amsterdam.

Voena, A. (2015): "Yours, Mine, and Ours: Do Divorce Laws Affect the Intertemporal Behavior of Married Couples?," American Economic Review, 105(8), 2295-2332. 
WeISS, Y. (1997): "The Formation and Dissolution of Families: Why Marry? Who Marries Whom? And What Happens upon Divorce," Handbook of Population and Family Economics, pp. 81-123.

Willis, R., AND S. Rosen (1979): "Education and Self-Selection,” Journal of Political Economy, 87(5), s7-s36, pt. 2.

WinTER, C. (2014): "Accounting for the Changing Role of Family Income in Determining College Entry," The Scandinavian Journal of Economics, 116(4), 909-963.

Zagorsky, J. L. (2007): "Do You Have to Be Smart to Be Rich? The Impact of IQ on Wealth, Income and Financial Distress," Intelligence, 35, 489-501. 


\section{Appendix for Publication}

Here we report externally specified parameter values and estimates from our main estimation exercise.

We also compare fitted and data values for our targeted moments. 


\begin{tabular}{|c|c|c|}
\hline Parameter & Value & Description \\
\hline \multicolumn{3}{|c|}{ Demographics } \\
\hline$\zeta_{j}$ & varies & Mortality rates for retired hh based on US Life Tables 2000. \\
\hline \multicolumn{3}{|c|}{ Preferences } \\
\hline$\gamma$ & 1.5 & Determines intertemporal elasticity of substitution $(0.5)$ \\
\hline$\nu_{j}^{m}$ & 5.5 & Determines avg Frisch elast. of labour supply for men and non-mothers $(0.33)$ \\
\hline$\nu_{30-45}^{f}$ & 5.7 & Determines avg Frisch elast. of labour supply for mothers $(0.67)$ \\
\hline$\tilde{\rho}$ & 1.4 & Economies of scale parameter (Voena, 2015) \\
\hline $\bar{t}$ & 0.25 & Requires students to study for $25 \%$ of time endowment \\
\hline \multicolumn{3}{|c|}{ Technology } \\
\hline$\alpha$ & 0.33 & Capital share of GDP \\
\hline$\delta$ & 0.06 & Depreciation rate of capital \\
\hline \multicolumn{3}{|c|}{ Tax and Pension system } \\
\hline$\tau_{w}$ & 0.27 & Labor income tax rate \\
\hline$\tau_{c}$ & 0.05 & Consumption tax rate \\
\hline$\tau_{k}$ & 0.40 & Capital income tax rate \\
\hline$p(e)$ & $6.63,9.86,19.77$ & Pension for LH, HS and CL respectively $(\$ 6,198, \$ 10,845, \$ 21,744)$ \\
\hline \multicolumn{3}{|c|}{ Financial market } \\
\hline$\underline{a}^{C L}$ & 77.27 & Limits borrowing of CL households to $\$ 85,000$ \\
\hline$\underline{a}^{H S}$ & 22.73 & Limits borrowing of HS households to $\$ 25,000$ \\
\hline$\underline{a}^{L H}$ & 13.64 & Limits borrowing of LHS households to $\$ 15,000$ \\
\hline \multicolumn{3}{|c|}{ College loans \& grants } \\
\hline$\phi(q)$ & $7.30,9.26,9.74$ & Net tuition fees for $q=1,2,3$ students \\
\hline$\iota^{u}$ & 0.063 & Interest premium on unsubsidized Stafford loans \\
\hline$\underline{b}^{s}$ & 15.68 & Limits subsidized loans to $\$ 17,250$ for $q=1$ students \\
\hline$\underline{b}$ & 20.91 & Limits total student loans to $\$ 23,000$ for $q=1$ and $q=2$ students. \\
\hline$\underline{a}^{p}$ & 20.91 & Limits private loans to $\$ 23,000$ for $q=3$ students \\
\hline$\underline{w}^{\{q=1\}}$ & 77.27 & Full-time equiv. parental income threshold $(\$ 85,000)$ for $q=1$ status \\
\hline
\end{tabular}

Table 6.1: Externally set parameters. All sources listed in the main text. Other externally set parameters, whose estimation is discussed in Appendices B, C, and D, are parameters of: production function, income processes, and transition matrices for cognitive and non-cognitive skills. LH: Less than High-School, HS: High-School, CL: College. 


\begin{tabular}{|c|c|c|c|}
\hline Parameter & Description & Value & (s.e.) \\
\hline$\beta$ & Time discount factor & 0.9753 & $(0.0413)$ \\
\hline$\vartheta_{j}^{g}$ & Male and non-mother female leisure preference & 0.0415 & $(0.0053)$ \\
\hline$\vartheta_{30-45}^{f}$ & Mother leisure preference & 0.0857 & $(0.0049)$ \\
\hline$\psi$ & Redistributive transfer $(\$ 1,000$ ’s) & $\$ 5.31$ & $(0.1647)$ \\
\hline$\iota$ & Borrowing wedge that applies to all debt & 0.1325 & $(0.0355)$ \\
\hline$\iota^{p}$ & Interest premium for private student loans & 0.0590 & $(0.0141)$ \\
\hline$\underline{a}^{\{q=1\}}$ & Wealth threshold for subsidized govt. loans ( $q=1, \$ 1,000$ 's) & $\$ 123.6$ & $(4.272)$ \\
\hline$\underline{a}^{\{q=2\}}$ & Wealth threshold for unsubsidized govt. loans ( $q=2, \$ 1,000$ 's ) & $\$ 168.1$ & (4.933) \\
\hline$\omega^{f}$ & Altruism towards daughters & 0.4699 & $(0.0760)$ \\
\hline$\omega^{m}$ & Altruism towards sons & 0.5178 & $(0.1068)$ \\
\hline \multirow[t]{16}{*}{$\xi$} & Paternalistic utility gain from child graduating from college & 0.2833 & $(0.0379)$ \\
\hline & Moment Matched & Data Value & Model Value \\
\hline & Annualized capital-output ratio & 3.5 & 3.478 \\
\hline & Average male labor supply & 0.350 & 0.349 \\
\hline & Average labor supply of mothers & 0.220 & 0.219 \\
\hline & $\operatorname{Var}(\log$ disposable income)/var(log gross income) & 0.610 & 0.609 \\
\hline & Fraction of workers with negative net worth & 0.068 & 0.072 \\
\hline & Fraction of students who take out private loans & 0.134 & 0.164 \\
\hline & Fraction of students who take out subsidized loans & 0.419 & 0.424 \\
\hline & Fraction of students graduating with any govt. loans & 0.621 & 0.651 \\
\hline & Average IVT to female child ( $\$ 1000$ ’s) & $\$ 29.09$ & $\$ 28.95$ \\
\hline & Average IVT to male child ( $\$ 1000$ ’s) & $\$ 33.16$ & $\$ 33.04$ \\
\hline & Fraction of LH female population (cross-section) & 0.136 & 0.136 \\
\hline & Fraction of LH male population (cross-section) & 0.139 & 0.139 \\
\hline & Fraction of CL female population (cross-section) & 0.280 & 0.280 \\
\hline & Fraction of CL male population (cross-section) & 0.294 & 0.294 \\
\hline
\end{tabular}

Table 6.2: Top Panel: Parameters Internally Estimated by Method of Moments. Bottom Panel: Moments Matched. LH: Less than High-School, HS: High-School, CL: College. IVT: Inter vivos transfers. 


\begin{tabular}{cccc}
\hline \hline & \multicolumn{3}{c}{ High School Drop-Outs by Parental Wealth Quartile (Data) } \\
& \multicolumn{2}{c}{ Parental Wealth Quartile } & \\
1 & 2 & 3 & 4 \\
\hline 0.2221 & 0.1643 & 0.1146 & 0.0472 \\
\hline
\end{tabular}

High School Drop-Outs by Income Quartile (Data)

\begin{tabular}{cccc}
\multicolumn{5}{c}{ Parental Wealth Quartile } \\
1 & 2 & 3 & 4 \\
\hline 0.2372 & 0.1623 & 0.0834 & 0.0671 \\
\hline \multicolumn{4}{c}{ College Graduates by Parental Wealth Quartile (Data) } \\
\hline \multicolumn{4}{c}{ Parental Wealth Quartile } \\
\hline 0.1631 & 2 & 3 & 4 \\
\hline
\end{tabular}

College Graduates by Parental Income Quartile (Data)

Parental Wealth Quartile

\begin{tabular}{cccc}
1 & 2 & 3 & 4 \\
\hline 0.1413 & 0.2210 & 0.3269 & 0.4588 \\
\hline
\end{tabular}

Table 6.3: Attainment Rates - NLSY97 Data. 


\begin{tabular}{|c|c|c|c|}
\hline \multicolumn{4}{|c|}{ High School Drop-Outs by Parental Wealth Quartile (Model Simulation) } \\
\hline \multicolumn{4}{|c|}{ Parental Wealth Quartile } \\
\hline 1 & 2 & 3 & 4 \\
\hline 0.2169 & 0.1515 & 0.0903 & 0.0916 \\
\hline \multicolumn{4}{|c|}{ High School Drop-Outs by Income Quartile (Model Simulation) } \\
\hline \multicolumn{4}{|c|}{ Parental Wealth Quartile } \\
\hline 1 & 2 & 3 & 4 \\
\hline 0.2252 & 0.1476 & 0.0989 & 0.0795 \\
\hline \multicolumn{4}{|c|}{ College Graduates by Parental Wealth Quartile (Model Simulation) } \\
\hline \multicolumn{4}{|c|}{ Parental Wealth Quartile } \\
\hline 1 & 2 & 3 & 4 \\
\hline 0.2003 & 0.2166 & 0.2968 & 0.4344 \\
\hline
\end{tabular}

College Graduates by Parental Income Quartile (Model Simulation)

\begin{tabular}{cccc}
\multicolumn{5}{c}{ Parental Wealth Quartile } \\
1 & 2 & 3 & 4 \\
\hline 0.1932 & 0.2038 & 0.2534 & 0.4977 \\
\hline
\end{tabular}

Table 6.4: Attainment Rates - Model Simulations. 


\begin{tabular}{|c|c|c|c|c|}
\hline \multicolumn{5}{|c|}{ Skill Distribution of High School Drop-Outs (Data) } \\
\hline \multicolumn{5}{|c|}{ Cognitive tercile } \\
\hline & & 1 & 2 & 3 \\
\hline Non- & 1 & 0.4126 & 0.0800 & 0.0061 \\
\hline Cognitive & 2 & 0.2634 & 0.0380 & 0.0000 \\
\hline tercile & 3 & 0.1618 & 0.0354 & 0.0026 \\
\hline \multicolumn{5}{|c|}{ Skill Distribution of College Graduates (Data) } \\
\hline \multicolumn{5}{|c|}{ Cognitive tercile } \\
\hline & & 1 & 2 & 3 \\
\hline Non- & 1 & 0.0129 & 0.0607 & 0.1977 \\
\hline Cognitive & 2 & 0.0189 & 0.0804 & 0.2339 \\
\hline tercile & 3 & 0.0371 & 0.1020 & 0.2563 \\
\hline
\end{tabular}

Table 6.5: Attainment Rates - NLSY97 Data.

\begin{tabular}{|c|c|c|c|c|}
\hline \multicolumn{5}{|c|}{ Skill Distribution of High School Drop-Outs (Simulated) } \\
\hline \multicolumn{5}{|c|}{ Cognitive tercile } \\
\hline & & 1 & 2 & 3 \\
\hline Non- & 1 & 0.4149 & 0.0890 & 0.0080 \\
\hline Cognitive & 2 & 0.2662 & 0.0343 & 0.0024 \\
\hline tercile & 3 & 0.1721 & 0.0125 & 0.0007 \\
\hline \multicolumn{5}{|c|}{ Skill Distribution of College Graduates (Simulated) } \\
\hline \multicolumn{5}{|c|}{ Cognitive tercile } \\
\hline & & 1 & 2 & 3 \\
\hline Non- & 1 & 0.0136 & 0.0707 & 0.1854 \\
\hline Cognitive & 2 & 0.0201 & 0.0918 & 0.2206 \\
\hline tercile & 3 & 0.0337 & 0.1125 & 0.2517 \\
\hline
\end{tabular}

Table 6.6: Attainment Rates - Model Simulations 


\section{ONLINE APPENDIX}

\section{A Cost of College Attendance, Grants, and Loans}

To calculate the price of college attendance and the extent of government aid to higher education financing through grants we focus on the sample of full-time full year (FTFY) students enrolled in public and private not-for-profit 4-year post-secondary institutions. This group of students is the closest counterpart to students in the model. All our statistics refer to the year 2000 and nominal amounts are in 2000 dollars. According to the "Student Financing of Undergraduate Education: 19992000" (SFUE, thereafter), a report published by the National Center for Education Statistics (NCES), $65 \%$ of these students were enrolled in public colleges and 35\% were enrolled in private not-for-profit colleges (Table 1.10).

Cost of college: The cost of college attendance has three components: (i) tuition and fees, (ii) nontuition expenses that would only be incurred by a college-student, and (iii) institutional and private grants which reduce the cost to families. The publication "Trends in College Pricing, 2000" published by the College Board, reports that average tuition and fees in public institutions in 2000-2001 were $\$ 3,510$ in public institutions and $\$ 16,332$ in private ones. We add non-tuition expenses, which includes books and other supplies, amounting to $\$ 704$ and $\$ 730$, respectively, in the two types of colleges. We also add an additional $\$ 500$ to account for any commuting or room and board expenses that would not be incurred by a worker. Average tuition and non-tuition expenses (before grants) amount to \$9,210. According to the SFUE, average tuition and fees did not differ by income level of the family in public institutions. In private institutions (where only $1 / 4$ of students are enrolled), average fees were only roughly $20 \%$ lower for families whose income was between $\$ 20,000-40,000$ compared to fees faced by families whose income exceeded $\$ 100,000$ (Table 2.2-B).

Institutional and private grants are effectively a way to reduce the cost of attendance. Roughly half of these grants are based on pure merit and half are based on need. This fact, together with the negative empirical correlation between family need and students' merit, explains why both the fraction of students receiving grants and their amount is not strongly correlated with family income, as reported in Table A1 which is based on the SFUE, Table 1.2-G.

To arrive at our estimate of average net tuition $(\$ 6,710)$ we subtract average private and institutional grants from average tuition expenses.

Federal and state grants: Based on the "Guide to U.S. Department of Education Programs" (GDEP thereafter) published by the US Department of Education, we identify three main federal grant pro- 


\begin{tabular}{|c|c|c|c|c|c|}
\hline \multirow[b]{2}{*}{ Income } & \multicolumn{2}{|c|}{ Institutional Grants } & \multicolumn{2}{|c|}{ Private Grants } & \multirow[t]{2}{*}{ Average Amoun } \\
\hline & share receiving & Amount & share receiving & Amount & \\
\hline$<\$ 30 \mathrm{k}$ & 0.36 & $\$ 4,077$ & 0.12 & $\$ 2,061$ & $\$ 1,715$ \\
\hline$\$ 30 \mathrm{k}-80 \mathrm{k}$ & 0.34 & $\$ 5,474$ & 0.16 & $\$ 2,281$ & $\$ 2,234$ \\
\hline$>\$ 80 \mathrm{k}$ & 0.28 & $\$ 5,383$ & 0.14 & $\$ 2,338$ & $\$ 1,855$ \\
\hline
\end{tabular}

Table A1: Summary of institutional and private grants data used for the computation of the net tuition fees (NCES).

grams. The Federal Pell Grant Program is the largest single source of grants to undergraduates. It provides need-based grants to individuals to access post-secondary education. It is especially targeted to the lowest-income students. In 2000 it provided $\$ 7.3$ billion to 3.8 million students, with a maximum grant of $\$ 3,125$. The Federal Supplemental Education Opportunity Grant has a more modest endowment (approximately 15 times smaller). These are grants which supplement the amount received through Pell up to a maximum of $\$ 2,100$. Smart Grants are awarded to needy student who are enrolled in certain technical fields and maintain a cumulative GPA of at least 3.0 in the first year - and so they're partly merit based. The program is approximately as big as the Supplemental Opportunity grant program. State funding is very diverse, but most of the funds available are concentrated in 10 "high-aid" states. Only a very small fraction of state grant awards are merit-based (less that 18\%). The fraction of students receiving federal and state grants and their average amount by family income levels (from Table 1.2-G of the SFUE) is summarized in Table A2.

We use the average amount for these three income levels, and the joint distribution of income and wealth in the model, to calibrate the dependence of the transfers function $\mathfrak{g}(q, \boldsymbol{\theta})$ on assets (through the state variable $q$ ). In the baseline experiment, we do not allow $\mathfrak{g}$ to depend on $\boldsymbol{\theta}$. However in one of our policy experiments we consider the introduction of merit-based grants.

Federal loans: While grants are administered by both federal government and states, loans are almost entirely administered by the federal government (less than $1 \%$ of the total loan volume is state-based). The largest federal loan program in the US is the Federal Family Education Loan Program. The total volume of loans available in 2000 through this program was around $\$ 40$ billion, extended to around 10 million students. The program includes two main types of loans to students, Subsidized and Unsubsidized Stafford Loans. A third form of loan offered by the Federal Family Education Loan Program are Parent PLUS loans. These are loans made to the parents on behalf of a child to help pay for tuition by covering up to the cost of attendance less other aid. Eligibility for the PLUS Loan depends on a credit check and interest rates are similar to those in the private sector. Since this type of loan is equivalent to parents borrowing and then making a transfer to their child, we 


\begin{tabular}{|c|c|c|c|c|c|}
\hline \multirow[b]{2}{*}{ Income } & \multicolumn{2}{|c|}{ Federal Grants } & \multicolumn{2}{|c|}{ State Grants } & \multirow[t]{2}{*}{ Average Amount } \\
\hline & $\%$ receiving & Amount & $\%$ receiving & Amount & \\
\hline$<\$ 30 \mathrm{k}$ & 0.72 & $\$ 2,753$ & 0.38 & $\$ 826$ & $\$ 2,820$ \\
\hline$\$ 30 \mathrm{k}-80 \mathrm{k}$ & 0.14 & $\$ 1,579$ & 0.21 & $\$ 455$ & $\$ 668$ \\
\hline$<\$ 80 \mathrm{k}$ & 0.01 & $\$ 1,605$ & 0.07 & $\$ 133$ & $\$ 143$ \\
\hline
\end{tabular}

Table A2: Summary of federal and state grants by family income level (US Department of Education)

do not model them explicitly (Johnson, 2010, makes the same modelling choice). The other major source of financial aid for undergraduates, beyond the Federal Family Education Loan Program, is the William D. Ford Federal Direct Loan Program. This is, in essence, an alternative source of funding for Stafford loans whose total size is roughly half of that available through the Federal Family Education Loan Program. Finally, the Federal Perkins Loan Program provides low-interest loans to help needy students to finance undergraduate education whose conditions are similar to those of the subsidized Stafford loans. Its total funding is small though, roughly 3\% of Stafford loans. Because of their nature, we aggregate these loans with subsidized Stafford loans in our calculations. In light of this discussion, in calibrating the features of the Federal loan program, we focus on (subsidized and unsubsidized) Stafford loans only.

Subsidized Stafford Loans are loans to students who meet a financial needs test (based on family income and assets), with the interest paid by the government on behalf of borrowers while the student is in school. Interest payments after school are subsidized. In 2000, the total cumulative borrowing limit for subsidized loans over the four years of college was $\$ 17,125$.

Unsubsidized Stafford Loans are loans available to students who either do not meet a financial needs test or do qualify, but need to supplement their subsidized loans. The interest on the unsubsidized Stafford loan cumulates when in school, it is added to the principal, and the student starts repaying her debt after graduation. In 2000, the cumulative unsubsidized Stafford loans limit over the four years of college was $\$ 23,000$. For those students who do qualify for subsidized loans, $\$ 23,000$ is the total limit of their Stafford loan (i.e. subsidized plus unsubsidized loans). Therefore we fix the total cumulative (subsidized and unsubsidized) Stafford debt limit $\underline{b}^{s}+\underline{b}^{u}$ to $\$ 23,000$. Repayment plans for Stafford loans typically impose fixed monthly amount for a loan term of up to 10 years. But extended repayment periods can be obtained.

According to the SFUE, among graduating seniors in the year 2000, 62.1\% of students had (subsidized or unsubsidized) federal loans (Table 1.3-A). Furthermore, 84.1\% of federal loans were at least partly subsidized, implying that $52.5 \%$ of students would have subsidized loans (Table 1.6-A).

Private loans: The report "Private Loans and Choice in Financing Higher Education" published 
by the Institute for Higher Education Policy (2003) contains useful information on private borrowing with the purpose of funding post-secondary education. Available estimates suggest that private loans at that time composed only 12 percent of the total volume of Federal loans (page 9). For many student borrowers, a poor credit rating often is the largest barrier to obtaining a private loan. Less than $1 \%$ of private loan products were credit-blind, or available without a credit check (page 15). However, for those who qualify, interest rates on private loans are often more advantageous of those on Stafford Loans (Figure 2.2). In 2000, 8.3\% of graduating seniors received private (non-federal) loans (Student Financing of Undergraduate Education: 1999-2000, NCES, Table 1.4A).

Conversion of student loans into private bonds: In the model, we assume that student loans can be converted to private bonds at graduation. However, because higher interest rates apply to student loans, the principal is inflated up the point that the converted debt equals the net present value of student loans liabilities. Because of the fixed payment nature of student loans we can simply apply annuity formulas to derive the conversion factor. For example, for a federal loan:

$$
\text { factor }=\frac{r^{u}}{1-\left(1+r^{u}\right)^{-10}} \times \frac{1-\left(1+r^{-}\right)^{-10}}{r^{-}}
$$

where a 10-period (20 years) repayment schedule has been assumed. Thus, the equivalent private debt will be the outstanding student loan principal multiplied by the 'factor'. That is, $\tilde{a}_{3}=$ factor $\times \tilde{b}_{3}$ for federal loans. The same formula with $r^{p}$ in place of $r^{u}$ applies for private student loans.

\section{B Marital Matching}

\section{B.1 From Values of Singles to Values of Households}

The ex-post value of the match between a male $m$ and a female $f$ (a household, or family) is:

$$
W_{3}\left(e^{f}, e^{m}, \boldsymbol{\theta}^{f}, \boldsymbol{\theta}^{m}, \tilde{a}_{3}^{f}+\tilde{a}_{3}^{m}, z_{3}^{f}, z_{3}^{m}\right)
$$

a value that summarizes the present discounted utility that this household will generate. Note that, because of the full commitment assumption, individual assets - recalculated after the refinancing of education loans, hence the 'tilde' - are combined within the households.

Individuals entering the matching stage value their prospects as the expectation over potential outcomes, conditional on their own education. Let $Q^{f}\left(e^{f}, e^{m}\right) \in[0,1]$ be the probability that a woman 
in education group $e^{f}$ meets a man belonging to group $e^{m}$. Symmetrically, matching probabilities for men are denoted $Q^{m}\left(e^{m}, e^{f}\right)$. Then, for example, for a college educated female, the expected value of marriage is:

$V_{f 3}^{C L}\left(\boldsymbol{\theta}^{f}, a_{3}^{f}, z_{3}^{f}\right)=\frac{1}{2} \sum_{k \in\{L H, H S, C L\}} Q^{f}(C L, k) \mathbb{E}_{\boldsymbol{\theta}^{m}, a^{m}, z^{m}}\left[W_{3}\left(C L, e^{m}=k, \boldsymbol{\theta}^{f}, \boldsymbol{\theta}^{m}, a_{3}^{f}+a_{3}^{m}, z_{3}^{f}, z_{3}^{m}\right)\right]$

where the $1 / 2$ is the assumed sharing rule, constant because of full commitment. Ex-post, period by period transfers between the couple implement the sharing rule agreed ex-ante - recall equation (2.2).

The expectation is taken over the remaining state variables for the man (ability, wealth, and productivity) conditional on his his education.

\section{B.2 Counterfactual Marriage Matching}

In what follows we draw from Fernández and Rogerson (2001). Let $g_{m}$ be the distribution of male education and $g_{f}$ be the distribution of female education. These are both triples with measures of $l h$, hs and $c l$ individuals. For example, in the data we have $g_{m}=(.139, .567, .294)$ and $g_{f}=$ $(.136, .584, .280)$. These gender-specific education p.d.f. are the marginals of the joint distribution of husband/wife education pairs. Denote the joint distribution by $Q$. Let $Q^{\text {data }}$ be the observed joint distribution:

$$
Q^{d a t a}=\left[\begin{array}{ccc}
.107 & .027 & .002 \\
.030 & .498 & .056 \\
.002 & .042 & .236
\end{array}\right]
$$

In our counterfactuals we can always get the marginals from the education decision rules, but the joint distribution is determined by the model only at the matching stage. However, in counterfactuals, we cannot use the estimated probabilities because they may not be consistent with the new equilibrium education distribution. Thus, we need a strategy to determine marriage matching in counterfactuals.

Two examples of possible joint distributions are what we will label 'assortative' and 'non-assortative' joint distributions. The non-assortative joint distribution, denoted $Q_{N}$, is such that the education attainments of spouses are independent. This is easy to construct as it is the out product of the marginals:

$$
Q_{N}=g_{f}^{\prime} \cdot g_{m}
$$


For example, for the observed marginals we have:

$$
Q_{N}^{\text {data }}=\left[\begin{array}{lll}
.019 & .077 & .040 \\
.081 & .331 & .172 \\
.039 & .159 & .082
\end{array}\right]
$$

The 'assortative' matrix is defined as a joint distribution in which (i) the measure of exact spousal education matches is maximized, and then (ii) among the residual mass of agents the measure matched one attainment level away is maximized, and finally (iii) any remaining residual mass of agents is matched two attainment levels away. For example, for the data education distributions (shown above) the assortative joint distribution is:

$$
Q_{A}^{\text {data }}=\left[\begin{array}{ccc}
.136 & 0 & 0 \\
.003 & .567 & .014 \\
0 & 0 & .280
\end{array}\right]
$$

Next, note that for a given parameter $v \in(0,1)$ we can construct yet another candidate joint distribution by mixing the assortative and non-assortative distributions. Let $Q_{v}(v)=v Q_{A}+(1-$ $v) Q_{N}$ be such a mixture. We can estimate the degree of assortativeness in matching by estimating $v$ as $\hat{v}=\arg \min \left\|Q^{\text {data }}-Q_{v}^{\text {data }}(v)\right\|$, where $\|\cdot\|$ is the Euclidean Norm and $Q_{v}^{\text {data }}(v)=v Q_{A}^{\text {data }}+(1-$ $v) Q_{N}^{\text {data }}$. Doing this exercise yields $\hat{v}=0.265$, and the associated $Q_{v}^{\text {data }}(v)$ is:

$$
Q_{v}^{\text {data }}=\left[\begin{array}{lll}
.1050 & .0204 & .0106 \\
.0237 & .5045 & .0558 \\
.0103 & .0421 & .2276
\end{array}\right]
$$

Comparing $Q^{d a t a}$ and $Q_{v}^{d a t a}$ shows that the fit is very good.

For our counterfactuals we now take $v$ as given, which we interpret as holding the assortativeness of matching constant. For any pair of counterfactual marginal education distributions we can construct $Q_{N}$ and $Q_{A}$, and then recover $Q$ using the estimate $\hat{v}=0.265$. 


\section{Value Functions and Competitive Equilibrium}

\section{C.1 Working Households}

The value function for a married couple in periods before and after making transfers to their children is given by

$$
\begin{aligned}
W_{j}\left(\boldsymbol{x}_{j}\right)= & \max _{\substack{c_{j}^{m}, c_{j}^{f}, \ell_{j}^{m}, \ell_{j}^{f}, a_{j+1}\\
}}\left\{u_{j}\left(c_{j}^{m}, c_{j}^{f}, \ell_{j}^{f}, \ell_{j}^{m}\right)\right. \\
& \left.+\beta \mathbb{E}_{j}\left[W_{j+1}\left(\boldsymbol{x}_{j+1}\right)\right]\right\} \\
& \text { s.t. } \\
\left(1+\tau_{c}\right) c_{j}+a_{j+1}= & \sum_{g \in\{f, m\}}\left(1-\tau_{w}\right) w^{g, e} \varepsilon_{j}^{g, e}\left(\boldsymbol{\theta}^{g}, z_{j}^{g}\right)\left(1-\ell_{j}^{g}\right) \\
& +2 \psi+\left[1+r\left(1-\tau_{k}\right)\right] a_{j} \\
c_{j}= & {\left[\left(c_{j}^{m}\right)^{\tilde{\rho}}+\left(c_{j}^{f}\right)^{\tilde{\rho}}\right] } \\
a_{j+1} \geq & -\underline{a}^{e}, \quad c_{j}^{g} \geq 0, \quad \ell_{j}^{g} \in[0,1] \\
z_{j+1}^{g} \sim & \Gamma_{z}^{g, e^{g}}\left(z_{j+1}^{g} \mid z_{j}^{g}\right) .
\end{aligned}
$$

where $\boldsymbol{x}_{j}=\left(e^{f}, e^{m}, \boldsymbol{\theta}^{f}, \boldsymbol{\theta}^{m}, a_{j}, z_{j}^{f}, z_{j}^{m}\right)$ until the the age when the children are born $(j=8$, corresponding to 30-32) and their gender revealed, after which $\boldsymbol{x}_{j}$ includes also this additional state until the inter vivos stage. The main differences between this decision problem and that in equation (2.7) are that (i) two sources of labor supply are available to the family, and (ii) the economies of scale in consumption are present. With a slight abuse of notation we have used $r$ for both the interest rate on saving and the one on borrowing $\left(r=r^{-}+\iota\right.$ in the main text). Finally, recall that $u_{j}$ includes the utility transfers between spouses that implement the equal sharing rule but, because these transfers are separable in preferences, they do not affect optimal choices.

\section{C.2 Inter Vivos Transfers}

In section 2.4 we described the decision problem of a household in the period when parents choose transfers to their children. Formally, in the period of the inter vivos transfer, parents solve the follow- 
ing problem:

$$
\begin{aligned}
& W_{j^{i v t}}\left(\boldsymbol{x}_{j^{i v t}}\right)=\max _{c_{j}^{m}, c_{j}^{f}, \ell_{j}^{m}, \ell_{j}^{f}, \hat{a}_{0}, \hat{a}^{C L}, a_{j+1}}\left\{u_{j}\left(c_{j}^{m}, c_{j}^{f}, \ell_{j}^{m}, \ell_{j}^{f}\right)\right. \\
& +\beta \mathbb{E}_{z^{f}, z^{m}}\left[W_{j+1}\left(\boldsymbol{x}_{j+1}\right)\right] \\
& \left.+2 \omega_{\hat{g}} \mathcal{V}_{g 0}\left(\boldsymbol{x}_{0}\right)+2 \xi \cdot \mathbf{1}_{\{\hat{e}=C L\}}\right\} \\
& \text { s.t. } \\
& \left(1+\tau_{c}\right) c_{j}+a_{j+1}+2 \hat{a}+2 \frac{\hat{a}^{C L}}{1+r} \quad=\quad \sum_{g \in\{f, m\}}\left(1-\tau_{w}\right) w^{g, e} \varepsilon_{j}^{g, e}\left(\boldsymbol{\theta}^{g}, z_{j}^{g}\right)\left(1-\ell_{j}^{g}\right) \\
& +2 \psi+\left[1+r\left(1-\tau_{k}\right)\right] a_{j} \\
& c_{j}=\left[\left(c_{j}^{m}\right)^{\tilde{\rho}}+\left(c_{j}^{f}\right)^{\tilde{\rho}}\right]^{\frac{1}{\tilde{\rho}}} \\
& a_{j+1} \geq-\underline{a}, \quad \hat{a}_{0} \geq 0, \quad \hat{a}^{C L} \geq 0, \quad c_{j}^{g} \geq 0, \quad \ell_{j}^{g} \in[0,1] \\
& z_{j+1}^{g} \sim \Gamma_{z}^{g, e^{g}}\left(z_{j+1}^{g} \mid z_{j}^{g}\right) \\
& \hat{\theta}_{\text {cog }} \sim \Gamma_{\theta_{\text {cog }}}\left(\hat{\theta}_{\text {cog }} \mid \theta_{\text {cog }}^{f}\right), \quad \hat{\theta}_{\text {non }} \sim \Gamma_{\theta_{\text {non }}}\left(\hat{\theta}_{\text {non }} \mid \hat{\theta}_{\text {cog }}, e^{f}\right) \\
& \hat{q}= \begin{cases}1 & \text { if } a_{j} \leq \underline{a}^{\{q=1\}} \text { and } \max \left\{w^{m, e} \varepsilon_{j}^{m, e}, w^{f, e} \varepsilon_{j}^{f, e}\right\} \leq \underline{w}^{\{q=1\}} \\
2 & \text { if } a_{j} \leq \underline{a}^{\{q=1\}} \text { and } \max \left\{w^{m, e} \varepsilon_{j}^{m, e}, w^{f, e} \varepsilon_{j}^{f, e}\right\}>\underline{w}^{\{q=1\}} \\
2 & \text { if } \underline{a}^{\{q=1\}}<a_{j} \leq \underline{a}^{\{q=2\}} \\
3 & \text { if } a_{j}>\underline{a}^{\{q=2\}}\end{cases}
\end{aligned}
$$

where $\boldsymbol{x}_{j i v t}=\left(\boldsymbol{x}_{j} ; \hat{g}, \hat{\theta}, \hat{\kappa}_{\epsilon}\right)$ is the state space at the inter vivos giving stage, and $\boldsymbol{x}_{0}=\left(\hat{\boldsymbol{\theta}}, \hat{\kappa}_{\epsilon}, \hat{\boldsymbol{a}}, \hat{q}\right)$ is the state vector for the child at the start of life before the first decision between continuing high-school or entering the labor force. $\underline{w}^{\{q=1\}}$ is the full time equivalent parental earnings threshold below which a child can qualify for subsidized federal loans. Note that the conditional transfer is divided by the one period gross interest rate because it earns interests for a period before being paid out to children attending college. 


\section{C.3 Retired Households}

From period $j^{R E T}$ onwards couples enter the retirement stage, in which they solve the following problem:

$$
\begin{aligned}
W_{j}^{R}\left(\boldsymbol{x}_{j}\right) & =\max _{c_{j}^{m}, c_{j}^{f}, a_{j+1}}\left\{u\left(c_{j}^{m}, c_{j}^{f}, 1,1\right)+\beta \zeta_{j+1} W_{j+1}^{R}\left(\boldsymbol{x}_{j+1}\right)\right\} \\
\text { s.t. } & \left(1-\tau_{w}\right)\left[p\left(e^{f}\right)+p\left(e^{m}\right)\right]+2 \psi+\zeta_{j+1}^{-1}\left[1+r\left(1-\tau_{k}\right)\right] a_{j} \\
\left(1+\tau_{c}\right) c_{j}+a_{j+1} & \left.=\left(1-c_{j}^{m}\right)^{\tilde{\rho}}+\left(c_{j}^{f}\right)^{\tilde{\rho}}\right]^{\frac{1}{\tilde{\rho}}} \\
c_{j} & =\left[\quad c_{j}^{g} \geq 0 .\right.
\end{aligned}
$$

$\boldsymbol{x}_{j}=\left(e^{f}, e^{m}, a_{j}\right)$ is a retired household's state vector. Pension income $p\left(e^{g}\right)$ is dependent on education (see Section 2.2 and Table 6.1). The inflation of assets by a factor $\zeta_{j+1}^{-1}$ reflects the perfect annuity markets assumption.

\section{C.4 Stationary Recursive Competitive Equilibrium}

Recall that $\boldsymbol{x}_{j}^{*} \in S_{j}^{g, *}$ denotes the state vector for an individual still in school at age $j$. Similarly $\boldsymbol{x}_{j} \in S_{j}^{g, e}$ denotes the age-specific state vector of an individual (single or married) of gender $g$ and completed education $e$ that has entered the labor force and is working. As clear from the household problems described above, the state vector for a married individual includes also state variables of the spouse and, in certain periods, state variables of the children. Let $\mu_{j}^{g, *}$ and $\mu_{j}^{g, e}$ be the corresponding measures over Borel sigma-algebras defined using those state spaces.

A stationary recursive competitive equilibrium for this economy is a collection of: (i) HS students' decisions on education $\left\{d_{0}^{g, H S}\left(\boldsymbol{x}_{0}^{*}\right), d_{1}^{g, C L}\left(\boldsymbol{x}_{1}^{*}\right)\right\}$ and consumption $\left\{c_{0}^{g, *}\left(\boldsymbol{x}_{0}^{*}\right)\right\}$; (ii) CL students' decisions on consumption, leisure, wealth holdings and student debt $\left\{c_{j}^{g, *}\left(\boldsymbol{x}_{j}^{*}\right), \ell_{j}^{g, *}\left(\boldsymbol{x}_{j}^{*}\right), a_{j+1}^{g, *}\left(\boldsymbol{x}_{j}^{*}\right)\right.$, $\left.b_{j+1}^{g, *}\left(\boldsymbol{x}_{j}^{*}\right)\right\}$ with $j=1,2$; (ii) workers/retirees decisions on consumption, leisure, and wealth holdings $\left\{c_{j}^{g, e}\left(\boldsymbol{x}_{j}\right), \ell_{j}^{g, e}\left(\boldsymbol{x}_{j}\right), a_{j+1}^{g, e}\left(\boldsymbol{x}_{j}\right)\right\}$; (iii) inter-vivos transfer decisions $\left\{\hat{a}_{0}^{g}\left(\boldsymbol{x}_{j}{ }^{T R}\right), \hat{a}^{g, C L}\left(\boldsymbol{x}_{j}{ }^{T R}\right)\right\}$; (iv) value functions $\left\{\mathcal{V}_{g 0}\left(\boldsymbol{x}_{j}^{*}\right), V_{g j}^{*}\left(\boldsymbol{x}_{j}^{*}\right), W_{j}\left(\boldsymbol{x}_{j}\right), W_{j}^{R}\left(\boldsymbol{x}_{j}\right)\right\}$; (v) aggregate capital and labor inputs $\left\{K, H^{f, L H}, H^{f, H S}, H^{f, C L}, H^{m, L H}, H^{m, H S}, H^{m, C L}\right\}$; (vi) prices of capital and labor services $\left\{r, w^{f, L H}, w^{f, H S}, w^{f, C L}, w^{m, L H}, w^{m, H S}, w^{m, C L}\right\}$; (v) labor income tax $\left\{\tau_{w}\right\}$; (vi) measures for students and workers/retirees $\left\{\mu_{j}^{g, *}, \mu_{j}^{g, e}\right\}$, such that:

1. The decision rules of students, single workers, working and retired couples solve their re- 
spective household problems, and $\left\{\mathcal{V}_{g 0}\left(\boldsymbol{x}_{j}^{*}\right), V_{g j}^{*}\left(\boldsymbol{x}_{j}^{*}\right), W_{j}\left(\boldsymbol{x}_{j}\right), W_{j}^{R}\left(\boldsymbol{x}_{j}\right)\right\}$ are the associated value functions.

2. The representative firm optimally chooses factors of productions, and input prices equate their marginal products,

$$
\begin{aligned}
r+\delta & =F_{K}(K, \mathcal{H}) \\
w^{g, e} & =F_{H^{g, e}}(K, \mathcal{H}), \text { for } e \in\{L H, H S, C L\}, \text { and } g \in\{f, m\} .
\end{aligned}
$$

3. The labor market for each gender and education level clears

$$
H^{g, e}=\sum_{j=0}^{j^{R E T}-1} \int_{S_{j}^{g, e}} \varepsilon_{j}^{g, e}\left[1-\ell_{j}^{g, e}\left(\boldsymbol{x}_{j}\right)\right] d \mu_{j}^{g, e}+d_{1}^{g, C L}\left(\boldsymbol{x}_{1}^{*}\right) \sum_{j=j^{H S}+1}^{j^{C L}} \int_{S_{j}^{g, *}} \varepsilon_{j}^{g, H S}\left[1-\bar{t}-\ell_{j}^{g, *}\left(\boldsymbol{x}_{j}^{*}\right)\right] d \mu_{j}^{g, *}
$$

where the first term is the effective labor supply of single and married workers, and the second term only enters the calculation of HS human capital stocks and accounts for the effective labor supply of college students who supply HS-equivalent labor until they graduate college.

4. The asset market clears

$$
K=\sum_{g, e} \sum_{j=0}^{J} \int_{S_{j}^{g, e}} a_{j}^{g, e} d \mu_{j}^{g, e}+\sum_{g \in\{f, m\}} \sum_{j=0}^{j^{C O L}} \int_{S_{j}^{g, *}} a_{j}^{g, *} d \mu_{j}^{g, *}
$$

The aggregate capital stock demanded by firms equal total savings supplied by working individuals and students. Assets for married individuals $\left(j>j^{C O L}\right)$ are computed as half of household-level assets.

5. The goods market clears

$$
C+\delta K+G+\Phi+\Upsilon=F(K, \mathcal{H})
$$

where aggregate consumption is computed as

$$
C=\sum_{g, e} \sum_{j=0}^{J} \int_{S_{j}^{g, e}} c_{j}^{g, e}\left(\boldsymbol{x}_{j}\right) d \mu_{j}^{g, e}+\sum_{g \in\{f, m\}} \sum_{j=0}^{j C O L} \int_{S_{j}^{g, *}} c_{j}^{g, *}\left(\boldsymbol{x}_{j}\right) d \mu_{j}^{g, *} .
$$


Consumption for married individuals $\left(j>j^{C O L}\right)$ is computed as half of the CES aggregator of individual expenditures defined in equations (C1)-(C3), $\Phi$ is the aggregate amount of private expenditures in educational services by college students

$$
\Phi=\sum_{g \in\{f, m\}} \sum_{j=j^{H S}+1}^{j^{C L}} \phi(q, \boldsymbol{\theta}) \int_{S_{j}^{g, *}} d \mu_{j}^{g, *}
$$

and $\Upsilon$ is the value of the services provided by the financial intermediation sector, which consists of the aggregation of all intermediation costs on private student loans and on credit extended to the working age population.

6. The government budget constraint holds

$$
\begin{aligned}
& G+\sum_{g, e} \sum_{j=j^{R E T}}^{J} \int_{S_{j}^{g, e}} p(e) d \mu_{j}^{g, e}+\left[\sum_{g, e} \sum_{j=0}^{J} \int_{S_{j}^{g, e}} d \mu_{j}^{g, e}+\sum_{g \in\{f, m\}} \sum_{j=0}^{j} \int_{S_{j}^{g, *}} d \mu_{j}^{g, *}\right] \psi+E= \\
& =\tau_{c} C+\tau_{w} \sum_{g, e}\left[w^{g, e} H^{g, e}+\sum_{j=j^{R E T}}^{J} \int_{S_{j}^{g, e}} p(e) d \mu_{j}^{g, e}\right]+\tau_{k} r K .
\end{aligned}
$$

In the LHS of the government budget, the $\psi$ is a per-capita lump sum transfer while $E$ are aggregate net government expenditures on financial aid:

$$
\begin{aligned}
& E=\sum_{g \in\{f, m\}} \sum_{j=j^{H S}+1}^{j^{C L}} \int_{S_{j}^{g, *}}\left[\mathfrak{g}(q, \boldsymbol{\theta})-\Delta b_{j}^{g, *}\right] d \mu_{j}^{g, *}+\left(\iota+\iota^{u}\right) \sum_{g \in\{f, m\}} \sum_{j=j^{H S}+1}^{j^{C L}} \int_{S_{j}^{g, *}} b_{j}^{g, *} d \mu_{j}^{g, *} \\
& -r^{u} \sum_{g \in\{f, m\}} \sum_{j=j^{H S}+1}^{j^{C L}} \int_{S_{j}^{g, *}}\left[\mathbb{I}_{\left\{q=1, b_{j}^{g *}<-\underline{b}^{s}\right\}} \cdot\left(b_{j}^{g, *}+\underline{b}^{s}\right)+\mathbb{I}_{\{q=2\}} \cdot b_{j}^{g, *}\right] d \mu_{j}^{g, *}
\end{aligned}
$$

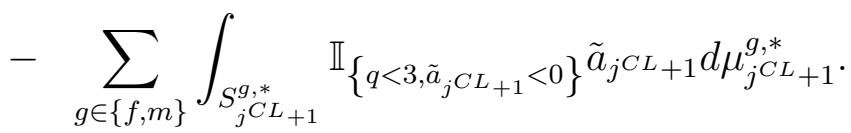

Government outlays (first row) are determined by grants $\mathfrak{g}$, plus the total amount of loans extended to college students, equal to the sum of the $-\Delta b_{j}$ increments each period, plus the intermediation cost incurred on these loans. Revenues (second and third rows) are determined by: (i) interest on unsubsidized loans during college and, (ii) debt repayments after graduation. Recall that student debt is refinanced into a single bond whose face value is $\tilde{a}_{j C L+1}$ and equals 
the present value of future student debt liabilities. Therefore, repayments of student loans are the sum of all negative $\tilde{a}_{j C L+1}$ by college graduates who draw government loans (i.e. those with $q<3)$.

7. Individual and aggregate behaviors are consistent. Given an initial measure $\mu_{0}^{g, *}$ the measures $\left\{\mu_{j}^{g, *}, \mu_{j}^{g, e}\right\}$, with $j>0$ are obtained recursively from the decision rules, the exogenous law of motion $\Gamma_{z}^{g, e}$, the exogenous matching probabilities, the institutional rules determining federal aid eligibility $q$, and the survival rates $\left\{\zeta_{j}\right\}$. In turn, the initial measure $\mu_{0}^{g, *}$ has to be consistent with all these other measures at $j>0$, given the exogenous transmission of ability across generations $\left\{\Gamma_{\theta_{c o g}}, \Gamma_{\theta_{n o n}}\right\}$ and the inter-vivos transfer functions that determines initial wealth of the children.

\section{C.5 Computation of Stationary Equilibrium}

This section describes the solution method for our long-run GE economy. The usual nested fixed point approach is extended in order to accommodate the novel features of our model. That is, the essence of our approach is to (i) guess a set of prices and taxes, (ii) compute decision rules (given prices and taxes), (iii) compute the stationary measures implied by the decisions and exogenous stochastic processes, and finally (iv) verify whether those are the stationary equilibrium prices and taxes. To accommodate endogenous inter vivos transfers we must also begin with guesses of value functions of age zero agents. To accommodate matching in the marriage market, we must also begin with an initial guess of the distribution of education levels among men and women.

Specifically, we execute the following steps:

1. Make an initial guess for the wage vector, $\boldsymbol{w}$, the real interest rate, $r$, and the age zero value functions in school $V_{0}^{*}$ and in work $V_{0}^{L H}$. Also make and initial guess for the joint conditional distribution of married household characteristics given the characteristics of unmarried age $j=$ 3 individuals, and label this guess $P_{\text {match }}$. In the policy experiments, an initial guess for the labor tax rate is also required.

2. Solve the household dynamic programming problems described in the main text at the prices $\boldsymbol{w}$ and $r$. This is a finite horizon problem easily solved by backward induction using Euler equation methods. At the age of inter vivos transfers, the initial guesses of $V_{0}^{*}$ and $V_{0}^{L H}$ are used. Continuing to solve recursively back to age $j=0$, updated guesses $\left\{V_{0}^{*}, V_{0}^{L H}\right\}^{\prime}$ are attained. Iterate on the life-cycle problem until $V_{0}^{*}$ and $V_{0}^{L H}$ converge to $\left\{V_{0}^{*}, V_{0}^{L H}\right\}^{\prime}$, respectively. In solving the problem of age $j=3$ individuals the distribution $P_{\text {match }}$ is used to calculate the 
expected continuation value. The solution yields optimal decision rules for education, take-up of student loans, consumption, leisure, private saving/borrowing, and inter vivos transfers.

3. Compute the probability measures $\boldsymbol{\mu}$ of households over the state-space. Begin with a guess of the initial density of age $j=0$ individuals $\left\{\mu_{0}^{g, *}\right\}$. Given this guess, use the transition function generated by the decision rules of individuals and the exogenous processes to compute up to $\left\{\mu_{3}^{g, *}\right\}$. Use $\left\{\mu_{3}^{g, *}\right\}$ in combination with the exogenous matching probabilites $Q^{g, e}$ to compute $\mu_{4}^{g, e}$, which is the probability measure over the state-space of age $j=4$ married couples. Continue computing the probability measure forward until the age of inter vivos transfers. At this point use $\mu_{j I V T}^{g, e}$, the decision rules of parents, and intergenerational ability transition matrix to compute a new measure $\left\{\mu_{0}^{g, *}\right\}^{\prime}$ over age $j=0$ individuals. Iterate on this entire process until $\left\{\mu_{0}^{g, *}\right\}$ and $\left\{\mu_{0}^{g, *}\right\}^{\prime}$ converge.

4. Using the solutions for $\left\{\mu_{3}^{g, *}\right\}$ and $\mu_{4}^{g, e}$ from the previous step, compute an updated conditional distribution of married household characteristics $P_{\text {match }}^{\prime}$. If $P_{\text {match }}^{\prime} \neq P_{\text {match }}$, go back to step 2 using and updated $P_{\text {match }}$ and repeat until convergence. If $P_{\text {match }}^{\prime}$ has converged to $P_{\text {match }}$ go to step 5. (We find using an average of $P_{\text {match }}^{\prime}$ and $P_{\text {match }}$ is useful in updating here.)

5. Compute the remaining probability measures for $j>4$, and then use them to compute aggregate quantities. If marginal products $\boldsymbol{w}^{\prime}$ and $r^{\prime}$ differ from initial guesses $\boldsymbol{w}$ and $r$, update these guesses and go back to step 1. Also check if the government budget constraint is satisfied, and in the case of a policy experiment update the guess of the labor tax rate accordingly. If prices have converged and the government budget constraint is satisfied, and equilibrium has been computed.

Once the fixed point has been attained, simulated data from the economy can be used to compute the various moments of interest.

\section{Aggregate Technology Parameters}

For the estimation of the aggregate technology parameters we use data from the Current Population Survey (CPS) for 1968-2001 (see Heckman et al., 1998a). The sample includes the adult universe (i.e., the population of marriageable age, with all individuals aged 15 and over unless they have missing or zero earnings, or missing educational attainment information $)^{49}$. We compute total wage bills in

\footnotetext{
${ }^{49}$ Since earnings data are top-coded in the CPS, we extrapolate the average of the top-coded values by using a tail approximation based on a Pareto distribution. ? provides evidence that this method closely approximates the average of
} 
billions of dollars for the three education groups, as well as for their subsets by gender. Dividing the relevant wage bill by the (normalized) marginal product of human capital estimated from PSID data (see discussion in Appendix E below), we obtain point estimates of total efficiency-weighted labor supply (human capital aggregates) by education, gender and year. Because of the well documented relative demand shifts over the period considered, we let share parameters vary over time. For example $s_{t}^{e}=\exp \left(s_{0}^{e}+g^{e} t\right)$, where $t$ denotes calendar year and $g^{e}$ captures the growth rate in each human capital share of type $e$. Shares are normalized to sum to one at every $t$.

We proceed sequentially. First, we estimate the parameters governing gender aggregation within education groups. Then, we use these estimates to derive education-specific stocks and estimate the parameters governing education aggregation.

Gender-specific parameters. For each given education group, we use variation in the genderspecific wage bills $\left(\varpi_{t}^{f, e}\right)$ over time to estimate the elasticity between labor input from different genders. Taking first-order conditions, and the log of both sides, we arrive at:

$$
\log \left(\frac{\varpi_{t}^{f, e}}{\varpi_{t}^{m, e}}\right)=\log \left(\frac{s_{t}^{f, e}}{s_{t}^{m, e}}\right)+\chi \log \left(\frac{H_{t}^{f, e}}{H_{t}^{m, e}}\right)
$$

an equation that holds for all education groups $e$. Recall that $\chi \in(-\infty, 1]$.

Under the null hypothesis that the elasticity parameter $\chi$ does not vary across education groups, we have three independent equations which can be jointly estimated and, then, used to test the isoelasticity assumption. We estimate a specification based on time differences of the equation (D1) above. This specification identifies the elasticity from changes over time in the ratios of wage bills and of human capital stocks of each education-gender group.

We control for endogeneity of these human capital stocks by using various sets of instruments. First, we use instruments based on different sets of lags of human capital aggregates. Next, we verify robustness of the results using, either as a replacement or in addition, instruments corresponding to the stock of men and women with a given education in a given year. The total number of people with a given education level, whether working or not, is a slow moving stock and therefore independent of the autocorrelated component in the right hand side variables. The estimation procedure is based on a stacking method which allows one to test for differences in the elasticity of substitution across different types of labor (like in a Chow test). The results are reported in Table D.1. Panel (A) reports point estimates of the substitutability parameter, panel (B) reports different tests of the iso-elasticity hypothesis, which cannot be rejected.

the top-coded tails by validating the fitted data through undisclosed and confidential non top-coded data available only at the BLS. 
The estimated 'education-conditional' elasticity of substitution between gender-specific aggregates ranges between 1.2 and 1.9. In numerical simulations, the gender weights for different education groups are set to the values estimated for the year 1999. Female shares are, respectively, $s^{f, L H}=0.34$, $s^{f, H S}=0.40$ and $s^{f, C L}=0.38$.

Education-specific parameters. After aggregating gender-specific stocks of human capital using equation (2.4), a similar procedure can be applied to estimate the elasticity of substitution between the three education-specific human capital aggregates. From aggregator (2.3) and the equilibrium condition in the labor market, we derive expressions for the wage bills $\varpi_{t}^{e}$. For education groups $H S$ and $C L$, for example, we write,

$$
\log \left(\frac{\varpi_{t}^{C L}}{\varpi_{t}^{H S}}\right)=\log \left(\frac{s_{t}^{C L}}{s_{t}^{H S}}\right)+\rho \log \left(\frac{H_{t}^{C L}}{H_{t}^{H S}}\right)
$$

We estimate the elasticity of substitution among labor inputs using the empirical counterparts of pair-wise ratios like the one in equation (D2). Also in this case we estimate a specification based on first-differences of equation $(D 2)$. We control for possible endogeneity of human capital inputs in the production function through an IV approach. We experiment with different sets of instruments. First, we use lagged regressors (lags up to 5 periods back are included in the first step, depending on the specification). Alternatively, and as a robustness check, we also instrument using the total number of people in each education group in a given year, including those people not working. This latter instrument, being a stock, is independent of the serial correlation properties of the technology shock.

Table D. 2 reports results for the estimation of the $\rho$ elasticity parameters. Panel (A) reports results obtained by using, as instruments, lags of human capital or education 'headcounts' or both. Panel (B) reports tests of the null hypothesis of iso-elasticity for the different specifications (more specifications and tests are available from the authors: results are fairly robust.) Overall, all specifications give rather similar results and we are unable to reject the null hypothesis that the aggregate technology is iso-elastic at the 5\% level of significance. The restricted model with a unique $\rho$ improves the efficiency of the estimator, which is particularly valuable since we are using a relatively short time series (approximately 30 observations).

The estimated value for $\rho$ ranges between 0.68 and 0.98 . In the simulations we use $\rho=0.7$. This corresponds to an elasticity of substitution of 3.3, which is within the range of our estimates and consistent with values discussed in the literature. The estimated values for the education weights used in the simulations are $s^{L H}=0.16, s^{H S}=0.38, s^{C L}=0.46$, which are those for the year 1999. 
Panel (A): Estimation

Specification

(1)
(2)

First stage IV Up to 3 lags Up to 4 lags

Number of obs.
75

Coefficient Coefficient
(3)
(4)
(5)

Edu.stock (L) Edu.stock (G) 4 Lags,Edu.stock (L+G)

84

84

72

Coefficient

Coefficient

\begin{tabular}{cccccc} 
& $($ S.E. $)$ & $($ S.E. & (S.E.) & (S.E.) & (S.E.) \\
\hline$\chi^{f, m \mid L H}$ & .06 & .14 & -.10 & .44 & .19 \\
& $(.12)$ & $(.10)$ & $(.39)$ & $(.18)$ & $(.08)$ \\
$\chi^{f, m \mid H S}$ & .62 & .51 & .23 & .56 & .47 \\
& $(.27)$ & $(.21)$ & $(.46)$ & $(.40)$ & $(.18)$ \\
$\chi^{f, m \mid C G}$ & .39 & .73 & .55 & .58 & .51 \\
& $(.47)$ & $(.35)$ & $(.45)$ & $(.68)$ & $(.23)$ \\
$\chi^{f, m \mid L H, H S, C G}$ & .17 & .25 & .19 & .47 & .26 \\
& $(.11)$ & $(.09)$ & $(.23)$ & $(.16)$ & $(.07)$ \\
\hline
\end{tabular}

Panel (B): Hypothesis Testing

Specification

(1)
(2)
(3)
(4)

Edu.stock

(G)

(L)
(5)

First stage IV Up to 3 lags Up to 4 lags

F-stat.

F-stat.

4 Lags,Edu.stock

F-stat.

F-stat.

\begin{tabular}{cccccc}
\hline$\chi^{f, m \mid L H}=\chi^{f, m \mid H S}$ & $F_{(1,69)}=3.58$ & $F_{(1,66)}=2.48$ & $F_{(1,78)}=.31$ & $F_{(1,78)}=.07$ & $F_{(1,66)}=1.88$ \\
& $\operatorname{Pr} .>F=.06$ & $\operatorname{Pr} .>F=.12$ & $\operatorname{Pr} .>F=.58$ & $\operatorname{Pr} .>F=.80$ & $\operatorname{Pr}>F=.18$ \\
$\chi^{f, m \mid H S}=\chi^{f, m \mid C G}$ & $F_{(1,69)}=0.18$ & $F_{(1,66)}=0.27$ & $F_{(1,78)}=.23$ & $F_{(1,78)}=.00$ & $F_{(1,66)}=.02$ \\
& $\operatorname{Pr} .>F=.67$ & $\operatorname{Pr} .>F=.61$ & $\operatorname{Pr} .>F=.63$ & $\operatorname{Pr}>F=.97$ & $\operatorname{Pr}>F=.90$ \\
$\chi^{f, m \mid L H}=\chi^{f, m \mid C G}$ & $F_{(1,69)}=0.46$ & $F_{(1,66)}=2.50$ & $F_{(1,78)}=1.17$ & $F_{(1,78)}=.04$ & $F_{(1,66)}=1.63$ \\
& $\operatorname{Pr} .>F=.50$ & $\operatorname{Pr} .>F=.12$ & $\operatorname{Pr} .>F=.28$ & $\operatorname{Pr} .>F=.85$ & $\operatorname{Pr} .>F=.21$ \\
$\chi^{f, m \mid L H}=\chi^{f, m \mid H S}=\chi^{f, m \mid C G}$ & $F_{(1,69)}=1.91$ & $F_{(2,66)}=2.23$ & $F_{(2,78)}=.59$ & $F_{(2,78)}=.05$ & $F_{(2,66)}=1.57$ \\
& $\operatorname{Pr} .>F=.16$ & $\operatorname{Pr} .>F=.12$ & $\operatorname{Pr} .>F=.56$ & $\operatorname{Pr} .>F=.95$ & $\operatorname{Pr} .>F=.22$ \\
\hline
\end{tabular}

$F_{(1,78)}=.07$

Table D.1: Panel (A): Estimates of $\chi$ for various specifications. $\chi^{e_{1}, e_{2}}$ denotes the parameter determining the elasticity of substitution between genders $g_{1}$ and $g_{2}$ estimated with the corresponding wage-bill ratio equation. $\chi^{f, m \mid C L, H S, L H}$ denotes the estimate from the restricted (iso-elastic) model. Labels (L) and (G) indicate whether the stock of people with given education enters in Level or Growth rate in the estimated equation. (B): Tests for equality of elasticities of substitution among labor inputs. P-values are reported below the F-statistic. 


\begin{tabular}{cccccc}
\hline \hline \multicolumn{5}{c}{ Panel (A): Estimation } \\
\hline & \multicolumn{5}{c}{ Specification } \\
\cline { 2 - 6 } & $(1)$ & $(2)$ & $(3)$ & $(4)$ & $(5)$ \\
First stage IV & Up to 3 lags & Up to 4 lags & Edu.stock(L) & Edu.stock(G) & 3 Lags,Edu.stock(L+G) \\
Number of obs. & 78 & 75 & 84 & 84 & 78 \\
& Coefficient & Coefficient & Coefficient & Coefficient & Coefficient \\
& (S.E.) & (S.E.) & (S.E.) & (S.E.) & (S.E.) \\
\hline$\rho^{H S, L H}$ & .40 & .70 & 4.69 & 2.10 & .73 \\
& $(.72)$ & $(.37)$ & $(13.27)$ & $(1.72)$ & $(.29)$ \\
$\rho^{C L, H S}$ & .26 & .58 & .33 & .27 & .51 \\
& $(1.05)$ & $(1.02)$ & $(2.60)$ & $(1.17)$ & $(.46)$ \\
$\rho^{C L, L H}$ & 1.93 & 1.59 & 1.04 & 1.05 & .99 \\
& $(1.17)$ & $(.88)$ & $(1.40)$ & $(.65)$ & $(.27)$ \\
$\rho^{C L, H S, L H}$ & .68 & .81 & .91 & 0.98 & .75 \\
& $(.31)$ & $(.24)$ & $(.33)$ & $(.34)$ & $(.13)$ \\
\hline
\end{tabular}

Panel (B): Hypothesis Testing

Specification

(1)
(2)

Up to 4 lags
(3)

Edu.stock
(4)

Edu.stock

(G)

F-stat.
(5)

\begin{tabular}{cccccc} 
First stage IV & Up to 3 lags & Up to 4 lags & $\begin{array}{c}\text { Edu.stock } \\
\text { (L) }\end{array}$ & $\begin{array}{c}\text { Edu.stock } \\
\text { (G) }\end{array}$ & $\begin{array}{c}\text { 3 Lags,Edu.stock } \\
\text { (L+G) }\end{array}$ \\
Null Hypothesis & F-stat. & F-stat. & F-stat. & F-stat. & F-stat. \\
\hline$\rho^{H S, L H}=\rho^{C L, H S}$ & $F_{(1,72)}=.01$ & $F_{(1,69)}=.01$ & $F_{(1,78)}=.10$ & $F_{(1,78)}=.78$ & $F_{(1,72)}=.16$ \\
& $\operatorname{Pr} .>F=.92$ & $\operatorname{Pr}>F=.91$ & $\operatorname{Pr}>F=.75$ & $\operatorname{Pr}>F=.38$ & $\operatorname{Pr}>F=.69$ \\
$\rho^{C L, H S}=\rho^{C L, L H}$ & $F_{(1,72)}=1.12$ & $F_{(1,69)}=.57$ & $F_{(1,78)}=.06$ & $F_{(1,78)}=.34$ & $F_{(1,72)}=.78$ \\
& $\operatorname{Pr} .>F=.29$ & $\operatorname{Pr} .>F=.45$ & $\operatorname{Pr} .>F=.81$ & $\operatorname{Pr} .>F=.56$ & $\operatorname{Pr}>F=.38$ \\
$\rho^{H S, L H}=\rho^{C L, L H}$ & $F_{(1,72)}=1.25$ & $F_{(1,69)}=.88$ & $F_{(1,78)}=.07$ & $F_{(1,78)}=.33$ & $F_{(1,72)}=.41$ \\
& $\operatorname{Pr} .>F=.27$ & $\operatorname{Pr} .>F=.35$ & $\operatorname{Pr} .>F=.79$ & $\operatorname{Pr} .>F=.57$ & $\operatorname{Pr} .>F=.52$ \\
$\rho^{C L, L H}=\rho^{C L, H S}=\rho^{H S, L H}$ & $F_{(2,72)}=.73$ & $F_{(2,69)}=.47$ & $F_{(2,78)}=.07$ & $F_{(2,78)}=.40$ & $F_{(2,72)}=.46$ \\
& $\operatorname{Pr} .>F=.49$ & $\operatorname{Pr} .>F=.63$ & $\operatorname{Pr} .>F=.93$ & $\operatorname{Pr} .>F=.67$ & $\operatorname{Pr} .>F=.64$ \\
\hline
\end{tabular}

Table D.2: Panel (A): Estimates of $\rho$ for various specifications. $\rho^{e_{1}, e_{2}}$ denotes the parameter determining the elasticity of substitution between groups $e_{1}$ and $e_{2}$ estimated with the corresponding wage-bill ratio equation. $\rho^{C L, H S, L H}$ denotes the estimate from the restricted (iso-elastic) model. Labels (L) and (G) indicate whether the education stock enters in Level or Growth rate in the estimated equation. (B): Tests for equality of elasticities of substitution among labor inputs. P-values are reported below the F-statistic. 


\section{E Individual Productivity Dynamics}

Wage-age profiles from the PSID: The Panel Study of Income Dynamics (PSID) is a longitudinal survey of the US population. We use data for the waves from 1968 to 2011 (referring to calendar years 1967 to 2010). Since 1997 the PSID has become biannual. We follow closely the sampling criteria of ? but consider both heads and spouses in the SRC sample, which was originally nationally representative, so we use no sample weights in the calculations. By selecting both heads and spouses we are able to separately estimate all relevant parameters separately for men and women. ${ }^{50}$ After excluding the SEO sample, and observations with no reported gender or marital status, our sample of heads and spouses includes 5,044 individuals (2,350 men and 2,694 women). We keep only people with 8 or more (possibly non continuous) individual-year observations, and we eliminate individuals with outliers in earnings growth, defined as changes in log-earnings larger than 4 or less than -2 , which reduces the sample to 3,748 individuals (1,684 men and 2,064 women).

The wage variable we use for our calculations is the hourly earnings (total labor income divided by total hours worked) for the head of the household expressed in 1992 dollars by deflating nominal wages through the CPI-U for all urban consumers. ${ }^{51}$ Information on the highest grade completed is used to allocate individuals to three education groups: high school drop-outs, high school graduates, and college graduates.

Quadratic age polynomials are separately estimated for men and women, by education group. We only use observations between ages 22 and 65. We don't use self-employment observations and include dummies for year and state. For women we also control for marital status and we use a Heckman-selection estimator to correct for observation bias in employment: more specifically, we construct Inverse Mills ratios by estimating a participation equation which exploits variation in unearned family income, net of transfers, to identify transitions into and out of market employment. ${ }^{52}$ In Table E.1 we present the point estimates for different education groups.

Price of labor inputs from PSID: Once we filter out age effects from hourly wages for all education/gender groups, we construct first-differences in logs. This also filters out ability, since it enters linearly in the log-wage equation. Performing this estimation in first differences is needed because the average ability by education and gender group is not constant over time due to composition changes

\footnotetext{
${ }^{50}$ In the PSID the head of the household is generally a male whenever there is a cohabiting male/female couple. However if the husband or boyfriend is incapacitated and unable to fulfill the functions of Head, then the FU will have a female Head. We identify 642 such cases in which the married head of household is a female.

${ }^{51}$ The earnings variable includes the labor part of both farm and business income, wages, bonuses, overtime, commissions, professional practice and others.

${ }^{52}$ The unearned income instruments appear to do a good job of identifying selection into employment, being highly significant in all first stage regressions. The Inverse Mills ratios all have the expected sign (results available from the authors).
} 


\begin{tabular}{cccc}
\hline \hline \multicolumn{4}{c}{ Dependent variable: Log hourly wages, men } \\
\hline \multirow{4}{*}{ Age } & .040936 & .0673272 & .1197059 \\
& $(.0045)$ & $(.0016467)$ & $(.0023598)$ \\
$\mathrm{Age}^{2}$ & -.000397 & -.0006699 & -.0011914 \\
& $(.0000514)$ & $(.0000197)$ & $(.0000285)$ \\
\hline \multirow{5}{c}{ Dependent variable: Log hourly wages, women } \\
\hline \multirow{4}{*}{$\mathrm{Age}^{2}$} & .0295213 & .033165 & .0794265 \\
& $(.0055355)$ & $(.0019255)$ & $(.0027072)$ \\
$\mathrm{Age}^{2}$ & -.0002874 & -.0003267 & -.000845 \\
& $(.0000633)$ & $(.0000232)$ & $(.0000332)$ \\
\hline
\end{tabular}

Table E.1: Estimated age polynomials' coefficients (PSID). S.E. in parenthesis.

within the group. Therefore, we can easily estimate through time dummies the time series of price growth in each education/gender group, i.e., the term $\Delta \log w_{t}^{g, e}$. Given a normalization one can recover spot prices year by year. ${ }^{53}$

Wage-ability gradient from NLSY: Ability is approximated by the AFQT89. We use the NLSY79 to estimate the effect of ability on wages. To overcome the problem that the NLSY provides observations only for workers between age 14 and 45, we use wage data from the PSID 1968-2011 to estimate age polynomials for different education groups. After the age profiles have been used to filter out age effects from the log wage observations in the NLSY79 -and assuming, as in the model, that any residual unobserved error term is uncorrelated with $\theta_{c o g}-$ we can identify the loading factors by running simple regressions. Separately for each gender and education group $e \in\{L H, H S, C L\}$ we estimate an OLS regression of log individual wages on time dummies and on log AFQT89 scores (as a proxy for $\theta_{\operatorname{cog}}$ ) in order to recover $\lambda^{g, e}$ (see equation 3.1). We use specifications with time dummies to control for time variation in market wages, but estimates are almost identical to those obtained without time dummies. We also include dummies to control for marital status and number of children. ${ }^{54}$ For hourly wages, we use the wage variable corresponding to the hourly rate of pay on

\footnotetext{
${ }^{53}$ We use a normalization based on the relative hourly wages observed in our PSID sample in 1989. First we compute average wages by education group for 1989 , and next we correct for ability composition using information from the NLSY79 (AFQT test scores distribution together with their education-specific gradient on wages). We choose 1989 because people from the NLSY79 are between age 23 and 31, which means most of them are already working. Additional details on the normalization and the ability adjustment are available upon request.

${ }^{54}$ To check robustness we run specifications based on wages which are not purged of the estimated PSID age-effects: again, results based on these measures are similar to those obtained for the age-free wages reported below.
} 
the current or most recent job (the so-called CPS job), available only from 1979 to 1994 . We start with the 11,878 individuals for which we have AFQT89 scores. We drop individuals for which we cannot observe the highest grade completed, which brings the sample to 11,844 individuals. Next, we drop observations for which the wage is missing, ending up with 11,222 individuals. We drop those observations with annual work hours missing or larger than 5,840: this reduces the sample to 11,207 individuals. Dropping individuals who report (at least once) hourly wages above $\$ 400$ or below $\$ 1$ further reduces the sample to 10,625 . We also eliminate individuals who report log wage increases larger than 4 or smaller than -2 , which leaves 10,433 workers in the sample. When we split this sample in 6 gender/education groups, we get the following: for HS drop-outs sample sizes are 1,280 individual men and 932 women (respectively, 10,303 and 5,337 person/year observations); for HS graduates our samples are 3,280 individual males and 3,425 individual females (respectively, 31,431 and 31,090 person/year observations); and for college graduates there are 731 individual men and 785 individual women (respectively, 6,629 and 7,441 person/year observations). ${ }^{55}$ Table 3.1 reports estimates of the ability gradient by education group, and for the pooled sample. All standard errors are corrected for individual clustering. The NLSY contains two additional measures of wages: (i) a variable corresponding to the hourly rate of pay in the first reported job, available only from 1979 to 2002; (ii) a hourly wage rate obtained dividing total earnings by total hours worked in the previous calendar year. The latter variable can be constructed for each wave between 1979 and 2002. The earnings' measure includes wages, salary, commissions or tips from all jobs, before deductions for taxes. The ability gradient estimated from our preferred wage measure is close to the estimated ability gradients estimated using these two alternative definitions of hourly wages. Differences are statistically insignificant and confirm the robustness of the estimated reduced-form ability gradients.

Estimation of error component model for wage residuals: The final step is estimating the parameters of the persistent-transitory shocks model for wage residuals. Wage residuals are obtained from NLSY data purging from individual log wages time dummies, the age component and the ability component, calculated as explained above.

For estimation, we use a Minimum Distance Estimator originally developed by ??. In a nutshell, as moments we use the covariances of wage residuals at various lags for different age groups. Table 3.2 reports the estimates of these parameters obtained for the 15 -year period between 1979 and $1993 .{ }^{56}$

\footnotetext{
${ }^{55}$ We use all workers including NLSY79 over-samples in our estimation to maximize the number of observations: a dummy is introduced to control for possible hourly wage differences of workers from the over-samples. Over-sample dummies are mostly not significant. Even when significant they are very small.

${ }^{56}$ More details are available from the authors upon request.
} 
Let the statistical model for wage residuals in $\log s$ be:

$$
z_{i j t}^{g, e}=\varrho^{g, e} z_{i, j-1, t-1}^{g, e}+\eta_{i j t}^{g, e}, \quad \eta_{i j t}^{g, e} \stackrel{i i d}{\sim} N\left(0, \sigma_{\eta t}^{g, e}\right) .
$$

We let the initial draw $z_{i 0 t}^{g, e} \sim N\left(0, \sigma_{z_{0}}^{g, e}\right)$. The persistence of idiosyncratic productivity $\varrho^{g, e}$, and the variance of idiosyncratic productivity innovations $\sigma_{\eta t}^{g, e}$ all vary by gender and education attainment.

By using an observable variable as a proxy for permanent heterogeneity, we reduce selection bias in the estimation of the process for $z_{i j t}^{g, e}$. Also note that if one estimates wage equations from individual panel data sets, as we do, selection bias attributable to persistent shocks becomes less severe. The issue of selection bias ensuing from persistent shocks is related to the so-called "incidental parameters problem" discussed in ?. The severity of the incidental parameters problem becomes smaller as the number of panel observation for each given individual in a sample increases.

\section{F Abilities Distribution and Transmission}

To measure the transmission of cognitive and non-cognitive abilities between generations, we use data from the 'Children of the NLSY79' survey, which provides test scores of cognitive skills and eduction for mothers, as well as cognitive and non-cognitive skills for children. We approximate non-cognitive skills using the first principal component factor among five measures from the behavioral problems index (antisocial, anxiety, headstrong, hyperactive and peer conflicts). Children's cognitive skills are measured as the first principal components among PIAT math, reading recognition and reading comprehension scores. Mothers' cognitive skills are approximated by AFQT scores. Mothers are also classified into three education attainment levels.

We focus on scores of children who are 14 years old. Pooling data across all available waves of the CNLSY79 we have 5899 mother-child pairs at that age. To smooth the data we fit an ordered probit and use the predicted values as estimates of the transition matrix cell probabilities. The dependent variable in this ordered probit has nine possible categories generated by three cognitive and three non-cognitive skill groups. The explanatory variables are mother's cognition dummies, mother's education dummies, and a full set of interactions between them. Table F.1 reports the full transition matrix generated by this exercise. 


\begin{tabular}{crrrrrrrrr}
\hline \hline Mother & \multicolumn{10}{c}{ Child Cog Tercile, Non-Cog Tercile) } \\
$($ AFQT Tercile, EDU) & $(1,1)$ & $(2,1)$ & $(3,1)$ & $(1,2)$ & $(2,2)$ & $(3,2)$ & $(1,3)$ & $(2,3)$ & $(3,3)$ \\
\hline$(1$, LH $)$ & 0.293 & 0.159 & 0.104 & 0.103 & 0.107 & 0.084 & 0.051 & 0.056 & 0.045 \\
$(2, \mathrm{LH})$ & 0.248 & 0.150 & 0.103 & 0.106 & 0.114 & 0.093 & 0.059 & 0.068 & 0.059 \\
$(3, \mathrm{LH})$ & 0.161 & 0.124 & 0.094 & 0.105 & 0.124 & 0.112 & 0.076 & 0.097 & 0.105 \\
$(1, \mathrm{HSG})$ & 0.187 & 0.133 & 0.098 & 0.107 & 0.122 & 0.106 & 0.071 & 0.087 & 0.088 \\
$(2, \mathrm{HSG})$ & 0.134 & 0.113 & 0.089 & 0.103 & 0.125 & 0.117 & 0.083 & 0.109 & 0.129 \\
$(3, \mathrm{HSG})$ & 0.112 & 0.102 & 0.083 & 0.099 & 0.124 & 0.120 & 0.087 & 0.120 & 0.152 \\
$(1, \mathrm{CLG})$ & 0.135 & 0.113 & 0.089 & 0.103 & 0.125 & 0.116 & 0.082 & 0.109 & 0.127 \\
$(2, \mathrm{CLG})$ & 0.076 & 0.080 & 0.071 & 0.089 & 0.119 & 0.123 & 0.095 & 0.139 & 0.209 \\
$(3, \mathrm{CLG})$ & 0.050 & 0.061 & 0.057 & 0.076 & 0.108 & 0.119 & 0.098 & 0.155 & 0.276 \\
\hline
\end{tabular}

Table F.1: Cognitive and non-cognitive transition probabilities: child achievement conditional on mother's ability tercile (1 lowest tercile, 3 highest) and level of education (LH: Less than High School, HSG: High School, CLG: College).

\section{G Inter-vivos Transfers}

Our source of information on inter-vivos transfers (i.e., gifts from parents to their children) is the NLSY97. We mostly use measures from the 'Income' subsection of the survey, complemented with information from the College Experience section. ${ }^{57}$

Transfers measured in the Income section refer to all income transferred from parents or guardians to youth that are neither loans nor regular allowance. This information is elicited through a series of questions, which also assess whether the individual lives with both, one or none of their parents. Our measure of inter-vivos transfers uses the inter vivos transfer variable from youth who live with both parents, when it is available. When the youth reports not living with both parents we sum the inter-vivos transfers from both living mother/mother figure and father/father figure. ${ }^{58}$ If any of these values are missing (e.g. mother's transfer) then we include only the non-missing value (in this example, father's transfer). Observations which have missing values for all three possibilities to report inter-vivos transfers are dropped from the sample: there are 370 individuals with no usable record of transfers, and they are excluded from the sample. ${ }^{59}$

\footnotetext{
${ }^{57}$ The College Experience section has information about parental transfers earmarked for financial aid while attending a post-secondary academic institution. These transfers are not fully consistent with the information in the 'Income' section, contain many skips and, most importantly, they do not cover all transfers. For this reason we only use limited information from this section and make sure to include it so as to minimize reports' error.

${ }^{58}$ Those individuals who do not live with a mother/mother figure or a father/father figure, and whose biological mother and father are not alive, are not asked questions on transfers.

${ }^{59}$ Further investigation reveals that these individuals also exhibit missing values for various other variables, and information about them appears incomplete.
} 


\begin{tabular}{lcccc}
\hline \multicolumn{2}{c}{ Women } & \multicolumn{2}{c}{ Men } \\
\hline \hline & Not in College & In College & Not in College & In College \\
\hline Less than HS & 3,021 & N/A & 3,658 & N/A \\
HS Graduate & 3,229 & N/A & 3,820 & N/A \\
College Graduate & 5,499 & 7,506 & 5,433 & 8,203 \\
& & & & \\
Average & 4,157 & & 4,737 & \\
\hline
\end{tabular}

Table G.1: Yearly inter-vivos transfers by gender and educational attainments, and by current college enrollment status of the child. Amounts are expressed in year 2000 dollars and include allowances.

For youth living at home we also compute the implicit transfer corresponding to the value of rent, which is based on the estimated average rent paid by independent youth of the same age.

We use waves from 1997 to $2003 .{ }^{60}$ This gives us an initial sample of 12,686 youths who were between age 12 and 16 in 1997. Only respondents that are part of the cross-sectional (representative) sample are kept, which leaves 6,748 individuals. We compute the cumulative transfers received between ages 16 and 22. When we drop observations for youth below age 16 in 1997, and 13 cases of obvious mis-reporting, we obtain a final sample of 6,346 youth and a total number of observations equal to 21,136 . In this final sample, approximately $75 \%$ of youth report living in households with at least one (biological or adoptive) parent as guardian. ${ }^{61}$ In the final sample from the Income section, one third of observations $(32.4 \%)$ report positive cash transfers elicited from the relevant survey questions, meaning 67.6\% reported not receiving any such transfers. However, when imputed rent is included, $75.1 \%$ of observations have positive transfers. The value of imputed rent varies from age to age with a minimum of $\$ 4,966$ per year for kids aged 16 and a maximum of $\$ 6,615$ for 22 year old youth.

In the College Experience section questions about financial help from parents are asked for each term in College and refer to transfers specifically provided for school. ${ }^{62}$ The sampling restrictions are the same as the ones used for the Income section. Parental aid variables are categorized by year for

\footnotetext{
${ }^{60}$ Data for 2004 are dropped as there are no comparable inter-vivos amounts available after that year.

${ }^{61}$ In principle, observations should be weighted when tabulating population characteristics. However, as suggested by the BLS, the use of weights is inappropriate in samples generated after dropping observations reporting item nonresponses. Nonetheless we also experiment using the BLS custom weighting engine to construct specific weights for our sample, with results changing only marginally. In what follows we use only results from the un-weighted sample.

${ }^{62}$ After one term has been reported, the respondent is asked if the information for the next term has changed from the previous term, and if it has not, the information is not recollected.
} 
each respondent, and then summed up to generate an average variable for each year between 1997 and 2003. Given the way questions were designed and asked, the transfers recorded in the College section should be a subset of the transfers recorded in the Income section. However in a large number of cases, especially for students enrolled in 4-year Colleges, the transfer measures in the College section are larger than those in the Income section. Following some correspondence with the BLS, we concluded that transfer measures from the College section are generally less reliable than those in the Income section. However, it is also possible that respondents included parental payments of tuition fees in the College section transfer (for instance, if the parents paid tuition fees directly and respondents chose not to report such amounts in the Income section).

To calculate inter-vivos transfers, we chose to use both sources of data. More specifically, we use completed schooling by survey year 2009 to classify individuals within three groups: (1) those who have completed a 4-year college degree, and those who are currently enrolled in, or have completed, a graduate degree; (2) those who have completed a high school degree, but are not in group (1); (3) those who have not completed a high school degree.

Table G.1 summarizes the average yearly transfer received by girls and boys with different education achievement (as of survey year 2009); in the case of College graduates we distinguish between transfers received while in College and transfers received in other years. For the years of College attendance we approximate the total inter-vivos transfer as the maximum between transfers recorded in the Income section and transfers recorded in the College Experience section. ${ }^{63}$

Using the gender-specific average transfers in Table G.1 we compute the total amount received by youth with less than a College degree over a 7 year period by simply multiplying estimated yearly transfers and allowances by seven (note that all amounts are expressed in year 2000 dollars). In the case of College graduates we compute the total transfer received over 7 years by summing up the average amount received while in College multiplied by four (which is the College duration in the model) and the amount received while out of College multiplied by three.

Looking separately at transfers by gender of the child, this procedure results in a total transfer of $\$ 29,096$ for women and $\$ 33,164$ for men. These figures are used to target transfers-by-gender in the benchmark economy. Transfers reported in Table G.1 include allowances.

\footnotetext{
${ }^{63}$ An alternative way to approximate transfers during College years is to sum the measures from the two sections, rather than taking the higher one. This results in very similar average yearly transfers.
} 


\section{Simulation with Year 2010 Parameters}

\begin{tabular}{ccccc}
\hline \hline & \multicolumn{2}{c}{ Model } & \multicolumn{2}{c}{ Data } \\
& Year 2000 & Year 2010 & Year 2000 & Year 2010 \\
\hline Male College Attainment & 0.29 & 0.35 & 0.29 & 0.35 \\
Female College Attainment & 0.28 & 0.35 & 0.28 & 0.36 \\
College Wage Premium & 0.58 & 0.61 & 0.58 & $0.65^{*}$ \\
Gender Earnings Gap ${ }^{* *}$ & 0.70 & 0.76 & 0.74 & 0.77 \\
\hline
\end{tabular}

(*) Due to lack of comparable estimates for 2010, the College-HS premium is based on estimates by ? for 2005 . An alternative estimate by ?, based on a different education grouping, suggests a college-HS premium of about $0.66 \log$ points in 2010 .

(**) The gender gap is measured as in Goldin (2014). It corresponds to the ratio of median earnings of full-time women to full-time men. We set $2 / 3$ of the equivalent of 40 hours as the full-time threshold ( 0.225 of the model time endowment).

Table H.1: Predicted and actual college attainment and skill/gender premia in 2010.

\section{H Extrapolating the Model: 2000 vs 2010}

To assess the 'out of sample' performance of the model, we have extrapolated its equilibrium implications to a different time period. In particular, we have set the following parameters to those prevailing in the year 2010: (i) share parameters of different human capital in production; (ii) tuition costs and value of other education expenditures; (iii) credit limits for both subsidized and unsubsidized college loans. ${ }^{64}$ Then, keeping all other parameters unchanged, we have computed a new equilibrium allocation to verify how well the model would approximate observed enrollment rates and education/gender premia in 2010. Results, presented in Table H.1, suggest that the model does a very reasonable job in approximating equilibrium outcomes ten years out of sample.

\footnotetext{
${ }^{64}$ Based on information from the National Centre for Education Statistics, the specific changes are: (i) adjustment of the production technology shares to $s^{L H}=.15, s^{H S}=.36, s^{C L}=.49, s^{m, L H}=.65, s^{m, H S}=.59, s^{m, C L}=.59$; (ii) tuition growth of roughly $\$ 1,100$ per year between 2000 and 2010 (in year 2000 dollars); (iii) debt limits' expansion to $\$ 19,000$ for subsidized and $\$ 31,000$ for unsubsidized/private loans (expressed in year 2010 dollars, equivalent to 15,447 and 25,203 in year 2000 dollars).
} 


\section{Welfare Decomposition}

To ease notation, in this section it is convenient to augment our state vector with gender, i.e. we let $\boldsymbol{x}_{0}^{*}$ be the initial individual state be $\left(g, \boldsymbol{\theta}, \kappa_{\epsilon}, \hat{\boldsymbol{a}}, q\right)$. In line with this slight change of notation, we let $\mu_{0}^{*}$ be its stationary equilibrium distribution, and $\mathcal{V}_{0}\left(\boldsymbol{c}, \boldsymbol{l} ; \boldsymbol{x}_{0}^{*}\right)$ be the expected lifetime utility of an individual with initial states $\boldsymbol{x}_{0}^{*}$ upon becoming adult, i.e. at the time of its first decision, the Less than High School decision at age $j=0$. This value, defined in equation (2.6), takes into account all uncertainty in future adult life with respect to marital matching, income shocks (recall that survival risk is perfectly insured through annuities) and abilities of children. The arguments $(\boldsymbol{c}, \boldsymbol{l})$ are meant to capture that this value is inclusive of all future utility coming from the random sequences of individual consumption and leisure before and after marriage, and consumption and leisure of the offsprings at the time of the inter vivos transfer (because of altruism). Finally, let the superscripts 'pre' and 'post' denote the pre-reform and post-reform economies, respectively.

The total ex-ante welfare gain from the policy reform $\left(\varphi_{t o t}\right)$, expressed as a leisure-compensated consumption equivalent variation, is

$$
\int_{S_{0}^{*}} \mathcal{V}_{0}\left(\boldsymbol{c}^{\text {post }}, \boldsymbol{l}^{\text {post }} ; \boldsymbol{x}_{0}^{*}\right) d \mu_{0}^{* \text { post }}=\int_{S_{0}^{*}} \mathcal{V}_{0}\left(\left(1+\varphi_{t o t}\right) \boldsymbol{c}^{\text {pre }}, \boldsymbol{l}^{\text {pre }} ; \boldsymbol{x}_{0}^{*}\right) d \mu_{0}^{* \text {,pre }}
$$

Benabou (2002) has proved that this total welfare change of the policy reform, conceptually, can be broken down into three components: (i) a level effect of the reform on the level of average consumption, (ii) an uncertainty effect on the volatility of the agents' consumption paths that affects welfare because of risk aversion and incomplete markets, and (iii) an inequality effect on the equilibrium distribution of initial conditions $\mu_{0}$. As shown in ?, if the utility function is homothetic in its arguments, this decomposition is additive. Our utility function does not satisfy this property though, and thus we have to define one of the three components residually.

We start from the computation of the level effect and denote by $\mathcal{V}_{0}\left(C^{\mathrm{pre}}, L^{\mathrm{pre}}\right)$ the value function in the pre-reform economy, where each realization of these sequences is replaced by the average consumption and average leisure in the population. Then, the leisure-compensated consumption level differential effect $\varphi_{\text {lev }}$ between the two economies pre and post reform (pre, post) can be defined as:

$$
\mathcal{V}_{0}\left(C^{\mathrm{post}}, L^{\mathrm{post}}\right)=\mathcal{V}_{0}\left(\left(1+\varphi_{\text {lev }}\right) C^{\mathrm{pre}}, L^{\mathrm{pre}}\right) .
$$

Note that in these values there is no heterogeneity left, meaning that $\mathcal{V}_{0}$ with arguments $(C, L)$ is the same independently of initial conditions, and there is no uncertainty left because the consumption 
and leisure sequences are constant forever and for everyone (individuals, their spouses, and their offsprings). We label $\varphi_{\text {lev }}$, the level effect of the policy reform.

Next, we compute certainty equivalent consumption for each type $\boldsymbol{x}_{0}^{*}$, i.e., we replace the random sequence $\boldsymbol{c}$ with a constant vector $\bar{c}$ for each $\boldsymbol{x}_{0}^{*}$ such that:

$$
\mathcal{V}_{0}\left(\bar{c}\left(\boldsymbol{x}_{0}^{*}\right), \boldsymbol{l} ; \boldsymbol{x}_{0}^{*}\right)=\mathcal{V}_{0}\left(\boldsymbol{c}, \boldsymbol{l} ; \boldsymbol{x}_{0}^{*}\right)
$$

This certainty equivalent calculation compensates for consumption uncertainty in individual income and income of the spouse, through risk in marital matching. ${ }^{65} \mathrm{Next}$, we calculate the average certainty equivalent consumption in the population in economy $j \in\{$ pre, post $\}$ :

$$
\bar{C}^{j}=\int_{S_{0}^{*}} \bar{c}\left(\boldsymbol{x}_{0}^{*}\right) d \mu_{0}^{*, j}
$$

And we compute the average welfare cost of uncertainty in our economy as:

$$
\mathcal{V}_{0}\left(\bar{C}^{j}, L^{j}\right)=\mathcal{V}_{0}\left(\left(1-p_{\text {unc }}\right) C^{j}, L^{j}\right)
$$

We do it for both economies $j \in\{$ pre, post $\}$, and calculate the welfare gain from reduced uncertainty, or the uncertainty effect, of the policy reform as:

$$
\varphi_{u n c}=\frac{1-p_{u n c}^{\text {post }}}{1-p_{u n c}^{\text {pre }}}-1
$$

In order to obtain an additive decomposition, we then define residually the welfare gain from reduced inequality as:

$$
\tilde{\varphi}_{\text {ine }}=\frac{1+\varphi_{\text {tot }}}{\left(1+\varphi_{\text {lev }}\right)\left(1+\varphi_{\text {unc }}\right)}-1
$$

We also performed an independent check that this residual component is close to its exact counterpart $\varphi_{\text {ine }}$ as follows. Define the cost of inequality in initial conditions in economy $j$ as:

$$
\int_{S_{0}^{*}} \mathcal{V}_{0}\left(\bar{c}\left(\boldsymbol{x}_{0}^{*}\right), L^{j} ; \boldsymbol{x}_{0}^{*}\right) d \mu_{0}^{j, *}=\mathcal{V}_{0}\left(\left(1-p_{\text {ine }}^{j}\right) \bar{C}^{j}, L^{j}\right)
$$

\footnotetext{
${ }^{65}$ We follow ? and, in the left hand side of (I3) we do not allow individuals to re-optimize their leisure in the counterfactual where we replace their random sequence of consumption with the certainty equivalent value. We have verified that our calculations are robust to this choice.
} 
Note that here we are using the certainty equivalent in the left-hand side of (I5) and therefore the concavity of $\mathcal{V}_{0}$ captures only the reduction in value due to dispersion in $x_{0}^{*}$ not to uncertainty in the consumption sequences. We do this calculation in both the pre and post reform economy, and define the exact welfare gain of reduced inequality as:

$$
\varphi_{\text {ine }}=\frac{1-p_{\text {ine }}^{\text {post }}}{1-p_{\text {ine }}^{\text {pre }}}-1
$$




\section{J Policy Experiments}

This Appendix reports additional outcomes of all the policy experiments on government financial aid to college students described in Section 5 in the main text. 


\section{Removal of Student Loans - Panel A (Enrollment)}

\begin{tabular}{cccc}
\hline Group & Benchmark & P.E. Short-run & G.E. Long-run \\
\hline \hline Male & 0.294 & 0.191 & 0.267 \\
Female & 0.280 & 0.194 & 0.248 \\
\hline$\theta_{\text {cog }}$ tercile 1 & 0.048 & 0.020 & 0.050 \\
$\theta_{\text {cog tercile 2 }}$ & 0.216 & 0.122 & 0.190 \\
$\theta_{\text {cog }}$ tercile 3 & 0.528 & 0.380 & 0.482 \\
$\theta_{\text {non }}$ tercile 1 & 0.195 & 0.113 & 0.164 \\
$\theta_{\text {non }}$ tercile 2 & 0.286 & 0.190 & 0.254 \\
$\theta_{\text {non }}$ tercile 3 & 0.387 & 0.280 & 0.365 \\
\hline$q=1$ & 0.235 & 0.076 & 0.137 \\
$q=2$ & 0.296 & 0.240 & 0.255 \\
$q=3$ & 0.385 & 0.385 & 0.449 \\
\hline Inter Vivos Tr. tercile 1 & 0.168 & 0.012 & 0.016 \\
Inter Vivos Tr. tercile 2 & 0.141 & 0.005 & 0.048 \\
Inter Vivos Tr. tercile 3 & 0.552 & 0.560 & 0.710 \\
Parent's Net Worth ter. 1 & 0.205 & 0.046 & 0.076 \\
Parent's Net Worth ter. 2 & 0.257 & 0.148 & 0.219 \\
Parent's Net Worth ter. 3 & 0.399 & 0.383 & 0.479 \\
Parent's Income tercile 1 & 0.183 & 0.031 & 0.064 \\
Parent's Income tercile 2 & 0.229 & 0.122 & 0.194 \\
Parent's Income tercile 3 & 0.449 & 0.423 & 0.516 \\
\hline Mother's Education LH & 0.136 & 0.038 & 0.064 \\
Mother's Education HS & 0.226 & 0.125 & 0.194 \\
Mother's Education CL & 0.488 & 0.408 & 0.525 \\
Father's Education LH & 0.154 & 0.041 & 0.074 \\
Father's Education HS & 0.228 & 0.125 & 0.198 \\
Father's Education CL & 0.464 & 0.393 & 0.489 \\
\hline
\end{tabular}

Table J.1: Response of college enrollment to the elimination of federal student loans 


\section{Removal of Student Loans - Panel B (Aggregates)}

\begin{tabular}{cccc}
\hline \hline & Benchmark & P.E. Short-run & G.E. Long-run \\
\hline \hline Wealth Coef. of Variation & 1.114 & - & 1.067 \\
Gender log-Wage Gap & 0.341 & - & 0.342 \\
Labor Income Tax Rate & 0.270 & - & 0.280 \\
$\% \Delta \bar{\theta}_{\operatorname{cog}}$ & - & - & $-0.39 \%$ \\
$\% \Delta$ GDP & - & - & $-1.98 \%$ \\
\hline Total Welfare CEV $\left(\varphi_{\text {tot }}\right)$ & - & - & $-2.84 \%$ \\
Level component $\left(\varphi_{\text {lev }}\right)$ & - & - & $-1.84 \%$ \\
Uncertainty component $\left(\varphi_{\text {unc }}\right)$ & - & - & $+0.54 \%$ \\
Inequality component $\left(\varphi_{\text {ine }}\right)$ & - & - & $-1.56 \%$ \\
\hline High School Graduation Rate & 0.862 & - & 0.858 \\
$\Delta \%$ Avg Student Labor & - & $+5.08 \%$ & $+6.69 \%$ \\
Male CL Price Premium* & 0.2851 & - & 0.3407 \\
Female CL Price Premium* & 0.3055 & - & 0.3621 \\
$\Delta \%$ Male CL Lifetime Earnings** & - & - & $+2.83 \%$ \\
$\Delta \%$ Female CL Lifetime Earnings** & - & - & $+4.39 \%$ \\
$\Delta \%$ Male HS Lifetime Earnings** & - & - & $-1.22 \%$ \\
$\Delta \%$ Female HS Lifetime Earnings** & - & - & $-1.28 \%$ \\
\hline IVT to Parental Wealth Ratio - Men & 0.231 & 0.236 & .238 \\
IVT to Parental Wealth Ratio - Women & 0.203 & 0.210 & .205 \\
\hline
\end{tabular}

Table J.2: Response of aggregate variables to the elimination of federal student loans. (*) The 'college price premium' is the difference in the price per unit of human capital supplied relative to HS workers. (**) The discounted earnings of an individual with median characteristics and a spouse with median characteristics.

\section{Removal of Student Loans - Panel C (Crowding In/Out)}

\begin{tabular}{ccccc}
\hline \hline & \multicolumn{2}{c}{ P.E. Short-run } & \multicolumn{2}{c}{ G.E. Long-run } \\
& \$ change & $\%$ change & \$ change & $\%$ change \\
\hline Average & $+5,337$ & $+8.55 \%$ & $+3,444$ & $+5.52 \%$ \\
Male & $+5,486$ & $+8.53 \%$ & $+4,645$ & $+7.22 \%$ \\
Female & $+5,214$ & $+8.63 \%$ & $+2,105$ & $+3.48 \%$ \\
$q=1$ & $+5,224$ & $+49.1 \%$ & $+10,162$ & $+95.4 \%$ \\
$q=2$ & $+10,516$ & $+20.2 \%$ & $+11,850$ & $+22.8 \%$ \\
$q=3$ & 0 & $+0 \%$ & $-19,536$ & $-14.6 \%$ \\
\hline
\end{tabular}

Table J.3: Crowding in/out of inter vivos transfers in response to the elimination of federal student loans. This table reports change in average inter vivos transfers received by individuals who finish college in both the benchmark and experiment. 


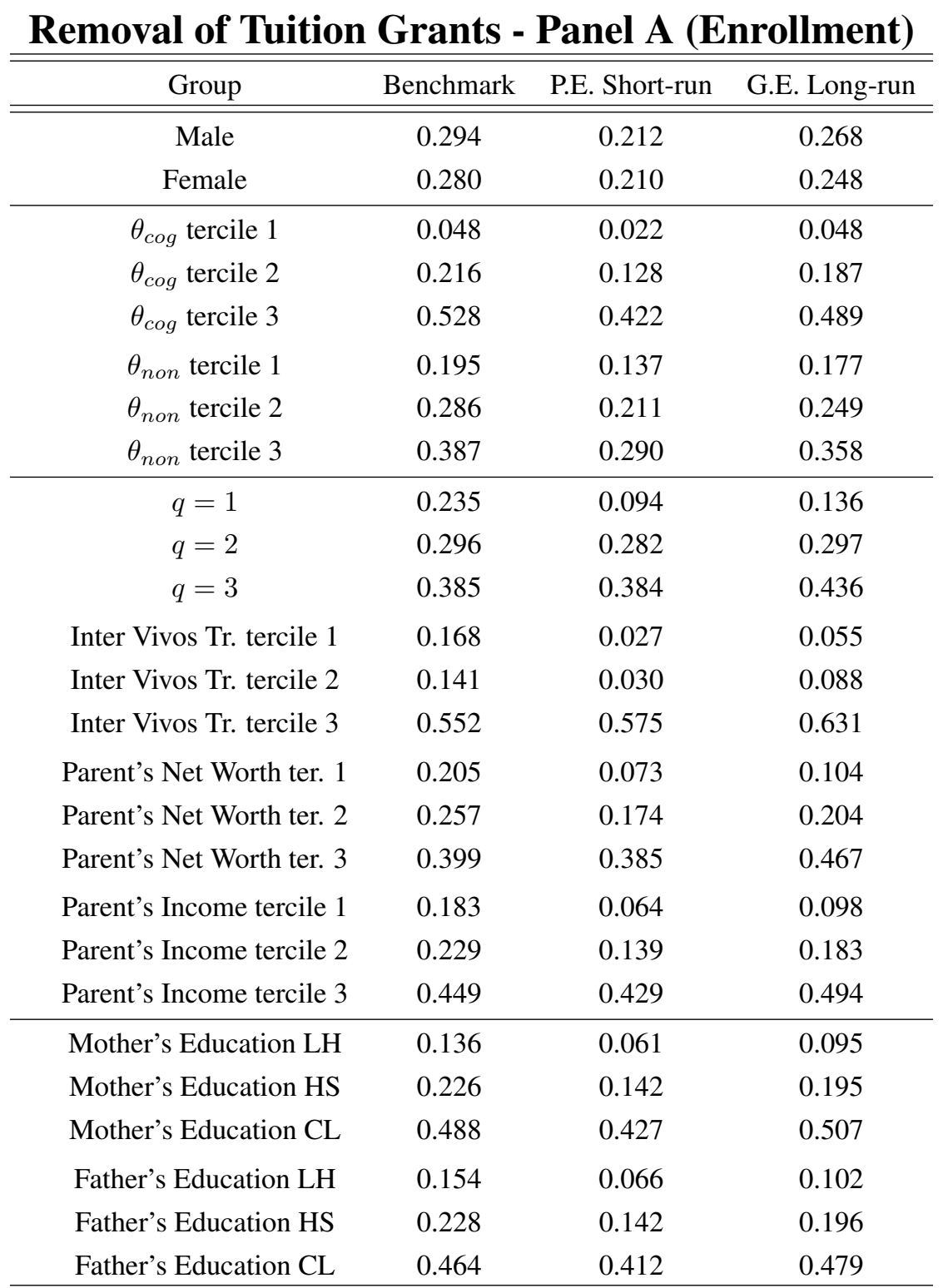

Table J.4: Response of college enrollment to the elimination of federal tuition grants. 


\section{Removal of Tuition Grants - Panel B (Aggregates)}

\begin{tabular}{cccc}
\hline \hline & Benchmark & P.E. Short-run & G.E. Long-run \\
\hline Wealth Coef. of Variation & 1.114 & - & 1.094 \\
Gender log-Wage Gap & 0.341 & - & 0.344 \\
Labor Income Tax Rate & 0.270 & - & 0.278 \\
$\% \Delta \bar{\theta}_{\text {cog }}$ & - & - & $-.41 \%$ \\
$\% \Delta$ GDP & - & - & $-1.97 \%$ \\
\hline Total Welfare CEV $\left(\varphi_{\text {tot }}\right)$ & - & - & $-2.81 \%$ \\
Level component $\left(\varphi_{\text {lev }}\right)$ & - & - & $-2.42 \%$ \\
Uncertainty component $\left(\varphi_{\text {unc }}\right)$ & - & - & $+1.31 \%$ \\
Inequality component $\left(\varphi_{\text {ine }}\right)$ & - & - & $-1.69 \%$ \\
\hline High School Graduation Rate & 0.862 & - & 0.858 \\
$\Delta \%$ Avg Student Labor & - & $+5.85 \%$ & $+0.62 \%$ \\
Male CL Price Premium* & 0.2851 & - & 0.3307 \\
Female CL Price Premium* & 0.3055 & - & 0.3597 \\
$\Delta \%$ Male CL Lifetime Earnings** & - & - & $+2.29 \%$ \\
$\Delta \%$ Female CL Lifetime Earnings** & - & - & $+3.82 \%$ \\
$\Delta \%$ Male HS Lifetime Earnings** & - & - & $-1.41 \%$ \\
$\Delta \%$ Female HS Lifetime Earnings** & - & - & $-1.73 \%$ \\
\hline IVT to Parental Wealth Ratio - Men & 0.231 & 0.232 & .228 \\
IVT to Parental Wealth Ratio - Women & 0.203 & 0.206 & .202 \\
\hline
\end{tabular}

Table J.5: Response of aggregate variables to the elimination of federal tuition grants. $(*)$ The 'college price premium' is the log-difference in the price per unit of human capital supplied Relative to HS workers. (**) Discounted lifetime earnings of an individual with median characteristics and a spouse with median characteristics.

\section{Removal of Tuition Grants - Panel C (Crowding In/Out)}

\begin{tabular}{ccccc}
\hline \hline & \multicolumn{2}{c}{ P.E. Short-run } & \multicolumn{2}{c}{ G.E. Long-run } \\
& $\$$ change & $\%$ change & \$ change & $\%$ change \\
\hline Average & $+2,573$ & $+4.12 \%$ & +23 & $+0.04 \%$ \\
Male & $+2,502$ & $+3.89 \%$ & +685 & $+1.07 \%$ \\
Female & $+2,681$ & $+4.44 \%$ & -776 & $-1.29 \%$ \\
$q=1$ & $+3,250$ & $+30.5 \%$ & $+3,594$ & $+33.8 \%$ \\
$q=2$ & $+1,048$ & $+2.01 \%$ & $-1,411$ & $-2.71 \%$ \\
$q=3$ & +15 & $+0.01 \%$ & $-11,480$ & $-8.59 \%$ \\
\hline
\end{tabular}

Table J.6: Crowding in/out of inter vivos transfers in response to the elimination of federal tuition grants. This table reports change in average inter vivos transfers received by individuals who finish college in both the benchmark and experiment. 


\section{Removal of Grants and Loans - Panel A (Enrollment)}

\begin{tabular}{cccc}
\hline Group & Benchmark & P.E. Short-run & G.E. Long-run \\
\hline Male & 0.294 & 0.148 & 0.246 \\
Female & 0.280 & 0.148 & 0.227 \\
\hline$\theta_{\text {cog }}$ tercile 1 & 0.048 & 0.019 & 0.069 \\
$\theta_{\text {cog }}$ tercile 2 & 0.216 & 0.110 & 0.198 \\
$\theta_{\text {cog }}$ tercile 3 & 0.528 & 0.278 & 0.414 \\
$\theta_{\text {non }}$ tercile 1 & 0.195 & 0.095 & 0.152 \\
$\theta_{\text {non }}$ tercile 2 & 0.286 & 0.142 & 0.241 \\
$\theta_{\text {non }}$ tercile 3 & 0.387 & 0.213 & 0.323 \\
\hline$q=1$ & 0.235 & 0.008 & 0.037 \\
$q=2$ & 0.296 & 0.203 & 0.241 \\
$q=3$ & 0.385 & 0.384 & 0.512 \\
Inter Vivos Tr. tercile 1 & 0.168 & 0.000 & 0.001 \\
Inter Vivos Tr. tercile 2 & 0.141 & 0.001 & 0.008 \\
Inter Vivos Tr. tercile 3 & 0.552 & 0.443 & 0.700 \\
Parent's Net Worth ter. 1 & 0.205 & 0.004 & 0.008 \\
Parent's Net Worth ter. 2 & 0.257 & 0.076 & 0.144 \\
Parent's Net Worth ter. 3 & 0.399 & 0.364 & 0.558 \\
Parent's Income tercile 1 & 0.183 & 0.004 & 0.012 \\
Parent's Income tercile 2 & 0.229 & 0.044 & 0.133 \\
Parent's Income tercile 3 & 0.449 & 0.397 & 0.564 \\
\hline Mother's Education LH & 0.136 & 0.026 & 0.048 \\
Mother's Education HS & 0.226 & 0.084 & 0.182 \\
Mother's Education CL & 0.488 & 0.342 & 0.507 \\
Father's Education LH & 0.154 & 0.021 & 0.048 \\
Father's Education HS & 0.228 & 0.082 & 0.184 \\
Father's Education CL & 0.464 & 0.336 & 0.480 \\
\hline
\end{tabular}

Table J.7: Response of college enrollment to the elimination of federal grants and federal student loans. 


\section{Removal of Grants and Loans - Panel B (Aggregates)}

\begin{tabular}{cccc}
\hline \hline & Benchmark & P.E. Short-run & G.E. - Long-run \\
\hline Wealth Coef. of Variation & 1.114 & - & 1.056 \\
Gender log-Wage Gap & 0.341 & - & 0.343 \\
Labor Income Tax Rate & 0.270 & - & 0.289 \\
$\% \Delta \bar{\theta}_{\text {cog }}$ & - & - & $-0.82 \%$ \\
$\% \Delta$ GDP & - & - & $-4.10 \%$ \\
\hline Total Welfare CEV $\left(\varphi_{\text {tot }}\right)$ & - & - & $-5.81 \%$ \\
Level component $\left(\varphi_{\text {lev }}\right)$ & - & - & $-4.51 \%$ \\
Uncertainty component $\left(\varphi_{\text {unc }}\right)$ & - & - & $+1.31 \%$ \\
Inequality component $\left(\varphi_{\text {ine }}\right)$ & - & - & $-2.63 \%$ \\
\hline High School Graduation Rate & 0.862 & - & 0.865 \\
$\Delta \%$ Avg Student Labor & - & $-11.2 \%$ & $-2.76 \%$ \\
Male CL Price Premium* & 0.2851 & - & 0.3834 \\
Female CL Price Premium* & 0.3055 & - & 0.4021 \\
$\Delta \%$ Male CL Lifetime Earnings** & - & - & $+3.50 \%$ \\
$\Delta \%$ Female CL Lifetime Earnings** & - & - & $+5.31 \%$ \\
$\Delta \%$ Male HS Lifetime Earnings** & - & - & $-2.68 \%$ \\
$\Delta \%$ Female HS Lifetime Earnings** & - & - & $-2.85 \%$ \\
\hline IVT to Parental Wealth Ratio - Men & 0.231 & 0.232 & .228 \\
IVT to Parental Wealth Ratio - Women & 0.203 & 0.204 & .202 \\
\hline
\end{tabular}

Table J.8: Response of aggregate variables to elimination of federal grants and federal loans. (*) The "college price premium' is the difference in the price per unit of human capital supplied relative to HS workers. (**) The discounted earnings of an individual with median characteristics and a spouse with median characteristics.

\begin{tabular}{ccccc}
\multicolumn{4}{c}{ Removal of Grants and Loans - Panel C (Crowding In/Out) } \\
\hline \hline \multicolumn{2}{c}{ P.E. Short-run } & \multicolumn{2}{c}{ G.E. Long-run } \\
& $\$$ change & $\%$ change & \$ change & $\%$ change \\
\hline Average & $+2,487$ & $+3.98 \%$ & $-2,260$ & $-3.62 \%$ \\
Male & $+2,260$ & $+3.51 \%$ & $-1,569$ & $-2.44 \%$ \\
Female & $+2,763$ & $+4.57 \%$ & $-2,999$ & $-4.97 \%$ \\
$q=1$ & $+2,778$ & $+26.1 \%$ & $+1,604$ & $+15.1 \%$ \\
$q=2$ & $+10,965$ & $+21.1 \%$ & $+12,224$ & $+23.5 \%$ \\
$q=3$ & +15 & $+0.01 \%$ & $-32,094$ & $-24.0 \%$ \\
\hline
\end{tabular}

Table J.9: Crowding in/out of inter vivos transfers in response to the elimination of all federal grants and federal student loans. This table reports change in average inter vivos transfers received by individuals who finish college in both the benchmark and experiment. 


\begin{tabular}{cccc}
\multicolumn{4}{c}{ Unconstrained Economy - Panel A (Enrollment) } \\
\hline Group & Benchmark & P.E. Short-run & G.E. Long-run \\
\hline Male & 0.294 & - & 0.317 \\
Female & 0.280 & - & 0.300 \\
\hline$\theta_{\text {cog }}$ tercile 1 & 0.048 & - & 0.056 \\
$\theta_{\text {cog }}$ tercile 2 & 0.216 & - & 0.239 \\
$\theta_{\text {cog }}$ tercile 3 & 0.528 & - & 0.552 \\
$\theta_{\text {non }}$ tercile 1 & 0.195 & - & 0.219 \\
$\theta_{\text {non } \text { tercile 2 }}$ & 0.286 & - & 0.310 \\
$\theta_{\text {non }}$ tercile 3 & 0.387 & - & 0.403 \\
\hline$q=1$ & 0.235 & - & 0.268 \\
q $=2$ & 0.296 & - & 0.322 \\
$q=3$ & 0.385 & - & 0.379 \\
Inter Vivos Tr. tercile 1 & 0.168 & - & 0.220 \\
Inter Vivos Tr. tercile 2 & 0.141 & - & 0.239 \\
Inter Vivos Tr. tercile 3 & 0.552 & - & 0.467 \\
Parent's Net Worth ter. 1 & 0.205 & - & 0.238 \\
Parent's Net Worth ter. 2 & 0.257 & - & 0.294 \\
Parent's Net Worth ter. 3 & 0.399 & - & 0.394 \\
Parent's Income tercile 1 & 0.183 & - & 0.229 \\
Parent's Income tercile 2 & 0.229 & - & 0.257 \\
Parent's Income tercile 3 & 0.449 & - & 0.440 \\
\hline Mother's Education LH & 0.136 & - & 0.164 \\
Mother's Education HS & 0.226 & - & 0.251 \\
Mother's Education CL & 0.488 & - & 0.481 \\
Father's Education LH & 0.154 & - & 0.185 \\
Father's Education HS & 0.228 & - & 0.255 \\
Father's Education CL & 0.464 & - & 0.454 \\
\hline & & & \\
\hline & - & - & - \\
\hline
\end{tabular}

Table J.10: Response of college enrollment to loosening of credit limits. 


\begin{tabular}{|c|c|c|c|}
\hline \multicolumn{4}{|c|}{ Unconstrained Economy - Panel B (Aggregates) } \\
\hline & Benchmark & P.E. Short-run & G.E. Long-run \\
\hline Wealth Coef. of Variation & 1.136 & - & 1.147 \\
\hline Gender log-Wage Gap & 0.340 & - & 0.341 \\
\hline Labor Income Tax Rate & 0.270 & - & 0.262 \\
\hline$\% \Delta \bar{\theta}_{\operatorname{cog}}$ & - & - & $+0.23 \%$ \\
\hline$\% \Delta \mathrm{GDP}$ & - & - & $+1.73 \%$ \\
\hline Total Welfare CEV $\left(\varphi_{t o t}\right)$ & - & - & $+4.23 \%$ \\
\hline Level component $\left(\varphi_{l e v}\right)$ & - & - & $+1.70 \%$ \\
\hline Uncertainty component $\left(\varphi_{\text {unc }}\right)$ & - & - & $+0.91 \%$ \\
\hline Inequality component $\left(\varphi_{\text {ine }}\right)$ & - & - & $+1.54 \%$ \\
\hline High School Graduation Rate & 0.863 & - & 0.869 \\
\hline$\Delta \%$ Avg Student Labor & - & - & $-25.6 \%$ \\
\hline Male CL Price Premium* & 0.2851 & - & 0.2533 \\
\hline Female CL Price Premium* & 0.3056 & - & 0.2746 \\
\hline$\Delta \%$ Male CL Lifetime Earnings $* *$ & - & - & $-2.05 \%$ \\
\hline$\Delta \%$ Female CL Lifetime Earnings** & - & - & $-2.02 \%$ \\
\hline$\Delta \%$ Male HS Lifetime Earnings** & - & - & $0.92 \%$ \\
\hline$\Delta \%$ Female HS Lifetime Earnings $* *$ & - & - & $1.43 \%$ \\
\hline IVT to Parental Wealth Ratio - Men & 0.232 & - & .219 \\
\hline IVT to Parental Wealth Ratio - Women & 0.203 & - & .199 \\
\hline
\end{tabular}

Table J.11: Response of aggregate variables to loosening of credit limits. $\left(^{*}\right)$ The 'college price premium' is the difference in the price per unit of human capital supplied relative to HS workers. $\left.{ }^{* *}\right)$ The discounted earnings of an individual with median characteristics and a spouse with median characteristics.

\begin{tabular}{ccccc}
\multicolumn{2}{c}{ Unconstrained Economy - Panel C } & (Crowding In/Out) \\
\hline \hline & \multicolumn{2}{c}{ P.E. Short-run } & \multicolumn{2}{c}{ G.E. Long-run } \\
& \$ change & $\%$ change & \$ change & $\%$ change \\
\hline Average & - & - & $-4,404$ & $-7.06 \%$ \\
Male & - & - & $-4,987$ & $-7.75 \%$ \\
Female & - & - & $-3,771$ & $-6.24 \%$ \\
$q=1$ & - & - & $-2,429$ & $-22.8 \%$ \\
$q=2$ & - & - & $-7,005$ & $-13.5 \%$ \\
$q=3$ & - & - & $-3,159$ & $-2.36 \%$ \\
\hline
\end{tabular}

Table J.12: Crowding in/out of inter vivos transfers in response to to loosening of credit limits. This table reports change in average inter vivos transfers received by individuals who finish college in both the benchmark and experiment. 
\$1,000 General Grant Expansion - Panel A (Enrollment)

\begin{tabular}{cccc}
\hline Group & Benchmark & P.E. Short-run & G.E. Long-run \\
\hline \hline Male & 0.294 & 0.335 & 0.311 \\
Female & 0.280 & 0.318 & 0.296 \\
\hline$\theta_{\text {cog }}$ tercile 1 & 0.048 & 0.069 & 0.058 \\
$\theta_{\text {cog }}$ tercile 2 & 0.216 & 0.263 & 0.234 \\
$\theta_{\text {cog }}$ tercile 3 & 0.528 & 0.577 & 0.544 \\
$\theta_{\text {non }}$ tercile 1 & 0.195 & 0.233 & 0.213 \\
$\theta_{\text {non }}$ tercile 2 & 0.286 & 0.325 & 0.303 \\
$\theta_{\text {non }}$ tercile 3 & 0.387 & 0.431 & 0.399 \\
\hline$q=1$ & 0.235 & 0.293 & 0.255 \\
$q=2$ & 0.296 & 0.323 & 0.313 \\
$q=3$ & 0.385 & 0.400 & 0.392 \\
Inter Vivos Tr. tercile 1 & 0.168 & 0.237 & 0.200 \\
Inter Vivos Tr. tercile 2 & 0.141 & 0.225 & 0.189 \\
Inter Vivos Tr. tercile 3 & 0.552 & 0.519 & 0.520 \\
Parent's Net Worth ter. 1 & 0.205 & 0.263 & 0.226 \\
Parent's Net Worth ter. 2 & 0.257 & 0.301 & 0.279 \\
Parent's Net Worth ter. 3 & 0.399 & 0.416 & 0.405 \\
Parent's Income tercile 1 & 0.183 & 0.247 & 0.213 \\
Parent's Income tercile 2 & 0.229 & 0.274 & 0.248 \\
Parent's Income tercile 3 & 0.449 & 0.459 & 0.449 \\
\hline Mother's Education LH & 0.136 & 0.179 & 0.154 \\
Mother's Education HS & 0.226 & 0.270 & 0.242 \\
Mother's Education CL & 0.488 & 0.517 & 0.489 \\
Father's Education LH & 0.154 & 0.201 & 0.174 \\
Father's Education HS & 0.228 & 0.273 & 0.245 \\
Father's Education CL & 0.464 & 0.490 & 0.465 \\
\hline
\end{tabular}

Table J.13: Response of college enrollment to a $\$ 1,000$ per year increase in federal grants ( $\$ 4,000$ total). 


\section{\$1,000 General Grant Expansion - Panel B (Aggregates)}

\begin{tabular}{cccc}
\hline & Benchmark & P.E. Short-run & G.E. Long-run \\
\hline Wealth Coef. of Variation & 1.114 & - & 1.120 \\
Gender log-Wage Gap & 0.341 & - & 0.340 \\
Labor Income Tax Rate & 0.270 & - & 0.266 \\
$\% \Delta \bar{\theta}_{\text {cog }}$ & - & - & $+0.15 \%$ \\
$\% \Delta$ GDP & - & - & $+1.10 \%$ \\
\hline Total Welfare CEV $\left(\varphi_{\text {tot }}\right)$ & - & - & $+1.72 \%$ \\
Level component $\left(\varphi_{\text {lev }}\right)$ & - & - & $+1.27 \%$ \\
Uncertainty component $\left(\varphi_{\text {unc }}\right)$ & - & - & $-0.16 \%$ \\
Inequality component $\left(\varphi_{\text {ine }}\right)$ & - & - & $+0.60 \%$ \\
\hline High School Graduation Rate & 0.862 & - & 0.865 \\
$\Delta \%$ Avg Student Labor & - & $-4.55 \%$ & $-6.24 \%$ \\
Male CL Price Premium* & 0.2851 & - & 0.2616 \\
Female CL Price Premium* & 0.3055 & - & 0.2886 \\
$\Delta \%$ Male CL Lifetime Earnings** & - & - & $-1.42 \%$ \\
$\Delta \%$ Female CL Lifetime Earnings** & - & - & $-1.15 \%$ \\
$\Delta \%$ Male HS Lifetime Earnings** & - & - & $+0.91 \%$ \\
$\Delta \%$ Female HS Lifetime Earnings** & - & - & $+0.97 \%$ \\
\hline IVT to Parental Wealth Ratio - Men & 0.231 & 0.222 & .228 \\
IVT to Parental Wealth Ratio - Women & 0.203 & 0.197 & .202 \\
\hline
\end{tabular}

Table J.14: Response of aggregate variables to $\$ 1,000$ per year increase in federal grants $(\$ 4,000$ total). $(*)$ The 'college price premium' is the difference in the price per unit of human capital supplied relative to HS workers. $(* *)$ The discounted earnings of an individual with median characteristics and a spouse with median characteristics.

\section{\$1,000 General Grant Expansion - Panel C (Crowding In/Out)}

\begin{tabular}{ccccc}
\hline \hline & \multicolumn{2}{c}{ P.E. Short-run } & \multicolumn{2}{c}{ G.E. Long-run } \\
& \$ change & $\%$ change & \$ change & $\%$ change \\
\hline Average & $-2,354$ & $-3.77 \%$ & -974 & $-1.56 \%$ \\
Male & $-2,694$ & $-4.19 \%$ & $-1,157$ & $-1.80 \%$ \\
Female & $-1,989$ & $-3.29 \%$ & -778 & $-1.29 \%$ \\
$q=1$ & $-3,298$ & $-31.0 \%$ & $-1,778$ & $-16.8 \%$ \\
$q=2$ & $-2,242$ & $-4.30 \%$ & $-1,241$ & $-2.38 \%$ \\
$q=3$ & $-2,138$ & $-1.60 \%$ & -769 & $-0.58 \%$ \\
\hline
\end{tabular}

Table J.15: Crowding in/out of inter vivos transfer in response to a $\$ 1,000$ per year increase in federal grants $(\$ 4,000$ total). This table reports change in average inter vivos transfers received by individuals who finish college in both the benchmark and experiment. 


\section{Means Tested Grant Expansion - Panel A (Enrollment)}

\begin{tabular}{cccc}
\hline \hline Experiment Characteristics & Benchmark & P.E. Short-run & G.E. Long-run \\
\hline Male & 0.294 & 0.342 & 0.310 \\
Female & 0.280 & 0.325 & 0.294 \\
\hline$\theta_{\text {cog }}$ tercile 1 & 0.048 & 0.074 & 0.061 \\
$\theta_{\text {cog }}$ tercile 2 & 0.216 & 0.269 & 0.236 \\
$\theta_{\text {cog }}$ tercile 3 & 0.528 & 0.585 & 0.536 \\
$\theta_{\text {non }}$ tercile 1 & 0.195 & 0.240 & 0.208 \\
$\theta_{\text {non }}$ tercile 2 & 0.286 & 0.332 & 0.305 \\
$\theta_{\text {non }}$ tercile 3 & 0.387 & 0.435 & 0.398 \\
\hline$q=1$ & 0.235 & 0.320 & 0.279 \\
$q=2$ & 0.296 & 0.304 & 0.289 \\
$q=3$ & 0.385 & 0.386 & 0.366 \\
Inter Vivos Tr. tercile 1 & 0.168 & 0.256 & 0.222 \\
Inter Vivos Tr. tercile 2 & 0.141 & 0.231 & 0.211 \\
Inter Vivos Tr. tercile 3 & 0.552 & 0.513 & 0.471 \\
Parent's Net Worth ter. 1 & 0.205 & 0.288 & 0.248 \\
Parent's Net Worth ter. 2 & 0.257 & 0.306 & 0.286 \\
Parent's Net Worth ter. 3 & 0.399 & 0.406 & 0.371 \\
Parent's Income tercile 1 & 0.183 & 0.268 & 0.235 \\
Parent's Income tercile 2 & 0.229 & 0.282 & 0.253 \\
Parent's Income tercile 3 & 0.449 & 0.450 & 0.417 \\
\hline Mother's Education LH & 0.136 & 0.188 & 0.166 \\
Mother's Education HS & 0.226 & 0.278 & 0.246 \\
Mother's Education CL & 0.488 & 0.520 & 0.472 \\
Father's Education LH & 0.154 & 0.212 & 0.190 \\
Father's Education HS & 0.228 & 0.282 & 0.248 \\
Father's Education CL & 0.464 & 0.490 & 0.447 \\
\hline
\end{tabular}

Table J.16: Response of college enrollment to a proportional 53\% proportional increase in federal grants (equal fiscal cost in PE as a $\$ 1,000$ per year expansion). 


\section{Means Tested Grant Expansion - Panel B (Aggregates)}

\begin{tabular}{cccc}
\hline \hline & Benchmark & P.E. Short-run & G.E. Lomg-run \\
\hline Wealth Coef. of Variation & 1.114 & - & 1.123 \\
Gender log-Wage Gap & 0.341 & - & 0.340 \\
Labor Income Tax Rate & 0.270 & - & 0.267 \\
$\% \Delta \bar{\theta}_{\text {cog }}$ & - & - & $+0.13 \%$ \\
$\% \Delta$ GDP & - & - & $+0.77 \%$ \\
\hline Total Welfare CEV $\left(\varphi_{\text {tot }}\right)$ & - & - & $+1.40 \%$ \\
Level component $\left(\varphi_{\text {lev }}\right)$ & - & - & $+1.01 \%$ \\
Uncertainty component $\left(\varphi_{\text {unc }}\right)$ & - & - & $+0.19 \%$ \\
Inequality component $\left(\varphi_{\text {ine }}\right)$ & - & - & $+0.19 \%$ \\
\hline High School Graduation Rate & 0.862 & - & 0.865 \\
$\Delta \%$ Avg Student Labor & - & $-4.19 \%$ & $-4.56 \%$ \\
Male CL Price Premium* & 0.2851 & - & 0.2635 \\
Female CL Price Premium* & 0.3055 & - & 0.2905 \\
$\Delta \%$ Male CL Lifetime Earnings** & - & - & $-1.78 \%$ \\
$\Delta \%$ Female CL Lifetime Earnings** & - & - & $-1.21 \%$ \\
$\Delta \%$ Male HS Lifetime Earnings** & - & - & $+0.65 \%$ \\
$\Delta \%$ Female HS Lifetime Earnings** & - & - & $+0.67 \%$ \\
\hline IVT to Parental Wealth Ratio - Men & 0.231 & 0.224 & .228 \\
IVT to Parental Wealth Ratio - Women & 0.203 & 0.199 & .202 \\
\hline
\end{tabular}

Table J.17: Response of aggregate variables to proportional 53\% increase in federal grants (equal fiscal cost in PE as a $\$ 1,000$ per year expansion). (*) The 'college price premium' is the difference in the price per unit of human capital supplied relative to HS workers. (**) The discounted earnings of an individual with median characteristics and a spouse with median characteristics.

\begin{tabular}{ccccc}
\multicolumn{2}{c}{ Means Tested Grant Expansion - Panel C (Crowding In/Out) } \\
\hline \hline & \multicolumn{2}{c}{ P.E. Short-run } & \multicolumn{2}{c}{ G.E. Long-run } \\
& \$ change & $\%$ change & \$ change & $\%$ change \\
\hline Average & $-1,134$ & $-1.82 \%$ & $-1,223$ & $-1.96 \%$ \\
Male & $-1,237$ & $-1.92 \%$ & $-1,358$ & $-2.11 \%$ \\
Female & $-1,006$ & $-1.66 \%$ & $-1,061$ & $-1.76 \%$ \\
$q=1$ & $-3,567$ & $-33.5 \%$ & $-2,855$ & $-26.8 \%$ \\
$q=2$ & -776 & $-1.49 \%$ & +588 & $+1.13 \%$ \\
$q=3$ & -172 & $-0.11 \%$ & $+7,166$ & $+5.37 \%$ \\
\hline
\end{tabular}

Table J.18: Crowding in/out of inter vivos transfers in response to a $53 \%$ increase in federal grants (equal fiscal cost in $\mathrm{PE}$ as a $\$ 1,000$ per year expansion). This table reports change in average inter vivos transfers received by individuals who finish college in both the benchmark and experiment. 


\begin{tabular}{|c|c|c|c|}
\hline \multicolumn{4}{|c|}{ Ability Tested Grant Expansion - Panel A (Enrollment } \\
\hline Experiment Characteristics & Benchmark & P.E. Short-run & G.E. Long-run \\
\hline Male & 0.294 & 0.325 & 0.310 \\
\hline Female & 0.280 & 0.310 & 0.295 \\
\hline$\theta_{\operatorname{cog}}$ tercile 1 & 0.048 & 0.064 & 0.050 \\
\hline$\theta_{\operatorname{cog}}$ tercile 2 & 0.216 & 0.251 & 0.229 \\
\hline$\theta_{\operatorname{cog}}$ tercile 3 & 0.528 & 0.566 & 0.550 \\
\hline$\theta_{\text {non }}$ tercile 1 & 0.195 & 0.224 & 0.212 \\
\hline$\theta_{\text {non }}$ tercile 2 & 0.286 & 0.315 & 0.303 \\
\hline$\theta_{\text {non }}$ tercile 3 & 0.387 & 0.420 & 0.399 \\
\hline$q=1$ & 0.235 & 0.279 & 0.255 \\
\hline$q=2$ & 0.296 & 0.316 & 0.313 \\
\hline$q=3$ & 0.385 & 0.397 & 0.390 \\
\hline Inter Vivos Tr. tercile 1 & 0.168 & 0.217 & 0.199 \\
\hline Inter Vivos Tr. tercile 2 & 0.141 & 0.199 & 0.190 \\
\hline Inter Vivos Tr. tercile 3 & 0.552 & 0.537 & 0.518 \\
\hline Parent's Net Worth ter. 1 & 0.205 & 0.249 & 0.225 \\
\hline Parent's Net Worth ter. 2 & 0.257 & 0.291 & 0.278 \\
\hline Parent's Net Worth ter. 3 & 0.399 & 0.412 & 0.405 \\
\hline Parent's Income tercile 1 & 0.183 & 0.233 & 0.211 \\
\hline Parent's Income tercile 2 & 0.229 & 0.263 & 0.248 \\
\hline Parent's Income tercile 3 & 0.449 & 0.456 & 0.449 \\
\hline Mother's Education LH & 0.136 & 0.168 & 0.151 \\
\hline Mother's Education HS & 0.226 & 0.259 & 0.240 \\
\hline Mother's Education CL & 0.488 & 0.511 & 0.492 \\
\hline Father's Education LH & 0.154 & 0.189 & 0.171 \\
\hline Father's Education HS & 0.228 & 0.262 & 0.244 \\
\hline Father's Education CL & 0.464 & 0.484 & 0.466 \\
\hline
\end{tabular}

Table J.19: Response of college enrollment to an increase in federal grants that is proportional to ability $1.72 \times \theta_{\operatorname{cog}}$ (equal fiscal cost in PE as a $\$ 1,000$ per year expansion). 


\begin{tabular}{cccc}
\multicolumn{5}{c}{ Ability Tested Grant Expansion - Panel B (Aggregates) } \\
\hline & Benchmark & P.E. Short-run & G.E. Long-run \\
\hline Wealth Coef. of Variation & 1.114 & - & 1.119 \\
Gender log-Wage Gap & 0.341 & - & 0.340 \\
Labor Income Tax Rate & 0.270 & - & 0.266 \\
$\% \Delta \bar{\theta}_{\text {cog }}$ & - & - & $+0.19 \%$ \\
$\% \Delta$ GDP & - & - & $+1.20 \%$ \\
\hline Total Welfare CEV $\left(\varphi_{\text {tot }}\right)$ & - & - & $+1.89 \%$ \\
Level component $\left(\varphi_{\text {lev }}\right)$ & - & - & $+1.39 \%$ \\
Uncertainty component $\left(\varphi_{\text {unc }}\right)$ & - & - & $-0.12 \%$ \\
Inequality component $\left(\varphi_{\text {ine }}\right)$ & - & - & $+0.61 \%$ \\
\hline High School Graduation Rate & 0.862 & - & 0.866 \\
$\Delta \%$ Avg Student Labor & - & $-3.39 \%$ & $-6.69 \%$ \\
Male CL Price Premium* & 0.2851 & - & 0.2603 \\
Female CL Price Premium* & 0.3055 & - & 0.2862 \\
$\Delta \%$ Male CL Lifetime Earnings** & - & - & $-1.14 \%$ \\
$\Delta \%$ Female CL Lifetime Earnings** & - & - & $-0.99 \%$ \\
$\Delta \%$ Male HS Lifetime Earnings** & - & - & $+0.98 \%$ \\
$\Delta \%$ Female HS Lifetime Earnings** & - & - & $+1.10 \%$ \\
\hline IVT to Parental Wealth Ratio - Men & 0.231 & 0.225 & .229 \\
IVT to Parental Wealth Ratio - Women & 0.203 & 0.199 & .203 \\
\hline
\end{tabular}

Table J.20: Response of aggregate variables to an increase in federal grants that is proportional to ability $1.72 \times \theta_{\operatorname{cog}}$ (equal fiscal cost in PE as a \$1,000 per year expansion). $(*)$ The 'college price premium' is the difference in the price per unit of human capital supplied relative to HS workers. (**) The discounted earnings of an individual with median characteristics and a spouse with median characteristics.

\section{Ability Tested Grant Expansion - Panel C (Crowding In/Out)}

\begin{tabular}{ccccc}
\hline \hline & \multicolumn{2}{c}{ P.E. Short-run } & \multicolumn{2}{c}{ G.E. Long-run } \\
& \$ change & $\%$ change & \$ change & $\%$ change \\
\hline Average & $-1,655$ & $-2.65 \%$ & $-1,039$ & $-1.66 \%$ \\
Male & $-1,803$ & $-2.80 \%$ & $-1,438$ & $-2.23 \%$ \\
Female & $-1,482$ & $-2.45 \%$ & -623 & $-1.03 \%$ \\
$q=1$ & $-2,508$ & $-23.6 \%$ & $-1,903$ & $-17.7 \%$ \\
$q=2$ & $-1,669$ & $-3.20 \%$ & $-1,867$ & $-3.58 \%$ \\
$q=3$ & $-1,664$ & $-1.25 \%$ & +119 & $+0.09 \%$ \\
\hline
\end{tabular}

Table J.21: Response of inter vivos transfers to an increase in federal grants that is proportional to ability $1.72 \times \theta_{\operatorname{cog}}$ (equal fiscal cost in $\mathrm{PE}$ as a $\$ 1,000$ per year expansion). This table reports change in average inter vivos transfers received by individuals who finish college in both the benchmark and experiment. 


\section{Sensitivity to Closed Economy Assumption}

\begin{tabular}{ccc}
\hline \hline Removal of Student Loans & Closed Economy & Small Open Economy \\
\hline$\Delta \%$ GDP & $-1.98 \%$ & $-0.58 \%$ \\
$\Delta$ college attainment rate & -0.030 & -0.025 \\
$\% \Delta \bar{\theta}_{\text {cog }}$ & $-0.39 \%$ & $-0.31 \%$ \\
Avg Crowding in/out of IVTs* & $+5.52 \%$ & $+11.1 \%$ \\
\hline \hline Removal of Tuition Grants & Closed Economy & Small Open Economy \\
\hline$\Delta \%$ GDP & $-1.97 \%$ & $-0.44 \%$ \\
$\Delta \%$ college attainment & -0.029 & -0.026 \\
$\% \Delta \bar{\theta}_{\text {cog }}$ & $-0.41 \%$ & $-0.34 \%$ \\
Avg Crowding in/out of IVTs* & $+0.04 \%$ & $+4.40 \%$ \\
\hline
\end{tabular}

Table K.1: This table illustrates the sensitivity of our main results to the assumption that interest rates are exogenously set (as in a small open economy). (*) The "average crowding in/out" figure corresponds to the average \% change in IVTs to children who go to college in both the benchmark and experiment. For the IVTs "+" refers to crowding in and "-" to crowding out.

\section{K Sensitivity Analysis}

\section{K.1 Sensitivity of Policy Outcomes to Closed Economy Assumption}

One possible concern about our results may relate to the endogenous determination of interest rates. The general equilibrium adjustments might be different if the price of credit was exogenously given. To check the robustness of our results we therefore consider a 'small open economy' alternative: the annual interest rate is exogenously set at the benchmark equilibrium rate $3.43 \%$. We compute the outcomes of the grant and loan removal policies in this alternative equilibrium where only human capital prices and tax rates adjust. The results, reported in Table K.1, show that aggregate effects are reduced. For example, when government student loans are removed, GDP falls by $0.58 \%$ in the long-run, rather than by $1.98 \%$ as we find for a closed economy. The mechanics of this GDP reduction are slightly different. Within an open economy, drops in college enrollment are less severe while changes in ability composition of college graduates are more severe. Thus, the stock of college educated human capital falls by comparable amounts, but for rather different reasons. Differences in the crowding out of parental transfers offer an insight into why this happens: in the open economy parents boost their transfers to college-going kids by much more when government aid is removed, which is an indication that selection into college due to parental wealth has become more important. In such open economy scenario the interest rate cannot fall, whereas in the closed economy case it falls by nearly 20 basis points. Any significant downward adjustment in the returns to assets implies 


\section{Sensitivity to Elasticity of Substitution Between $H^{e}$ Aggregates in Production}

\begin{tabular}{cccc}
\hline \hline & \multicolumn{3}{c}{ Elasticity $(1 /(1-\rho))$} \\
\cline { 2 - 4 } Removal of Tuition Grants & 2.5 & 3.3 & 5.0 \\
\hline$\Delta \%$ GDP & $-1.38 \%$ & $-1.97 \%$ & $-2.69 \%$ \\
$\Delta$ college attainment rate & $-2.28 \%$ & $-2.90 \%$ & $-4.05 \%$ \\
$\Delta \%$ avg ability college grads & $+0.26 \%$ & $+0.34 \%$ & $+0.45 \%$ \\
Avg Crowding out of IVTs* & $-3.37 \%$ & $+0.04 \%$ & $+2.33 \%$ \\
\hline \hline & \multicolumn{2}{c}{ Elasticity $(1 /(1-\rho))$} \\
\cline { 2 - 4 } Removal of Student Loans & 2.5 & 3.3 & 5.0 \\
\hline$\Delta \%$ GDP & $-1.58 \%$ & $-1.98 \%$ & $-2.89 \%$ \\
$\Delta \%$ college attainment & $-2.31 \%$ & $-2.95 \%$ & $-4.24 \%$ \\
$\Delta \%$ avg ability college grads & $-0.30 \%$ & $-0.12 \%$ & $+0.09 \%$ \\
Avg Crowding out of IVTs* & $+7.73 \%$ & $+5.52 \%$ & $+2.28 \%$ \\
\hline
\end{tabular}

Table K.2: This table illustrates the sensitivity of our main results to variation in the estimated value of $\rho$. In the benchmark economy we have an elasticity of 3.3, corresponding to $\rho=0.7$. (*) The "average crowding out" figure corresponds to the average $\%$ change in IVTs to children who go to college in both the benchmark and experiment.

a fall in the incomes of wealth rich families who provide relatively larger inter vivos transfers to their children. ${ }^{66}$

When returns to holding wealth do not adjust downward, low ability children from relatively richer families displace high ability children from poorer families to a larger extent than would occur in a closed economy.

\section{K.2 Sensitivity of Policy Outcomes to $\rho$}

When examining the effects of education policies, it is interesting to gauge how sensitive equilibrium outcomes are to alternative values of the production parameter $\rho$, which dictates the elasticity of substitution between $H^{e}$ aggregates. In Table K.2 we report results for a sensitivity analysis in which we consider different values of $\rho$ and we compare education policy outcomes to those obtained under the benchmark parametrization (that is, $\rho=.7$ ). As expected, changes in college attainment rates are larger when the elasticity of substitution is lower. Moreover, even when considering a fairly high elasticity (equal to five), one can still detect sizable GE effects on GDP, ability composition and inter vivos transfers.

\footnotetext{
${ }^{66}$ The inter vivos crowding in/out statistics refer to the selected sample who go to college in both benchmark and experiment. Unconditional changes in IVTs are smaller.
} 